
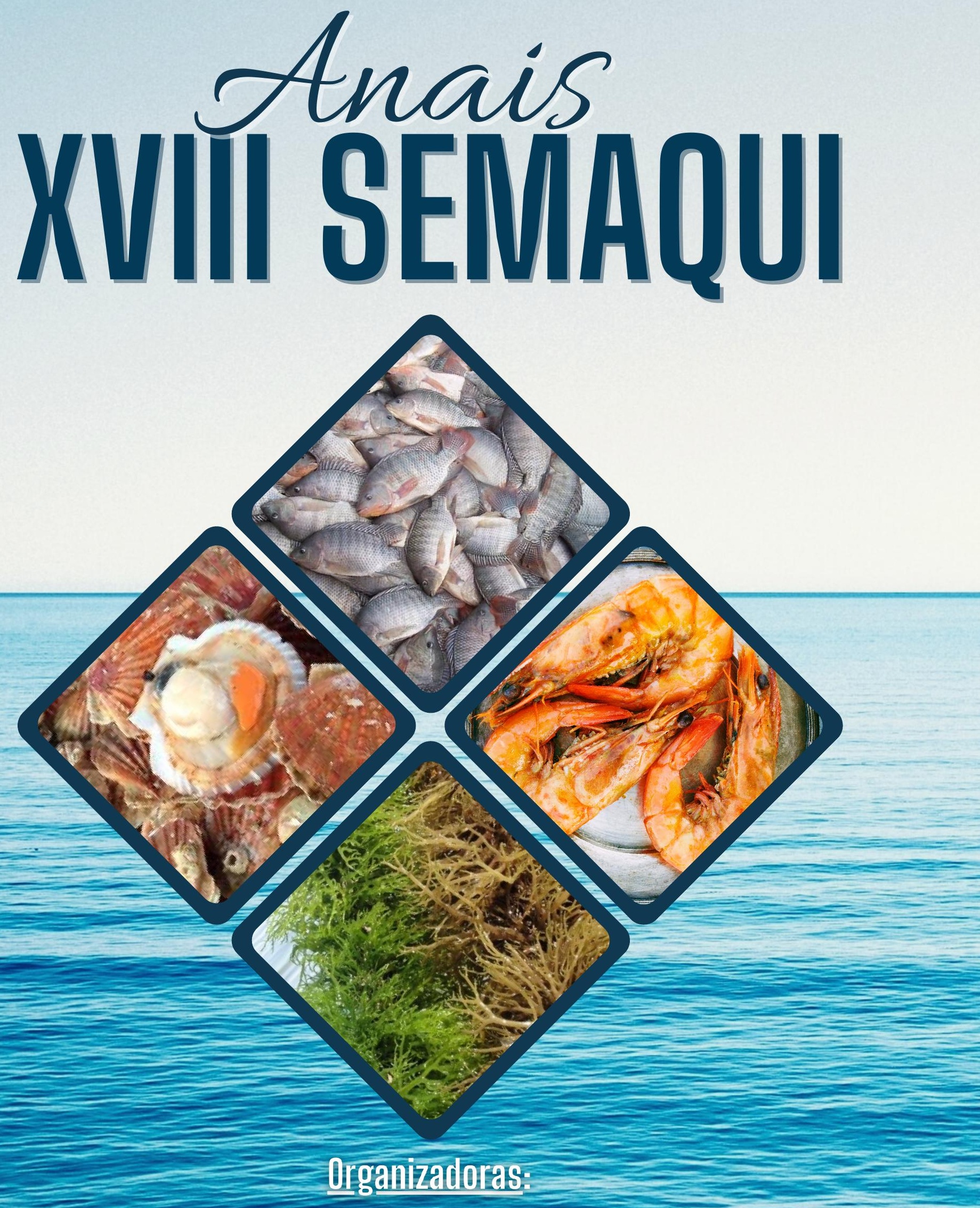

Anita Rademaker Valença

Poliana Ribeiro dos Santos

Luciana Guzella 
ANAIS DO XVIII SEMAQUI 


\title{
ANAIS DO XVIII SEMAQUI
}

\author{
QRGANIZADORAS \\ ANITA RADEMAKER VALENÇA \\ PLLIANA RIBEIRI DOS SANTUS \\ LUCIANA GUZELLA
}

1 A EDIÇÃa

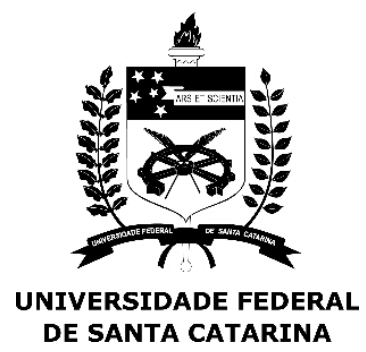

$978-65-872 \square 6-2 \square-2$ 


\section{UNIVERSIDADE FEDERAL DE SANTA CATARINA}

\section{Reitor}

Ubaldo Cesar Balthazar

\section{Vice-Reitora}

Alacoque Lorenzini Erdmann

\section{Conselho Editorial}

Ana Paula Lira De Souza

Bruno Da Silva Pierri

Caio Magnotti

Cecília De Souza Valente

Debora Machado Fracalossi

Esmeralda Chamorro Legarda

Fábio Carneiro Sterzelecki

Katt Regina Lapa

Raoani Cruz Mendonça

Walter Quadros Seiffert

\section{Comitê Científico}

Ana Paula Morais

Bianca Maria Soares Scaranto

Bruna Roque Loureiro

Carlos Frederico Gurgel

Carlos Peres Silva

Carolina Antonieta Lopes

Cristina Vaz Avelar De Carvalho

Gabriel Adan Araujo Leite

Gabriela Tomas Jerônimo Giustino Tribuzi

Isabela Pinheiro

Jamilly Sousa Rocha

Jaqueline Da Rosa Coelho

Jorgelia De Jesus Pinto Castro

Julianna Paula Do Vale Figueiredo

Luciany Do Socorro De Oliveira Sampaio

Maria Fernanda Oliveira Da Silva

Marialuiza Maciel

Miguel Angel Saldaña Serrano

Priscila Costa Rezende

Rafael Sales

Ramires Eloise Queiroz Rafael

Scheila Anelise Pereira

Tania Maria Lopes Dos Santos

Wanessa Costa

William Eduardo Furtado 


\section{Copyright $\odot 2020$ by Universidade Federal de Santa Catarina}

Conselho editorial: Ana Paula Lira De Souza; Bruno Da Silva Pierri; Caio Magnotti; Cecília De Souza Valente; Debora Machado Fracalossi; Esmeralda Chamorro Legarda; Fábio Carneiro Sterzelecki; Katt Regina Lapa; Raoani Cruz Mendonça; Walter Quadros Seiffert.

Organizadoras da obra: Anita Rademaker Valença, Poliana Ribeiro dos Santos e Luciana Guzella.

\section{Capa: Marcelli Rezende Queiroz}

Diagramação: Poliana Ribeiro dos Santos

\section{Revisão: Anita Rademaker Valença}

0 conteúdo desta obra é de responsabilidade dos(as) autores(as) e não expressa posição técnica ou institucional das Organizadoras, Conselho editorial e da Universidade Federal de Santa Catarina. Da mesma forma, o conteúdo de cada resumo é de inteira e exclusiva responsabilidade de seus(as) respectivos(as) autores(as). Assim como o padrão ortográfico, o sistema de citações e referências bibliográficas são prerrogativas de cada autor(a).

Os trabalhos que compõe esta obra foram submetidos à dupla avaliação cega (double-blind review) por pareceristas ad hoc, pós-graduados.

Catalogação na fonte pela Biblioteca Universitária da Universidade Federal de Santa Catarina

C749a Congresso de Engenharia de Aquicultura (18. : 2020 : Florianópolis)

Anais do XVIII SEMAQUI / organizadoras da obra Anita Rademaker Valença, Poliana Ribeiro dos Santos e

Luciana Guzella - Florianópolis: UFSC, 2020.

100 p. : il.

E-book (PDF)

Disponível em: https://semaqui.ufsc.br/

ISBN 978-65-87206-20-2

DOI: https://doi.org/10.29327/526640

1. Aquicultura - Congressos. I. Valença, Anita Rademaker, org. II. Santos, Poliana Ribeiro dos, org. III. Guzella, Luciana, org.

CDU: 639.3

Elaborada pelo bibliotecário Fabrício Silva Assumpção - CRB-14/1673

$10.29327 / 526640$

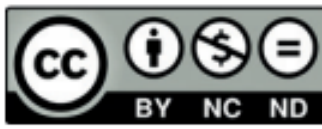

Este livro está sob a licença Creative Commons, que segue o princípio do acesso público à informação. O livro pode ser compartilhado desde que atribuídos os devidos créditos de autoria. Não é permitida nenhuma forma de alteração ou a sua utilização para fins comerciais. br.creativecommons.org 


\section{XVIII - Congresso de Engenharia de Aquicultura UFSC - SEMAQUI}

\section{Equipe Organizadora do Evento}

Coordenação Geral

Dra. Debora Machado Fracalossi

Coordenação Científica

Dra. Anita Rademaker Valença

Comissão Organizadora do Evento

Giovanni Martins Busanello

Luciana Guzella

Marcelli Rezende Queiroz

Poliana Ribeiro dos Santos

Comissão Organizadora da Mostra de Pesquisa

Luciana Guzella

Poliana Ribeiro dos Santos 


\section{Patrocinadores e Apoiadores do Evento}

A Comissão Organizadora do XVIII SEMAQUI agradece a todos os patrocinadores e apoiadores que se dispuseram a colaborar com o evento, contribuindo para a construção de um espaço de debates de alta qualidade e relevância para os participantes.

\section{Patrocinadores}
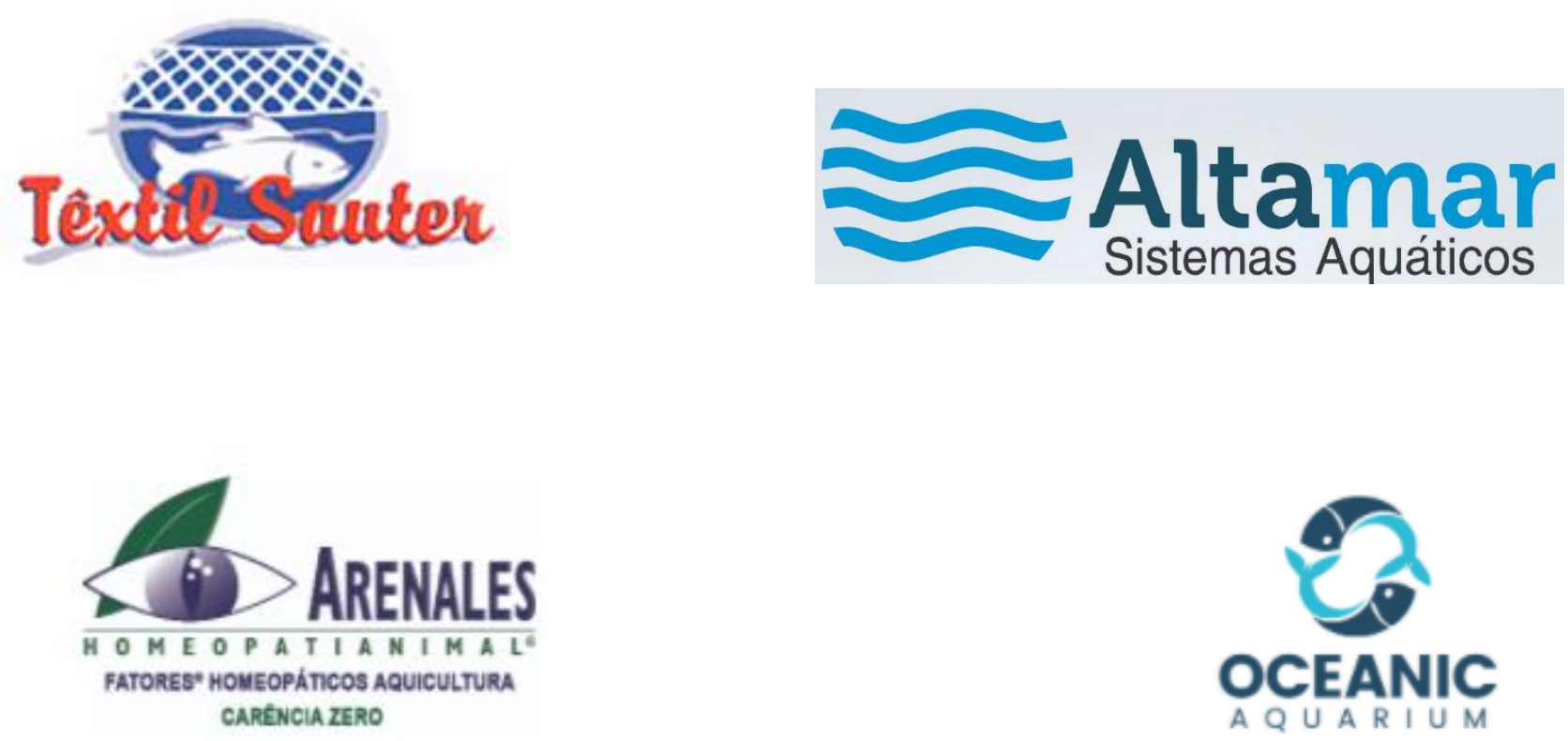

\section{Realizadores}
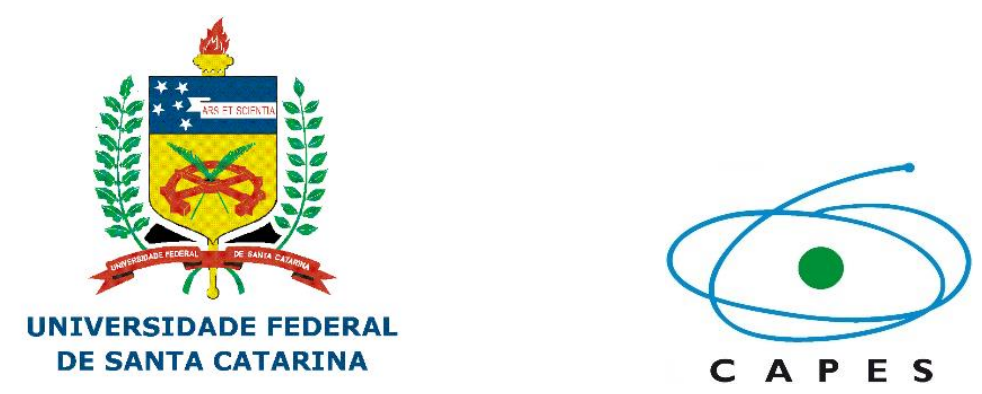


\section{Conselho Editorial}

Ana Paula Lira de Souza

Universidade Federal de Santa Catarina

Bruno Da Silva Pierri

Universidade Federal de Santa Catarina

Caio Cesar Franca Magnotti

Universidade Federal de Santa Catarina

Cecília de Souza Valente

National University of Ireland Galway

Debora Machado Fracalossi

Universidade Federal de Santa Catarina

Esmeralda Chamorro Legarda

Universidade Federal de Santa Catarina

Fabio Carneiro Sterzelecki

Universidade Federal Rural da Amazônia

Katt Regina Lapa

Universidade Federal de Santa Catarina

Raoani Cruz Mendonça

Instituto Federal do Pará

Walter Quadros Seiffert

Universidade Federal de Santa Catarina 


\section{Pareceristas da Obra}

Os trabalhos que compõe a presente obra foram submetidos à dupla avaliação cega (double-blind review) por pareceristas ad hoc, pós-graduados:

Ana Paula Mariane de Morais Universidade Federal de Santa Catarina

Bianca Maria Soares Scaranto Universidade Federal de Santa Catarina

Bruna Roque Loureiro Universidade Federal de Santa Catarina

Carlos Frederico Deluqui Gurgel Universidade Federal de Santa Catarina

Carlos Peres Silva

Universidade Federal de Santa Catarina

Carolina Antonieta Lopes

Universidade Federal de Santa Catarina

Cristina Vaz Avelar de Carvalho Universidade Federal de Santa Catarina

Gabriel Adan Araujo Leite Universidade Federal de Santa Catarina

Gabriela Tomas Jerônimo Universidade Federal do Amazonas

Giustino Tribuzi

Universidade Federal de Santa Catarina

Isabela Claudiana Pinheiro

Universidade Federal de Santa Catarina

Jamilly Sousa Rocha

Universidade Federal de Santa Catarina

Jaqueline da Rosa Coelho

Universidade Federal de Santa Catarina
Jorgelia De Jesus Pinto Castro

Universidade Federal de Santa Catarina

Julianna Paula do Vale Figueiredo

Universidade Federal de Santa Catarina

Luciany do Socorro de Oliveira Sampaio

Universidade Federal de Santa Catarina

Maria Fernanda Oliveira Da Silva

Universidade Federal de Santa Catarina

Maria Luiza Toschi Maciel

Universidade Federal de Santa Catarina

Miguel Angel Saldaña Serrano

Universidade Federal de Santa Catarina

Priscila Costa Rezende

Universidade Federal de Santa Catarina

Rafael Sales

Universidade Federal de Santa Catarina

Ramires Eloise Queiroz Rafael

Universidade Federal de Santa Catarina

Scheila Anelise Pereira

Universidade Federal de Santa Catarina

Tania Maria Lopes Dos Santos

Universidade Federal de Santa Catarina

Wanessa de Melo Costa

Fundação Instituto de Pesca do Estado do Rio de Janeiro

William Eduardo Furtado City University of Hong Kong 


\section{SUMÁRIO}

APRESENTAÇÃO. 18

\section{NUTRIÇÃo}

SUPLEMENTAÇÃo DIETÉTICA COM Ulva fasciata AUMENTA O TEOR DE ÁCIDO DOCOSAHEXAENÓICO (DHA) NO FILÉ DE Seriola dorsalis..

Esmeralda Chamorro Legarda; Maria Teresa Viana; Oscar Basilio Del Rio Zaragoza; André Luiz Braga; Marco Antonio de Lorenzo; Felipe do Nascimento Vieira.

SUBSTITUIÇÃO DA FARINHA DE PEIXE POR SPIRULINA (Arthrospira platensis) NO DESEMPENHO ZOOTÉCNICO DE JUVENIS DE PACU (Piaractus mesopotamicus).

William Franco Carneiro; Pedro Leite de Castro Uzeda; Tassia Flavia Dias Castro; Carlos Antonio Martínez-Palácios; Luis David Solis Murgas.

AVALIAÇÃO DA FREQUÊNCIA ALIMENTAR NO DESEMPENHO PRODUTIVO DE JUVENIS DE ACARÁ-BANDEIRA (Pterophyllum scalare). 23

Thayná de Souza Pardo; Layon Carvalho de Assis; Paola de Oliveira Santos; Samuel Oliveira da Silva; Paula Del Caro Selvatici; Pedro Pierro Mendonça.

TAURINA EM DIETAS PARA JUNDIÁ (Rhamdia quelen): IMPACTOS NO DESEMPENHO E DEPOSIÇÃO DE NUTRIENTES

Gregorio Cargnin; Ana Maria Liberalesso de Freitas; Suziane Ghedini Martinelli; Taida Juliana Adorian; Leila Picolli da Silva.

AVALIAÇÃO DE METODOLOGIA DE TEMPO DE COLETA EM EXPERIMENTOS DE DIGESTIBILIDADE DE PROTEÍNA BRUTA DE JUVENIS DE TILÁPIAS DO NILO (Oreochromis niloticus, Linnaeus, 1758)

Samuel Oliveira da Silva; Layon Carvalho de Assis; Paola de Oliveira Santos; Thayná de Souza Pardo; Tchesley Lyrio Queiroz; Pedro Pierro Mendonça.

EFEITO DA DIETA À BASE DE Nauphoeta cinerea NO CRESCIMENTO, SISTEMA IMUNE E ATIVIDADE ENZIMÁTICA EM Litopenaeus vannamei. 26 Cristina Rios; Karolina Victória Rosa; Carlos Peres Silva.

AVALIAÇÃO DA RESTRIÇÃO ALIMENTAR NO DESEMPENHO PRODUTIVO DE JUVENIS DE ACARÁ BANDEIRA (Pterophyllum scalare). 27

Paola de Oliveira Santos; Layon Carvalho de Assis; Samuel de Oliveira da Silva; Thayná de Souza Pardo; Paula Del Caro Selvatici; Pedro Pierro Mendonça.

EFEITOS DO ÁCIDO FÍTICO NO DESEMPENHO E ESTRESSE OXIDATIVO DE JUNDIÁS Rhamdia quelen. .28

Éverton Augusto Kowalski; Aline Neis Knob; Letícia Lopes da Costa; Taida Juliana Adorian; Leila Picolli da Silva. 
FATORES ANTINUTRICIONAIS DA SEMENTE DE FAVEIRA BENTH Parkia platycephala SOBRE 0 DESEMPENHO DA TAMBATINGA Colossoma macropomum $x$ Piaractus brachypomus.

Pamella Talita da Silva Melo; Rafael Carvalho da Silva; Queila Regina Rodrigues Barbosa de Sousa; Renan Ribeiro e Silva; Leonardo Rocha Vidal Ramos.

$$
\text { Algicultura (Macroalgas e Microalgas) }
$$

EFEITOS DE DIFERENTES MEIOS DE CULTIVO NO TEOR DE PROTEÍNA DA MACROALGA Ulva fasciata. 31

Andrezza Carvalho Chagas; Estefanny Caroline de França Silva; Tomaz Soligo de Mello Ayres; Mariana Holanda Paes Barboza; Luís Henrique da Silva Poersch; Gamze Turan.

MÉTODOS DE SECAGEM DA MACROALGA Kappaphycus alvarezii CULTIVADA EM FLORIANÓPOLIS...

Leonardo Pereira Felicidade; Isadora Carminatti da Silva; Sarah de Jesus Cantarino; Leila Hayashi.

ANÁLISES FÍSICO-QUÍMICAS DO ÁGAR DAS MACROALGAS Gracilaria birdiae, $\boldsymbol{G}$. domingensis e $G$. intermedia EXTRAÍDO COM USO DE ÁCIDOS E BASES NATURAIS............33 Andreline Jordana Coelho de Mendonça; Marco Aurélio Pereira Leite; Sandra Helena de Mesquita Pinheiro; Margarida Maria Monteiro Vasconcelos.

ACLIMATAÇÃO DA MACROALGA Ulva ohnoi EM DIFERENTES SALINIDADES NO SISTEMA DE BIOFLOCOS.

Ana Paula Mariane de Morais; Weverson Ailton da Silva; Julianna Paula do Vale Figueiredo ${ }^{3}$ Felipe do Nascimento Vieira.

LEVANTAMENTO QUALITATIVO DO CULTIVO EM TANQUES DA MACROALGA Kappaphycus alvarezii EM FLORIANÓPOLIS

Pollyanna de França Lima; Sarah de Jesus Cantarino; Leila Hayashi.

LEVANTAMENTO QUANTITATIVO DA PRODUÇÃO ACADÊMICA RELACIONADA AO CULTIVO DA MACROALGA Kappaphycus alvarezii EM SANTA CATARINA

Thiago César dos Santos; Isadora Carminatti da Silva; Thallis Felipe Boa Ventura; Alex Alves dos Santos; Leila Hayashi.

ADIÇÃO DE BICARBONATO DE SÓDIO COMO ESTRATÉGIA DE OTIMIZAÇÃO PARA O CULTIVO indoor DA MACROALGA Kappaphycus alvarezii.

Tatiane Beatriz Malinowski Baran; Fernando Zwierzikowski da Silva; Leila Hayashi.

AVALIAÇÃO DO CRESCIMENTO DA MACROALGA Ulva fasciata EM SOLUÇÃo VON-STOSCH E EM EFLUENTE DE CULTIVO DE CAMARÃO MARINHO EM BFT

Esthefany Caroline de França Silva; Andrezza Carvalho Chagas; Mariana Holanda Paes Barboza; Luís Henrique da Silva Poersch; Gamze Turan. 
ESTUDO DA BIOMASSA E PERCENTUAL DE COBERTURA ALGAL DAS MACROALGAS VERMELHAS Gracilaria domingensis e $G$. intermedia, NA PRAIA DO COQUEIRO, LUÍS CORREIA-PI 39

Andreline Jordana Coelho de Mendonça; Marco Aurélio Pereira Leite; Sandra Helena de Mesquita Pinheiro; Margarida Maria Monteiro Vasconcelos.

Sanidade, manejo e patologia na aquicultura

LETALIDADE DOS SANITIZANTES HIPOCLORITO DE SÓDIO E DICLOROISOCIANURATO DE SÓDIO EM GIRINOS DE RÃ-TOURO (Lithobates catesbeianus) 41 Rafael Lucas de Oliveira Silva; Fernando Mazzioli Braga; Híviny Francis de Oliveira Santos; Lucas Sousa de Freitas Santos; Maria Carolina Bastos Amaral; Oswaldo Pinto Ribeiro Filho.

ANÁLISE DE PREVALÊNCIA, INTENSIDADE E ABUNDÂNCIA DE ECTO E ENDOPARASITOS DO TAMBAQUI Colossoma macropomum NA REGIÃO AMAZÔNICA lana Elza Costa Fernandes;Raquel Emilia dos Santos Pereira; Sílvia Umeda Gallani; Gustavo Moraes Ramos Valladão.

MONITORAMENTO DE BACTÉRIAS NO TAMBAQUI Colossoma macropomum. 43 Aline Baggio Wanderley; Michelle Valério e Silva; Carlos Eduardo Baldin; Ingrid Schifelbein de Oliveira; Guilherme Campos Tavares; Gustavo Moraes Ramos Valladão; Silvia Umeda Gallani.

TESTES DE TOXICIDADE AGUDA DE COMPOSTOS ISOLADOS DE PLANTAS EM TAMBAQUIS (Colossoma macropomum)

Carolina de Souza Pereira; Rebeca Machado do Nascimento; Gustavo Moraes Ramos Valladão.

PARÂMETROS IMUNOLÓGICOS DE TILÁPIAS-DO-NILO APÓS SUPLEMENTAÇÃO COM DIFERENTES CONCENTRAÇÕES DO ÁCIDO ORGÂNICO BENZOICO E DESAFIADAS VIA GAVAGEM COM Streptococcus agalactiae. 45 Maria Clara Miguel Libanori; Gracienhe Gomes dos Santos; Scheila Anelise Pereira; Matheus Berlofa Ferreira; Marco Shizuo Owatari Maurício Laterça Martins; José Luiz Pedreira Mouriño.

USO DO LEVAMISOL CONTRA O ACANTOCÉFALO Neoechinorhynchus buttnerae. 46 Indra Mary Costa Fernandes; Sílvia Umeda Gallani; Gustavo Moraes Ramos Valladão.

PREVALÊNCIA E POTENCIAL PATOGÊNICO DE BACTÉRIAS DO ACARÁ-DISCO (Symphysodon aequifasciatus) E DO ACARÁ-BANDEIRA (Pterophyllum scalare). 47 Ingrid Schifelbein de Oliveira; Carlos Eduardo Xavier Baldin; Aline Baggio Wanderley; Franscisco Yan Tavares Reis; Guilherme Campos Tavares; Gustavo Moraes Ramos Valladão; Sílvia Umeda Gallani. 
CONCENTRAÇÃO LETAL MÉDIA (CL $\left.{ }_{50} 24 \mathrm{H}\right)$ DO PERMANGANATO DE POTÁSSIO EM GIRINOS DE RÃ-TOURO (Lithobates catesbeianus). .48

Fernando Mazzioli Braga; Rafael Lucas de Oliveira Silva; Oswaldo Pinto Ribeiro Filho; Híviny Francis de Oliveira Santos; Lucas Sousa de Freitas Santos; Maria Carolina Bastos Amaral

DIAGNÓSTICO E PREVALÊNCIA DE AGENTES BACTERIANOS EM PEIXES DE PRODUÇÃO NATIVOS DA AMAZÔNIA

Carlos Eduardo Baldin; Michelle Valério e Silva; Aline Baggio Wanderley; Ingrid Schifelbein de Oliveira; Guilherme Campos Tavares; Gustavo Moraes Ramos Valladão; Silvia Umeda Gallani.

POTENCIAL ANTIBACTERIANO DO TOMILHO Thymus vulgaris CONTRA Aeromonas jandaei isoladas DO ACARÁ-DISCO Symphysodon spp. E DO ACARÁ-BANDEIRA Pterophyllum scalare. .50

Taísa Freitas Botinelly; Claire Juliana Francisco; Sílvia Umeda Gallani.

PISCICULTURA

ISOLAMENTO E IDENTIFICAÇÃO DE BACTÉRIAS ÁCIDO LÁCTICAS NO INTESTINO DE TAMBAQUIS (Colossoma macropomum) COM POTENCIAL PROBIÓTICOS 52

Deborah Jacob Freire da Paz; Larissa Salgado da Cunha; Guilherme Campos Tavares; Rodrigo Yukihiro Gimbo.

DIAGNÓSTICO DA PISCICULTURA NO DISTRITO FEDERAL E RIDE-DF 53 Amanda Hellen Soares Alves; Ana Carolina Silva Brandizzi ; Eduardo Pickler Schulter; Maria Fernando Nince Ferreira.

DETERMINAÇÃO DA VAZÃO HÍDRICA NECESSÁRIA PARA O SISTEMA DE CULTIVO SEMIINTENSIVO DE TILÁPIAS DO NILO (Oreochromis niloticus, Linnaeus, 1758), NO SETOR DE AQUICULTURA DO IFES - CAMPUS DE ALEGRE. . .54

Samuel Oliveira da Silva; Emanuela Rodrigues Meneghetti; Jéferson Luiz Ferrari.

BEM-ESTAR EM SISTEMAS DE CRIAÇÃO DE PEIXES ORNAMENTAIS E DE PRODUÇÃO.....55 Ana Luiza Nunes Galdino; Andressa de Sousa Martins; Brenda Cordeiro Bastos; Diélica da Silva Brandão; Érica Fabiana da Silva Lima; Juliana Orlando Silva; Lucas Agueiro de Carvalho; Thaís Ágata Veiga Ferreira; Victória Cristina Feitosa de Souza; Tamyres Izarelly Barbosa da Silva.

ONTOGENIA DA CARPA CAPIM Ctenopharyngodon idellus. 56

Rafael Vieira Da Silva; Erivelto Oliveira De Souza; Pedro Pierro Mendonça.

EFEITO DA SALINIDADE NO CRESCIMENTO DE TILÁPIA DO NILO (Oreochromis niloticus) EM SISTEMA DE BIOFLOCOS

Julianna Paula do Vale Figueiredo; Ana Paula Mariane de Morais; Weverson Ailton da Silva; Ramires Eloíse Queiroz Rafael; Edemar Roberto Andreatta; Frank Belettini; Felipe do Nascimento Vieira. 
BETA-GLUCANOS COMO AGENTE PREBIÓTICO PARA TILÁPIAS: METANÁLISE SOBRE PARÂMETROS DE DESEMPENHO E ATIVIDADE DA LISOZIMA. 58 Aline Neis Knob; Éverton Augusto Kowalski; Taida Juliana Adorian; Leila Picolli da Silva; Luciana Pötter.

Tecnologia do pescado

QUALIDADE FÍSICO QUÍMICA DE FILÉS DE TILÁPIA DO NILO (Oreochromis niloticus) ......60 Guilherme Masteloto da Rosa; Alexandra Pretto; Rejane Sigaran Aguiar; Fernanda R. Goulart Ferrigolo.

ESTUDO DE CASO DE RENDIMENTO PIRAPITINGA (Piaractus brachypomus), TAMBATINGA (Colossoma macropomum X Piaractus brachypomus) EVISCERADO FRESCO EM FAIXAS DE PESO COMERCIAL. .61

Shadai Mendes Silva; Juan Rafael Ramirez Buitrago; Shekinah Mendes Silva.

PROCEDÊNCIA E TECNOLOGIAS DE CONSERVAÇÃO APLICADAS NO PESCADO COMERCIALIZADO EM FEIRA DO MUNICÍPIO DE HUMBERTO DE CAMPOS-MA.

Hugo Moreira Gomes; Henrique Chaves Silva; Lucilia Silva Conceição; Laila Freitas Oliveira de Assis

CARACTERIZAÇÃO NUTRICIONAL DE FILÉS DE PEIXES COMERCIALIZADOS NA CIDADE DE URUGUAIANA-RS

Rejane Sigaran de Aguiar; Alexandra Pretto; Guilherme Masteloto da Rosa; Fernanda Goulart Rodrigues Ferrigolo.

ESTUDO DE CASO DE RENDIMENTO DE TAMBAQUI (Colossoma macropomum) EVISCERADO FRESCO EM FAIXAS DE TAMANHO COMERCIAL .64

Shadai Mendes Silva; Juan Rafael Ramirez Buitrago; Shekinah Mendes Silva.

\section{Carcinicultura}

EFEITO DA ADIÇÃO DE ALGAS PARDAS NA DIETA PARA O CAMARÃO BRANCO-DOPACÍFICO CRIADO EM SISTEMA DE BIOFLOCOS. . .66

Camilla Souza Miranda; Priscila Costa Rezende; Felipe do Nascimento Vieira.

ALGAS PARDAS COMO ADITIVO ALIMENTAR PARA CAMARÃO BRANCO PACÍFICO, CULTIVADO EM SISTEMA DE BIOFLOCOS, MELHORA A RESISTÊNCIA AO ESTRESSE TÉRMICO E AO VÍRUS DA SÍNDROME DA MANCHA BRANCA

Priscila Costa Rezende; Norha Constanza Bolívar Ramíre; Felipe do Nascimento Vieira.

AVALIAÇÃO DE PROBIÓTICOS COMERCIAIS DURANTE A FASE DE BERÇÁRIO DE Litopenaeus vannamei (BOONE, 1934) EM SISTEMA DE BIOFLOCOS .68 Laís de Lima; Caio Henrique do Nascimento Ferreira; Fabrício Martins Dutra; Willian Favetta; Eduardo Luis Cupertino Ballester. 
AVALIAÇÃO DO USO DE PROBIÓTICOS COMERCIAIS NO BEM-ESTAR DE PÓS-LARVA Litopenaeus vannamei (BOONE, 1931) EM SISTEMA DE BIOFLOCOS

Caio Henrique do Nascimento Ferreira;Laís de Lima; Fabrício Martins Dutra; Ademir Heldt; Eduardo Luis Cupertino Ballester.

UTILIZAÇÃO DE CARVACROL COMO ALTERNATIVA AOS ANTIBIÓTICOS NO CONTROLE DE ENFERMIDADES BACTERIANAS NA CARCINICULTURA

Jaqueline da Rosa Coelho; Karolina Victória Rosa; Jamilly Sousa Rocha; Norha Constanza Bolívar Ramírez; Felipe do Nascimento Vieira.

Nannochloropsis sp. COMO ADITIVO ALIMENTAR NA DIETA DO CAMARÃO-BRANCO-DOPACÍFICO: EFEITOS NA MICROBIOLOGIA DO INTESTINO, RESISTÊNCIA AO ESTRESSE TÉRMICO E IMUNOLOGIA

Ariane Martins Guimarães; Jaqueline da Rosa Coelho; Priscila Costa Rezende; Renata Oselame Nóbrega; Felipe do Nascimento Vieira.

Legislação

OS MARCOS REGULATÓRIOS ESTADUAIS E SEUS EFEITOS SOBRE A TILAPICULTURA NA REGIÃO HIDROGRÁFICA TOCANTINS-ARAGUAIA 73

Rafael Ramos Correa; Marcos Ferreira Brabo.

LICENCIAMENTO AMBIENTAL AQUÍCOLA E A NOVA ÉTICA DO ANTROPOCENO 74

Luciana Guzella; Poliana Ribeiro dos Santos; Anita Rademaker Valença.

AS COTAS DE RESERVA AMBIENTAL (CRA) COMO FERRAMENTA ECONÔMICA PARA 0 PISCICULTOR CATARINENSE .75

Bruna Roque Loureiro; Darci Pitton Filho; Alex Pires de Oliveira Nuñer.

LICENÇA AMBIENTAL DE PISCICULTURA EM SANTA CATARINA 76

Anita Rademaker Valença; Poliana Ribeiro dos Santos; Luciana Guzella; Eduardo Gomes Sanches.

Genética, biologia, reprodução e fisiologia de espécies aquáticas

ASPECTOS DA LARVICULTURA E ASSENTAMENTO DE BERBIGÕES Anomalocardia brasiliana EM FLORIANÓPOLIS/SC 78 João Guzenski; Francisco Carlos da Silva.

AVALIAÇÃO MORFOMÉTRICA DO TECIDO HEPATOPANCREÁTICO DE ZEBRAFISH (Danio rerio) COM OBESIDADE INDUZIDA POR DIETA

Bárbara do Carmo Rodrigues Virote; Amanda Maria Siqueira Moreira; Isabela Miranda Guimarães; André Rodrigues da Cunha Barreto Vianna; Luis David Solis Murgas.

UTILIZAÇÃO DO DILUENTE TRIS PARA PRESERVAÇÃO DE AMOSTRAS DE SANGUE DO Arapaima gigas SUBMETIDAS A PROTOCOLO DE EXTRAÇÃO DE DNA. 80 Hélen Clarice Chaves Costa; Carlos Riedel Porto Carreiro. 
Espécies ornamentais e aquarismo

COMO REGULARIZAR UMA PISCICULTURA ORNAMENTAL 82

Anita Rademaker Valença; Poliana Ribeiro dos Santos; Luciana Guzella; Eduardo Gomes Sanches.

FREQUÊNCIA INCUBATÓRIA DE FÊMEAS DE CAMARÃO ORNAMENTAL Neocaridina davidi 83

Gilson Bueno Júnior; Wilson Alessandro Moura; Jean de Araújo Schneider; Bruno Estevão de Souza.

DISSEMINANDO O CONHECIMENTO CIENTÍFICO SOBRE O ACARÁ DISCO (Symphysodon spp., Chiclidae)

Anita Rademaker Valença; Gabriel Henrique de Mendonça Cardoso; Poliana Ribeiro dos Santos; Luciana Guzella; Eduardo Gomes Sanches.

DESAFIOS NA CRIAÇÃO COMERCIAL DO ACARÁ DISCO (Symphysodon spp., Chiclidae)... 85 Anita Rademaker Valença; Gabriel Henrique de Mendonça Cardoso; Poliana Ribeiro dos Santos; Luciana Guzella; Eduardo Gomes Sanches.

\author{
Malacocultura
}

ANÁLISE DO CULTIVO DE BERBIGÕES Anomalocardia brasiliana EM SISTEMA SUSPENSO FLUTUANTE.

João Guzenski.

AVALIAÇÃO ECONÔMICA DO CULTIVO DE OSTRAS Crassostrea gigas EM FLORIANÓPOLIS/SC 88

Felipe Matarazzo Suplicy

Ecologia e meio ambiente aplicados a aquicultura e/ou biologia aquática

CULTIVO DO COPEPODA Acartia tonsa COM DIETA BIALGAL SUPLEMENTADA COM BACTÉRIA PROBIÓTICA

Marcia Vanacor Barroso; Raoní Gonçalves de Souza; Bárbara Pereira Storck; Luiz Fernando Loureiro Fernandes; Flávia Regina Spago.

Tratamento de efluente e qualidade de água aplicados a aquicultura e/ou biologia aquática CARACTERIZAÇÃO DAS VARIÁVEIS LIMNOLÓGICAS DE TRÊS PISCICULTURAS PERTENCENTES A REGIÃO DO VALE DO GUAPORÉ-MT. 92 Bruno Mendes Visoni; Tatiani Botini Pires. 
Outros assuntos que possuem relação com a aquicultura e/ou biologia aquática MOBILE LEARNING: UMA FERRAMENTA DIGITAL PARA A AQUICULTURA NA PALMA DA MÃO. 94

Willian de Vargas; Eduarda Soares Serpa Camboim; Cíntia Torres; Felipe Cardoso Martins; Lissandra Souto Cavalli.

ESTUDO DO DESENVOLVIMENTO INICIAL EM PEIXES: CONSIDERAÇÕES ACERCA DAS TÉCNICAS DE OBSERVAÇÃO, COLETA, ANÁLISE E CONSERVAÇÃO DE AMOSTRAS .95 John Alejandro Clavijo-Ayala

DIMENSIONAMENTO DE UMA FAZENDA AQUÍCOLA PARA UMA TRIBO INDÍGENA DE ARAQUARI-SC.

Laila Freitas Oliveira de Assis ; Tayna Silveira da Costa; Alexandre Rodrigues Mariano.

VARIAÇÃO DOS PREÇOS DE PEIXES COMERCIALIZADOS EM DIFERENTES LOCAIS DA GRANDE ILHA DE SÃO LUÍS-MARANHÃO 97

Henrique Chaves Silva; Hugo Moreira Gomes; Lucilia Silva Conceição.

METODOLOGIAS PARTICIPATIVAS PARA A CARACTERIZAÇÃO DA MARISCAGEM NO MUNICÍPIO DE AREZ-RN. .98

Renata Bezerra Gomes Rebouças; Izaura Recy Souza Freire Sales; André Luiz Machado Trajano; Ellano José da Silva. 


\section{APRESENTAÇÃO}

O XVIII SEMAQUI - Congresso de Engenharia de Aquicultura da Universidade Federal de Santa Catarina (UFSC), realizou-se entre os dias 23 à 27 de novembro de 2020, na Universidade Federal de Santa Catarina, de modo virtual (online). O evento contou com a IV Mostra de Pesquisa Científica, a qual teve a submissão de mais de 150 trabalhos, entre resumos e trabalhos completos.

No primeiro semestre de 2020 foi realizado um pré-evento, com o objetivo de estimular as pesquisas durante a pandemia, por conta do coronavírus, e de incentivar a participação do público no evento principal. O pré-evento foi intitulado de pré-semaqui, contando com a realização de palestras de modo online.

O objetivo principal do evento é valorizar e incentivar a pesquisa acadêmica e proporcionar um espaço de debate e interação entre os pesquisadores da área de engenharia de aquicultura.

Foi proporcionado aos(as) participantes uma semana de palestras, oficinas, minicursos e exposição de trabalhos científicos, para a capacitação dos(as) inscritos(as) no evento.

A presente obra reúne os resumos dos trabalhos submetidos e apresentados no evento. Ressalta-se que todos os trabalhos foram submetidos a dupla avaliação às cegas.

Boa leitura!

Poliana Ribeiro dos Santos 


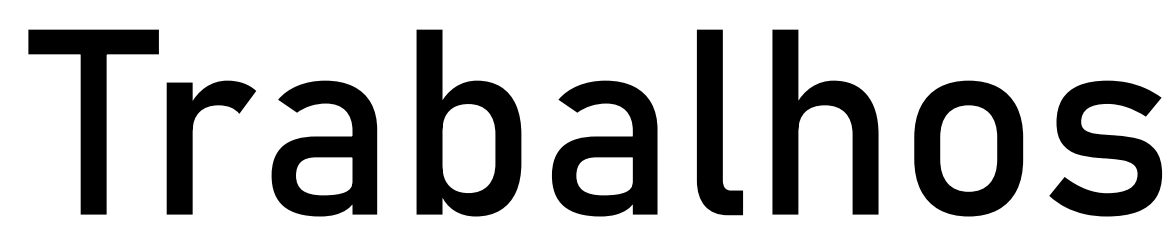

Apresentados 


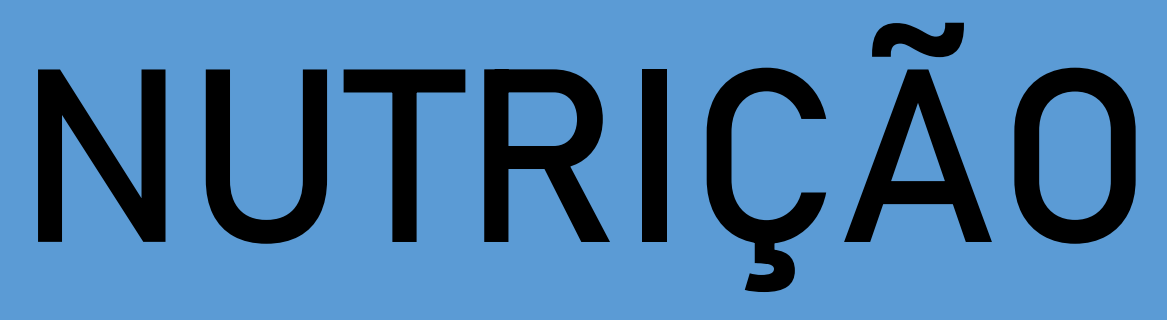




\section{SUPLEMENTAÇÃO DIETÉTICA COM Ulva fasciata AUMENTA O TEOR DE ÁCIDO DOCOSA-HEXAENÓICO (DHA) NO FILÉ DE Seriola dorsalis}

Esmeralda Chamorro Legarda ${ }^{1}$; Maria Teresa Viana ${ }^{2}$; Oscar Basilio Del Rio Zaragoza ${ }^{3}$; André Luiz Braga $^{4}$; Marco Antonio de Lorenzo ${ }^{5}$; Felipe do Nascimento Vieira ${ }^{6}$.

A procura por alimentos saudáveis como peixes com altos teores de ácidos graxos tem aumentado nos últimos anos. Os peixes são capazes de reter esses lipídeos no músculo a partir da dieta, alguns compostos provenientes de macroalgas podem ajudar no aumento dessa retenção.

O objetivo do presente trabalho foi avaliar o efeito de diferentes níveis de adição de Ulva fasciata em dietas para Seriola dorsalis sobre o crescimento, hematologia e perfil de ácidos graxos no filé.

Os peixes foram alimentados por 48 dias com dietas que continham $0 \%$ (U-0), $0,5 \%$ (U-5), $1 \%$ (U10) e $2 \%$ (U-20) de Ulva fasciata, com três repetições. Os peixes foram mantidos em um sistema de recirculação com 12 tanques de $500 \mathrm{~L}$ cada, com aeração e aquecimento constantes. Foram estocados 10 peixes em cada tanque e alimentados com relação de $5 \%$ da biomassa com sua respectiva dieta. Foi avaliado o desempenho dos peixes (ganho de peso, sobrevivência e fator de condição), índices hepatossomáticos, viscerossomáticos e hematológicos.

O ganho de peso foi similar entre os tratamentos. A adição de U. fasciata na dieta de $S$. dorsalis não afetou a contagem de eritrócitos nem leucócitos, contudo o hematócrito incrementou. A adição de $U$. fasciata resultou em um incremento de $49 \%$ de DHA no filé e diminuição do ácido linoleico em $20 \%$ (Tabela 1).

\begin{tabular}{|c|c|c|c|c|c|}
\hline $\begin{array}{l}\text { Ácidos graxos } \\
\text { mg g }^{-1}\end{array}$ & U-0 & U-5 & U-10 & U-20 & $p$-valor ANOVA \\
\hline 14:0 & $3.01 \pm 0.15^{\mathrm{ab}}$ & $3.3 \pm 0.51^{\mathrm{a}}$ & $2.31 \pm 0.23^{\mathrm{b}}$ & $2.31 \pm 0.32^{\mathrm{b}}$ & 0.024 \\
\hline $16: 0$ & $17.03 \pm 0.27$ & $16.64 \pm 0.09$ & $17.61 \pm 0.94$ & $16.42 \pm 0.32$ & 0.180 \\
\hline 18:0 & $5.88 \pm 0.15^{\mathrm{b}}$ & $5.88 \pm 0.32^{\mathrm{b}}$ & $6.53 \pm 0.28^{\mathrm{ab}}$ & $6.55 \pm 0.19^{\mathrm{a}}$ & 0.031 \\
\hline $16: 1$ & $4.23 \pm 0.28^{\mathrm{ab}}$ & $4.29 \pm 0.63^{\mathrm{b}}$ & $2.74 \pm 0.20^{\mathrm{ab}}$ & $2.72 \pm 0.25^{\mathrm{a}}$ & 0.034 \\
\hline $18: 1 n 9$ & $25.03 \pm 0.15^{\mathrm{a}}$ & $26.31 \pm 0.72^{\mathrm{a}}$ & $17.09 \pm 1.68^{\mathrm{b}}$ & $16.50 \pm 1.31^{\mathrm{b}}$ & $<0.001$ \\
\hline $18: \ln 7$ & $2.20 \pm 0.03$ & $2.33 \pm 0.07$ & $2.32 \pm 0.05$ & $2.16 \pm 0.14$ & 0.144 \\
\hline $20: \ln 9$ & $0.43 \pm 0.07^{\mathrm{ab}}$ & $0.49 \pm 0.04^{\mathrm{a}}$ & $0.34 \pm 0.05^{\mathrm{b}}$ & $0.30 \pm 0.04^{\mathrm{b}}$ & 0.006 \\
\hline $18: 2 n 6$ & $14.31 \pm 0.66^{\mathrm{a}}$ & $14.15 \pm 0.08^{\mathrm{a}}$ & $11.48 \pm 0.49^{\mathrm{b}}$ & $11.97 \pm 0.34^{\mathrm{b}}$ & $<0.001$ \\
\hline $20: 2$ & $0.29 \pm 0.01$ & $0.31 \pm 0.01$ & $0.37 \pm 0.06$ & $0.29 \pm 0.04$ & 0.177 \\
\hline $18: 3 n 6$ & $0.77 \pm 0.00^{\mathrm{ab}}$ & $0.86 \pm 0.08^{\mathrm{b}}$ & $0.61 \pm 0.07^{\mathrm{a}}$ & $0.64 \pm 0.06^{\mathrm{a}}$ & 0.019 \\
\hline $18: 3 n 3$ & $0.23 \pm 0.00$ & $0.29 \pm 0.07$ & $0.33 \pm 0.07$ & $0.21 \pm 0.04$ & 0.184 \\
\hline $20: 4 n 6$ & $2.81 \pm 0.77$ & $2.90 \pm 0.58$ & $3.08 \pm 0.73$ & $3.26 \pm 0.96$ & 0.924 \\
\hline $20: 5 n 3$ & $2.83 \pm 1.27$ & $2.09 \pm 0.88$ & $3.22 \pm 1.08$ & $3.53 \pm 0.87$ & 0.387 \\
\hline $22: 6 n 3$ & $15.27 \pm 0.81^{\mathrm{b}}$ & $14.66 \pm 2.20^{\mathrm{b}}$ & $24.82 \pm 2.60^{\mathrm{a}}$ & $22.81 \pm 2.29^{\mathrm{a}}$ & 0.002 \\
\hline I MUFA & $26.26 \pm 0.27$ & $25.82 \pm 0.29$ & $24.28 \pm 2.78$ & $25.29 \pm 0.54$ & 0.383 \\
\hline 乏 MUFA & $31.89 \pm 0.16^{\mathrm{a}}$ & $31.95 \pm 2.39^{\mathrm{a}}$ & $21.66 \pm 1.42^{\mathrm{b}}$ & $21.68 \pm 1.64^{\mathrm{b}}$ & $<0.001$ \\
\hline$\Sigma$ PUFA & $21.42 \pm 1.02^{\mathrm{a}}$ & $19.82 \pm 2.57^{\mathrm{a}}$ & $32.07 \pm 3.48^{\mathrm{b}}$ & $30.45 \pm 2.42^{\mathrm{b}}$ & 0.002 \\
\hline LC-PUFA n3 & $18.22 \pm 0.30^{\mathrm{a}}$ & $17.03 \pm 1.72^{\mathrm{a}}$ & $28.37 \pm 3.11^{\mathrm{b}}$ & $26.55 \pm 1.46^{\mathrm{b}}$ & $<0.001$ \\
\hline LC-PUFA n6 & $17.50 \pm 0.65$ & $16.94 \pm 1.67$ & $15.18 \pm 1.23$ & $15.88 \pm 1.27$ & 0.067 \\
\hline n3/n6 & $1.04 \pm 0.06^{\mathrm{a}}$ & $1.01 \pm 0.13^{\mathrm{a}}$ & $1.87 \pm 0.17^{\mathrm{b}}$ & $1.67 \pm 0.04^{\mathrm{b}}$ & $<0.001$ \\
\hline DHA:EPA & $6.08 \pm 3.01$ & $7.94 \pm 3.35$ & $8.28 \pm 2.93$ & $6.90 \pm 2.73$ & 0.853 \\
\hline Outros & $4.69 \pm 0.27$ & $7.08 \pm 2.12$ & $6.06 \pm 2.47$ & $9.43 \pm 5.14$ & 0.456 \\
\hline
\end{tabular}

Conclui-se que a farinha de $U$. fasciata proveniente de um cultivo multitrófico em sistema de bioflocos (AMTI-BFT) pode ser adicionado na dieta de $S$. dorsalis, incrementando o DHA no filé, sem afetar a saúde do peixe.

Palavras-chave: Olhete. Macroalga. Compostos bioativos. Ácido docosa-hexaenóico. Apoio: CNPq; CAPES; CONACYT.

\footnotetext{
${ }^{1}$ Doutora em Aquicultura pela Universidade Federal de Santa Catarina. Postdoc no Laboratório de Camarões Marinhos. http://lattes.cnpq.br/2002899878946112. esmeralda.cl@ posgrad.ufsc.br

${ }^{2}$ Doutora em bioquímica marinha pela University of Troms $\emptyset$. Professora Pesquisadora do Instituto de Investigaciones Oceanológicas Universidad Autónoma de Baja California. mtviana@ hotmail.com

${ }^{3}$ Doutor em ciencias con orientación en acuicultura en el Centro de Investigación en Alimentación y Desarrollo de Sinaloa.oscar.delrio@uabc.edu.mx

${ }^{4}$ Doutor em Oceanografia biológica. Professor pesquisador do Instituto de Investigaciones Oceanológicas Universidad Autónoma de Baja California. andre.braga@uabc.edu.mx

${ }^{5}$ Doutor em Aquicultura pela Universidade Federal de Santa Catarina. Técnico do Biotério central da Universidade Federal de Santa Catarina. lorenzoocram@gmail.com

${ }^{6}$ Doutor em Aquicultura Pela Universidade Federal de Santa Catarina. Supervisor do Laboratório de Camarões Marinhos da Universidade Federal de Santa Catarina. felipe.vieira@ufsc.br
} 


\title{
SUBSTITUIÇÃO DA FARINHA DE PEIXE POR SPIRULINA (Arthrospira platensis) NO DESEMPENHO ZOOTÉCNICO DE JUVENIS DE PACU (Piaractus mesopotamicus)
}

\author{
William Franco Carneiro ${ }^{1}$; Pedro Leite de Castro Uzeda ${ }^{2}$; Tassia Flavia Dias Castro ${ }^{3}$; Carlos \\ Antonio Martínez-Palácios ${ }^{4}$; Luis David Solis Murgas ${ }^{5}$.
}

A presença de compostos imunoestimulantes, antioxidantes, moduladoras do metabolismo e elevado teor de proteína bruta (50 a $70 \%$ ) fazem das microalgas ingredientes promissores na alimentação de peixes. Dentre as diversas espécies de microalgas, a Arthrospira platensis - comercialmente conhecida como spirulina (SP), vem recebendo atenção como suplemento ou até mesmo como fonte de proteína em dietas para peixes.

O objetivo deste estudo foi avaliar a substituição da farinha de peixe (FP) por SP no desempenho zootécnico, eficiência alimentar e parâmetros bioquímicos de juvenis de pacu (Piaractus mesopotamicus).

Um total de 180 juvenis de pacu $(0,97 \pm 0,04 \mathrm{~g})$ foram distribuídos aleatoriamente em 12 aquários de vidro de $45 \mathrm{~L}$, acoplados a um sistema de recirculação de água com filtro mecânico e biológico. Os tratamentos foram compostos de quatros níveis de substituição de FP por SP: 0, 2, 4 e $6 \%$. Os peixes foram alimentados três vezes ao dia até a saciedade aparente por um período de 45 dias. Os parâmetros de qualidade de água monitorados diariamente foram temperatura e $\mathrm{pH}$, que apresentaram uma média de $28,6 \pm 1,4^{\circ} \mathrm{C}$ e $7,8 \pm 0,7$, respectivamente. As medições semanais de oxigênio dissolvido e amônia total foram em média $6,9 \pm 1,2 \mathrm{mg} / \mathrm{L}$ e $0,06 \pm 0,07 \mathrm{mg} / \mathrm{L}$, respectivamente. Realizou-se uma biometria final, sendo pesados e medidos todos os animais. Foram coletadas amostras de sangue $(200 \mu \mathrm{l})$ por punção caudal de quatro animais por repetição para a avaliação dos parâmetros bioquímicos plasmáticos. Os dados foram submetidos à ANOVA e, em caso de diferenças significativas aplicouse Tukey à $5 \%$ de probabilidade.

Os resultados demonstraram que os peixes alimentados com as dietas contendo 4 e $6 \%$ de SP apresentaram maior peso final, ganho de peso e taxa de crescimento específico em comparação com os peixes alimentados sem SP na dieta. A eficiência alimentar e taxa de eficiência proteica não apresentaram diferenças significativas entre os tratamentos. Por outro lado, o consumo diário de ração foi significativamente maior nos peixes alimentados com $4 \%$ de SP na dieta quando comparados aos peixes que não receberam SP. Os pacus alimentados com as dietas 4 e $6 \%$ de SP apresentaram os menores níveis de colesterol total, triglicerídeos e LDL quando comparados com o tratamento sem SP.

Conclui-se que a dieta com 4 e $6 \%$ de spirulina melhorou o desempenho zootécnico e demonstrou ser eficaz na redução do colesterol, triglicerídeos e LDL.

Palavras-chave: Aquicultura. Peixe neotropical. Nutrição. Microalgas. Parâmetros bioquímicos

Apoio: CNPq; CAPES; FAPEMIG, UFLA.

\footnotetext{
1 Doutorando em Zootecnia pela Universidade Federal de Lavras. https://orcid.org/0000-0002-5163-4615. willfc14@gmail.com.

2 Graduando em Biologia pela Universidade Federal de Lavras. http://lattes.cnpq.br/0759178286291975. pedro.lc.uzeda@hotmail.com.

${ }_{3}^{3}$ Doutoranda em Ciências Veterinárias pela Universidade Federal de Lavras. https://orcid.org/0000-0003-3299-2633. tassia_fd@hotmail.com.

${ }^{4}$ Instituto de Investigaciones Agropecuarias y Forestales, Universidad Michoacana de San Nicolas de Hidalgo, México. http://orcid.org/0000-0003-0703-4599. cpalacios@umich.mx.

${ }_{5}^{5}$ Professor do Departamento de Medicina Veterinária da Universidade Federal de Lavras. https://orcid.org/0000-00020066-7505.1smurgas@ufla.com.
} 


\title{
AVALIAÇÃO DA FREQUÊNCIA ALIMENTAR NO DESEMPENHO PRODUTIVO DE JUVENIS DE ACARÁ-BANDEIRA (Pterophyllum scalare)
}

\author{
Thayná de Souza Pardo하 Layon Carvalho de Assis²; Paola de Oliveira Santos ${ }^{3}$; Samuel Oliveira da \\ Silva ${ }^{4}$; Paula Del Caro Selvatici ${ }^{5}$; Pedro Pierro Mendonça ${ }^{6}$.
}

O mercado de peixes ornamentais é um dos setores mais lucrativos da aquicultura, dentre os animais mais comercializados podemos citar o Acará-bandeira (Pterophyllum scalare). O Acará-bandeira se destaca por sua beleza, diversidade de coloração e sua fácil adaptação á aquários. Dentro da produção aquícola ornamental, o custo com ração não ultrapassa os 30\%, porém este valor pode subir caso o manejo alimentar não seja realizado de forma correta. Uma variável ser analisada no manejo alimentar é a frequência de alimentação, que é caracterizada como o número de vezes que o alimento é ofertado aos animais e, quando trabalhada de maneira correta pode trazer benefícios ao produtor. Desta forma o objetivo do presente estudo foi avaliar a influência da frequência alimentar no desempenho de juvenis de Acará-bandeira (P. scalare).

Foram utilizados 288 juvenis de acará-bandeira com peso médio de $561 \mathrm{mg}$ e comprimento total médio de $1,86 \mathrm{~cm}$. Os animais foram distribuídos em 48 unidades experimentais, totalizando 6 animais por unidade. $\mathrm{O}$ experimento teve duração de 60 dias. A taxa de arraçoamento foi de $8 \%$ do peso vivo distribuídos ao longo do dia em 4 frequências alimentares (1,2,4 e 6x ao dia). Foi fornecida ração comercial com $45 \%$ de proteína bruta. Para manutenção da qualidade de água, os parâmetros: pH, oxigênio dissolvido e amônia foram analisados diariamente. A biometria dos animais foi realizada aos 0, 20, 40 e 60 dias de experimentação e foram avaliados os parâmetros de desempenho produtivo. Os dados foram coletados e avaliados através do programa Sisvar 5.6 build 86, sendo submetidos a análise de variância e posteriormente ao teste de Tukey a $1 \%$ de probabilidade.

Os parâmetros de qualidade de água não foram influenciados pela frequência alimentar. $\mathrm{O}$ comprimento total foi significativo, a maior média encontrada foi de $2,29 \pm 0,28 \mathrm{~cm}$, com frequência alimentar de $4 \mathrm{x}$ ao dia, este resultado pode ser explicado pela melhor distribuição do alimento no trato intestinal e consequentemente na maior absorção dos nutrientes pelo organismo do animal. Não houve diferença significativa na taxa de sobrevivência, foi observado em todos os tratamentos, maior mortalidade dos menores animais o que pode ser explicado pelo seu comportamento hierárquico. A taxa de crescimento específico e ganho de peso, conversão alimentar aparente e taxa de eficiência proteica também não apresentaram diferença significativa o que é de grande importância em um sistema produtivo, visto que maior frequência alimentar resulta em maior demanda de mão de obra. A partir dos resultados obtidos, conclui-se que a frequência na alimentação de juvenis de acará bandeira não interfere significativamente na maioria das variáveis analisadas, o que é um resultado positivo visto que indica uma menor demanda na mão de obra.

Palavras-chave: Aquicultura. Ornamental. Juvenis. Frequência alimentar.

\footnotetext{
1 Graduanda em Engenharia de Aquicultura pelo Instituto Federal do Espírito Santo. http://lattes.cnpq.br/9659777525837376.eng.thaynapardo@gmail.com.

2 Graduando em Engenharia de Aquicultura pelo Instituto Federal do Espírito Santo. http://lattes.cnpq.br/3957061263756363. layoncdeassis@gmail.com.

3 Graduanda em Engenharia de Aquicultura pelo Instituto Federal do Espírito Santo. http://lattes.cnpq.br/3352096322602573. paolamanfredini111@gmail.com.

4 Graduando em Engenharia de Aquicultura pelo Instituto Federal do Espírito Santo. http://lattes.cnpq.br/2925485868309443. engaquisamuel@gmail.com.

${ }^{5}$ Mestre em Ciências Veterinárias pela Universidade Federal do Espírito Santo. http://lattes.cnpq.br/2173487297345219. Arena9956@uroak.com.

${ }^{6}$ Doutor em Ciência Animal pela Universidade Estadual do Norte Fluminense. Professor do Instituto Federal do Espírito Santo. http://lattes.cnpq.br/3992381145892105.ppierrom@ifes.edu.br.
} 


\title{
TAURINA EM DIETAS PARA JUNDIÁ (Rhamdia quelen): IMPACTOS NO DESEMPENHO E DEPOSIÇÃO DE NUTRIENTES
}

\author{
Gregorio Cargnin $^{1}$; Ana Maria Liberalesso de Freitas ${ }^{2}$; Suziane Ghedini Martinelli ${ }^{3}$; Taida Juliana \\ Adorian $^{4}$; Leila Picolli da Silva 5 .
}

A taurina (ácido 2-aminoetanossulfônico) é um promotor de crescimento em peixes e considerado condicionalmente essencial dependendo da espécie, hábito alimentar, ambiente em que vive e fase de vida. O jundiá (Rhamdia quelen), que é uma espécie de água doce, onívora, com tendência à carnivoria, entretanto não há informações suficientes quanto à eficácia de uso deste aminoácido na nutrição de juvenis de jundiá.

Em vista disso, o objetivo do presente trabalho foi avaliar a suplementação de níveis crescentes de taurina na dieta sobre o desempenho e deposição de nutrientes em juvenis de jundiá.

Foi conduzido um ensaio biológico durante 54 dias em sistema de recirculação de água, com 16 unidades experimentais de 15L (20 peixes/unidade). Utilizando 320 juvenis de jundiá $(5,00 \pm 0,06 \mathrm{~g})$, alimentados com dieta isoenergética e isoproteica (39\% PB e $3.400 \mathrm{Kcal} / \mathrm{Kg}$ ), com distintos níveis de suplementação de taurina $(0,0,5,1,5$ e $2 \%)$. Ao final do período experimental os peixes passaram por jejum e foram submetidos à biometria para coleta de dados (peso e comprimento), assim como de amostras utilizadas para determinação da composição corporal, utilizadas para o cálculo de deposição de nutrientes corporais. O delineamento experimental foi inteiramente ao acaso, com 4 tratamentos e 4 repetições. Os dados foram submetidos ao teste de normalidade (Shapiro-Wilk), as médias comparadas pelo teste de Duncan em nível de 5\% de probabilidade.

Os resultados nos mostraram que a suplementação de taurina em níveis superiores a $0,5 \%$, afeta negativamente o peso final $(1,5$ e $2,0 \%)$, taxa de crescimento específico $(2,0 \%)$ e o consumo de alimento $(2,0 \%)$ pelos peixes. Além disso, reduz a deposição de proteína e gordura corporal $(2,0 \%)$.

A partir destes resultados pode-se concluir que, nessa faixa de peso, a suplementação de taurina não é necessária para jundiás e que sua presença na dieta em níveis entre 1,5 e 2,0\% tem efeito negativo sobre o desempenho e deposição de nutrientes corporais.

Tabela 1 - Parâmetros de desempenho e deposição nutricional em jundiás suplementados com taurina na dieta

\begin{tabular}{lllll}
\hline & Tratamentos & & \\
\cline { 2 - 5 } Parâmetros & $0 \%$ & $0,5 \%$ & $1,5 \%$ & $2,0 \%$ \\
\hline Peso final $(\mathrm{g})$ & $21,72^{\mathrm{a}} \pm 1,24$ & $21,06^{\mathrm{ab}} \pm 1,05$ & $18,21^{\mathrm{bc}} \pm 0,96$ & $15,91^{\mathrm{c}} \pm 0,89$ \\
Taxa de crescimento específico (\%/dia) & $3,22^{\mathrm{a}} \pm 0,11$ & $3,16^{\mathrm{a}} \pm 0,09$ & $2,83^{\mathrm{ab}} \pm 0,09$ & $2,53^{\mathrm{b}} \pm 0,11$ \\
Consumo $(\mathrm{g})$ & $291,81^{\mathrm{a}} \pm 8,24$ & $279,93^{\mathrm{ab}} \pm 7,95$ & $278,12^{\mathrm{ab}} \pm 7,07$ & $258,22^{\mathrm{b}} \pm 9,75$ \\
\hline Deposição nutricional & & & & \\
\hline Deposição de proteína corporal (mg/dia) & $2,60^{\mathrm{a}} \pm 0,21$ & $2,59^{\mathrm{a}} \pm 0,16$ & $2,18^{\mathrm{ab}} \pm 0,13$ & $1,78^{\mathrm{b}} \pm 0,12$ \\
Deposição de gordura corporal (mg/dia) & $1,18^{\mathrm{a}} \pm 0,11$ & $1,19^{\mathrm{a}} \pm 0,07$ & $1,06^{\mathrm{a}} \pm 0,06$ & $0,74^{\mathrm{b}} \pm 0,05$ \\
\hline
\end{tabular}

Fonte: Elaborado pelas autoras. Médias terro padrão.

Palavras-chave: Aminoácidos. Nutrição. Peixe Nativo. Crescimento.

\footnotetext{
${ }^{1}$ Graduado em Zootecnia pela Universidade Federal de Santa Maria. Lattes.cnpq.br/0891753401882662. gregoriocargnin@hotmail.com.

${ }^{2}$ Graduanda em Zootecnia pela Universidade Federal de Santa Maria. Lattes.cnpq.br/2548153822930563. anamaria_lf@hotmail.com

${ }^{3}$ Doutora em Zootecnia pela Universidade Federal de Santa Maria. Professora do Instituto Federal de educação Ciência e Tecnologia. Lattes.cnpq.br/3177217454552432. suziane.martinelli@ifam.edu.br.

${ }^{4}$ Pós-doutoranda em Zootecnia pela Universidade Federal de Santa Maria. Lattes.cnpq.br/5315093891875912. taidajuliana@yahoo.com.br.

${ }^{5}$ Doutora em Zootecnia pela Universidade Federal do Rio Grande do Sul. Professora do Departamento de Zootecnia da Universidade Federal de Santa Maria. Lattes.cnpq.br/9378190351379861. leilapicollidasilva@gmail.com.
} 


\title{
AVALIAÇÃO DE METODOLOGIA DE TEMPO DE COLETA EM EXPERIMENTOS DE DIGESTIBILIDADE DE PROTEÍNA BRUTA DE JUVENIS DE TILÁPIAS DO NILO (Oreochromis niloticus, Linnaeus, 1758)
}

\author{
Samuel Oliveira da Silva ${ }^{1}$; Layon Carvalho de Assis ${ }^{2}$; Paola de Oliveira Santos ${ }^{3}$; Thayná de Souza \\ Pardo $^{4}$; Tchesley Lyrio Queiroz ${ }^{5}$; Pedro Pierro Mendonça ${ }^{6}$.
}

A aquicultura tem contribuído de forma significativa na produção de proteína animal e, assim como na criação de qualquer espécie, a alimentação é um importante fator para um bom desenvolvimento além de ser responsável por grande parte dos custos de produção. Ter o conhecimento de quanto o animal aproveita dos ingredientes da ração é um método de efetivar e melhorar seu desenvolvimento zootécnico. O estudo da digestibilidade da proteína é de grande importância na elaboração de rações, resultando em melhor balanceamento e com melhor precisão na dieta de organismos aquáticos, porém o método de coleta de fezes para a realização da análise é um processo exaustivo e deve ser feito em um curto período de tempo entre as coletas de amostras. O objetivo do trabalho foi avaliar a perda de compostos nitrogenados das fezes para água em diferentes espaços de tempo.

Para a realização do trabalho foram utilizados 640 peixes com peso médio de 4,72 $\pm 0,67 \mathrm{~g}$, distribuídos em 20 incubadoras, totalizando uma biomassa média $151 \mathrm{~g}$ por incubadora. As incubadoras eram equipadas com um coletor provido de registro, para a interrupção da passagem de água durante a coleta das fezes. Durante todo o experimento havia fluxo contínuo de ar individual para cada incubadora. A temperatura da água foi mantida em torno de $28{ }^{\circ} \mathrm{C}$ com auxílio de aquecedores com termostato e monitorada diariamente. Os animais foram alimentados $1 \mathrm{vez}$ ao dia, com ração comercial com $36 \%$ proteína bruta. As coletas foram distribuídas em cinco intervalos de tempo (tratamentos), quatro incubadoras para cada tratamento, em delineamento inteiramente casualizado (DIC). Os tratamentos foram distribuídos em uma, quatro, sete, dez e treze horas, após cada coleta as amostras foram armazenadas em freezer horizontal a $18^{\circ} \mathrm{C}$ até o fim do experimento. Ao fim do experimento as amostras foram secas em uma estufa com circulação e renovação de ar a $60{ }^{\circ} \mathrm{C}$ por 48 horas. As amostras secas foram levadas para a determinação de nitrogênio total e proteína bruta, conforme a metodologia adaptada de Kjeldahl. As análises estatísticas foram realizadas através do programa softwareR, com teste de normalidade dos resíduos Shapiro-Wilk, teste de homogeneidade de variância Bartlett e teste $\mathrm{F}$ a $1 \%$ de significância.

Os tratamentos não apresentaram diferença significativa entre si. Este resultado pode ser explicado pelo fato de que as proteínas desnaturadas pelo processo de digestão, não são tão hidrossolúveis quanto o seu arranjo primário, o que as mantém estáveis em contato com a água. Isso permite concluir que os trabalhos que avaliam a digestibilidade de Proteína Bruta de juvenis de tilápia podem ser planejados para que a sua execução ocorra com o espaço de coleta de até 13 horas, permitindo que o trabalho seja realizado de forma menos intensa.

Palavras-chave: Aquicultura. Nutrição. Alimentação. Arraçoamento. Manejo.

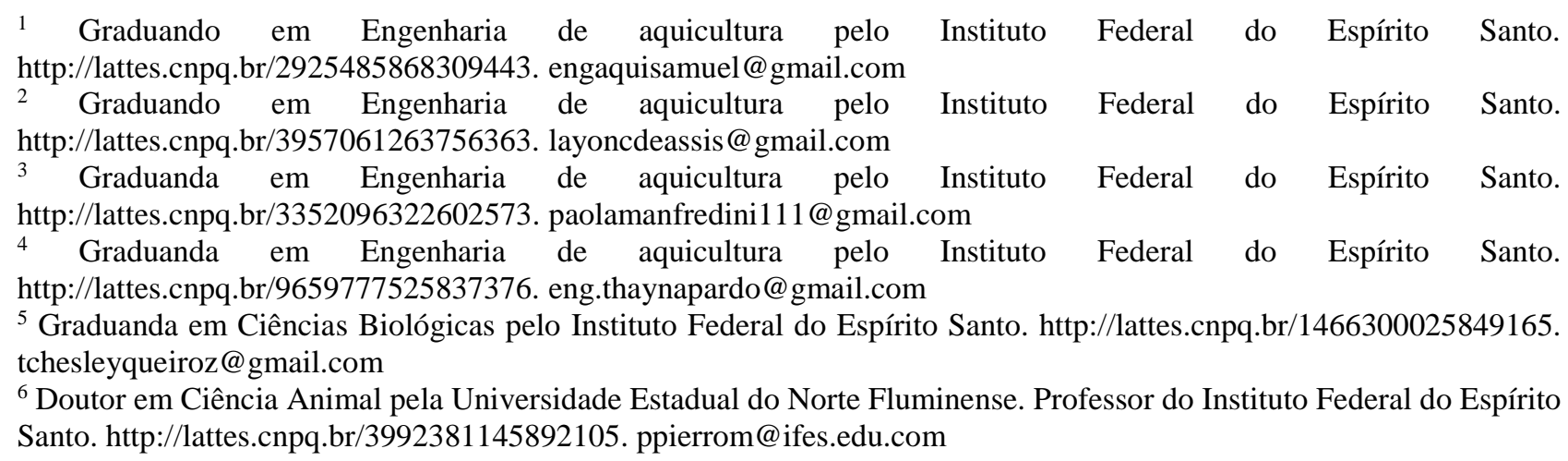




\title{
EFEITO DA DIETA À BASE DE Nauphoeta cinerea NO CRESCIMENTO, SISTEMA IMUNE E ATIVIDADE ENZIMÁTICA EM Litopenaeus vannamei
}

\author{
Cristina Rios ${ }^{1}$; Karolina Victória Rosa ${ }^{2}$; Carlos Peres Silva ${ }^{3}$.
}

O cultivo de camarões marinhos é uma atividade que contribui de maneira significativa para o crescimento econômico de muitos países. Dentre as principais espécies produzidas está o camarão branco-do-pacífico, Litopenaeus vannamei, a qual apresenta fatores zootécnicos favoráveis para criação em cativeiro. Um dos grandes entraves da produção do camarão branco-do-pacífico, Litopenaeus vannamei, além da fácil disseminação de agentes patogênicos, é o alto custo dos insumos como a alimentação.

Na nutrição de espécies aquícolas, é utilizado a farinha de peixe como principal ingrediente proteico, no entanto, busca-se fontes alternativas de proteínas mais sustentáveis e econômicas. Com isso, temse elaborado estudos com uso de farinha de inseto na alimentação de camarões. Este trabalho tem por objetivo avaliar o desempenho zootécnico, o perfil de enzimas digestivas e imunológicos de camarões juvenis da espécie Litopenaeus vannamei $(\mathrm{n}=36)$ alimentados com farinha do inseto Nauphoeta cinerea (NC), em diferentes níveis de substituição $(25 \%, 50 \%, 75 \%$ e $100 \%)$ e uma dieta controle utilizando apenas a farinha de peixe.

Após período de alimentação foi avaliado o desempenho zootécnico dos animais, como ganho de peso final e a sobrevivência. Além deste, foi coletado o hepatopâncreas dos animais para avaliar o perfil de enzimas digestivas por meio das atividades do tipo tripsina, quimotripsina e amilases, assim como fracionamento da atividade amilásica por zimograma. A coleta da hemolinfa foi realizada para avaliar parâmetros imunológicos como a Contagem Total de Hemócitos (THC), concentração total de proteínas do soro, atividade da enzima fenoloxidase (PO) e a capacidade aglutinante do soro. Os resultados demonstraram que não houve diferença significativa entre os tratamentos e o controle em nenhum dos parâmetros analisados.

Além disso, os dados obtidos no desempenho zootécnico revelam que o ganho de peso, a taxa de crescimento e a taxa de sobrevivência não foram alterados com a substituição da farinha de inseto na dieta dos camarões. Em conclusão, sugere-se que a farinha de $N$. cinerea pode substituir a farinha de peixe na alimentação dos camarões sem causar prejuízos no desempenho zootécnico, e na saúde dos animais.

Palavras-chave: Litopenaeus vannamei, Nutrição, Enzimas, Insetos.

Apoio: Roseane L. Panini, Jaqueline Da Rosa Coelho; Karolina Vitória Rosa; Norha C. B. Ramírez, Maria Fernanda Oliveira da Silva; Felipe Nascimento Vieira; Debora Machado Fracalossi; Carlos Peres Silva.

\footnotetext{
${ }^{1}$ Doutoranda em Bioquímica pela Universidade Federal de Santa Catarina. http://lattes.cnpq.br/0594287213383289. crisaqi1@gmail.com.

2 Graduanda em Engenharia de Aquicultura pela Universidade Federal de Santa Catarina. http://lattes.cnpq.br/5205773308062565. Karolina.vrosa@gmail.com.

3 Pós-doutorado no Departamento de Biologia e Bioquímica da University of Bath, Inglaterra. http://lattes.cnpq.br/1915826985515007. carlos.peres@ufsc.br.
} 


\title{
AVALIAÇÃO DA RESTRIÇÃO ALIMENTAR NO DESEMPENHO PRODUTIVO DE JUVENIS DE ACARÁ BANDEIRA (Pterophyllum scalare)
}

\author{
Paola de Oliveira Santos ${ }^{1}$; Layon Carvalho de Assis ${ }^{2}$; Samuel de Oliveira da Silva ${ }^{3}$; Thayná de \\ Souza Pardo ${ }^{4}$; Paula Del Caro Selvatici ${ }^{5}$; Pedro Pierro Mendonça ${ }^{6}$.
}

Com o passar dos anos a piscicultura ornamental tem se destacado cada vez mais no mercado aquícola, deste modo estudos de nutrição e fisiologia das espécies tornam-se cada vez mais importantes para o sucesso da atividade. O manejo alimentar correto propicia um melhor aproveitamento dos alimentos resultando em um menor custo de produção. Estratégias de alimentação com restrição alimentar fazem com que os peixes diminuam a demanda energética. Durante o jejum o metabolismo passa a funcionar utilizando de reservas endógenas de energia resultando na perda de peso. Porém as espécies respondem de forma diferente ao jejum. Sendo assim, o presente estudo buscou avaliar a restrição alimentar no desempenho de juvenis de acará bandeira (Pterophyllum scalare).

Foram utilizados 288 juvenis de acará-bandeira com peso médio de $561 \mathrm{mg}$ e comprimento total médio de $1,86 \mathrm{~cm}$. Os animais foram distribuídos em 48 unidades experimentais, totalizando 6 animais por unidade. O experimento teve duração de 60 dias. Neste período foram testadas 3 restrições alimentares (alimentados todos os dias, a cada 2 dias e a cada 4 dias). Foi fornecida aos animais ração comercial com $45 \%$ de proteína bruta. Para manutenção da qualidade de água, os parâmetros: pH, oxigênio dissolvido (OD) e amônia foram analisados diariamente. A biometria dos animais foi realizada aos $0,20,40$ e 60 dias de experimentação e foram avaliados: Sobrevivência, taxa de crescimento específico, ganho de peso, conversão alimentar aparente e taxa de eficiência proteica.

O resultado obtido para sobrevivência mostra que os animais submetidos ao jejum de 4 dias são mais

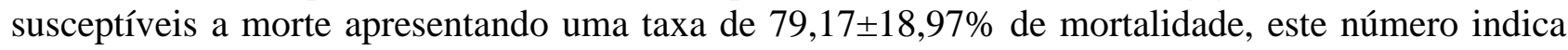
que as reservas endógenas de energia não são capazes de manter o funcionamento do metabolismo do animal, que na fase juvenil tem uma alta demanda energética. A taxa de crescimento específico mostrou que os animais não submetidos a restrição alimentar tem melhor desempenho que todos os intervalos de restrição testados $(1,68 \pm 0,31 \%)$, este resultado pode ser explicado pelo fato de que após o período de jejum, quando a alimentação é normalizada, os processos fisiológicos passam a ser reestabelecidos e o alimento serve para suprir as necessidades vitais e somente depois passa a ser usado no crescimento. Tal fato também explica o maior ganho de peso dos animais sem restrição $(157,82 \pm 31,15 \mathrm{mg})$. A conversão alimentar aparente (CAA) e a taxa de eficiência proteica (TEP), não foram afetadas pelos tratamentos.

$\mathrm{O}$ estudo mostrou que a maior parte das variáveis analisadas apresentaram diferença significativa, e indica que a alimentação diária resulta em um melhor desempenho para juvenis de acará bandeira.

Palavras-chave: Aquicultura. Ornamental. Juvenis. Restrição alimentar.

\footnotetext{
1 Graduanda em Engenharia de Aquicultura pelo Instituto Federal do Espírito Santo. http://lattes.cnpq.br/3352096322602573. paolamanfredini111@gmail.com.

2 Graduando em Engenharia de Aquicultura pelo Instituto Federal do Espírito Santo. http://lattes.cnpq.br/3957061263756363. layoncdeassis@gmail.com.

3 Graduando em Engenharia de Aquicultura pelo Instituto Federal do Espírito Santo. http://lattes.cnpq.br/2925485868309443. engaquisamuel@gmail.com.
Graduanda em Engenharia de Aquicultura pelo Instituto Federal do Espírito Santo. http://lattes.cnpq.br/9659777525837376. eng.thaynapardo@gmail.com

${ }^{5}$ Mestre em Ciências Veterinárias pela Universidade Federal do Espírito Santo. http://lattes.cnpq.br/2173487297345219. Arena9956@uroak.com.

${ }^{6}$ Doutor em Ciência Animal pela Universidade Estadual do Norte Fluminense. Professor do Instituto Federal do Espírito Santo. http://lattes.cnpq.br/3992381145892105.ppierrom@ifes.edu.br.
} 


\title{
EFEITOS DO ÁCIDO FÍTICO NO DESEMPENHO E ESTRESSE OXIDATIVO DE JUNDIÁS Rhamdia quelen
}

\author{
Éverton Augusto Kowalski ${ }^{1}$; Aline Neis $\mathrm{Knob}^{2}$; Letícia Lopes da Costa ${ }^{3}$; Taida Juliana Adorian ${ }^{4}$; \\ Leila Picolli da Silva ${ }^{5}$.
}

O ácido fítico é a forma química predominante de armazenamento de fósforo nas sementes dos vegetais, geralmente associado a efeitos indesejáveis. Por outro lado, pesquisas têm demonstrado que este composto possui ação moderadora do estresse oxidativo em peixes.

Na nutrição de peixes, a escassez de informações sobre os efeitos do ácido fítico motivaram o desenvolvimento desse estudo com objetivo de avaliar o efeito da suplementação de diferentes níveis de ácido fítico em dietas para juvenis de jundiá (Rhamdia quelen), sobre parâmetros de desempenho e de estresse oxidativo.

Para isso, quatro dietas foram preparadas (38\% de PB/3200 kcal de ED) com distintos níveis de ácido fítico $(0 ; 1 ; 1,5$ e $2 \%)$. Os animais foram alimentados três vezes ao dia, durante 50 dias, em sistema de recirculação de água composto por 16 tanques ( 15 peixes/tanque $-7,00 \pm 2.30 \mathrm{~g}$ ). Após o período experimental, os peixes passaram por jejum (18h) e foram submetidos a biometria para coleta de peso e comprimento, para determinar o desempenho, e de tecido hepático, para determinação da atividade de enzimas antioxidantes. $\mathrm{O}$ delineamento experimental foi inteiramente casualizado, com quatro tratamentos e quatro repetições. Os dados foram submetidos à análise de variância e as médias comparadas pelo teste de Tukey $(\mathrm{P}<0,05)$.

Os resultados mostram que o consumo de ácido fítico na concentração de $10,00 \mathrm{~g} / \mathrm{kg}(1 \%)$, promove maior ganho de peso $(27,88 \mathrm{~g})$ e taxa de crescimento específico $(3,20 \%)$ aos peixes. Além de aumentar a atividade das enzimas antioxidantes superóxido dismutase e catalase.

Assim, podemos concluir que a administração de ácido fítico, de forma correta e dirigida, age como promotor de desempenho e com efeito protetivo ao estresse oxidativo para jundiás.

Tabela 1 - Desempenho e atividade de enzimas antioxidantes hepáticas de jundiás alimentados com ácido fítico na dieta

\begin{tabular}{lllllll}
\hline Tratamentos & $0 \%$ & $1 \%$ & $1,5 \%$ & $2 \%$ & EP & P-valor \\
\hline Ganho de peso $(\mathrm{g})$ & $25,3^{\mathrm{b}}$ & $27,8^{\mathrm{a}}$ & $21,10^{\mathrm{b}}$ & $19,66^{\mathrm{b}}$ & 0,93 & 0,006 \\
Taxa de crescimento específico (\%/dia) & $3,06^{\mathrm{ab}}$ & $3,20^{\mathrm{a}}$ & $2,78^{\mathrm{b}}$ & $2,67^{\mathrm{b}}$ & 0,06 & 0,006 \\
Conversão alimentar aparente & 1,28 & 1,27 & 1,46 & 1,54 & 0,06 & 0,631 \\
\hline Atividade de enzimas antioxidantes & & & & & & \\
\hline Superóxido dismutase (UI/mg proteína) & $3,58^{\mathrm{b}}$ & $5,49^{\mathrm{a}}$ & $3,70^{\mathrm{b}}$ & $3,64^{\mathrm{b}}$ & 0,13 & $<0,001$ \\
Catalase ( $\mu \mathrm{mol} / \mathrm{min} / \mathrm{mg}$ proteína) & $3,23^{\mathrm{b}}$ & $4,73^{\mathrm{a}}$ & $3,15^{\mathrm{b}}$ & $3,05^{\mathrm{b}}$ & 0,16 & $<0,001$ \\
\hline
\end{tabular}

Fonte: Elaborado pelos autores. EP: erro padrão, P-valor: nível descritivo do teste $(\mathrm{P}<0.05)$.

Palavras-chave: Antioxidantes. Fitato. Nutrição. Piscicultura.

\footnotetext{
${ }^{1}$ Mestrando em Zootecnia pela Universidade Federal de Santa Maria. lattes.cnpq.br/9082839831311729. evertonzootecnia@outlook.com.

${ }^{2}$ Graduanda em Zootecnia pela Universidade Federal de Santa Maria. lattes.cnpq.br/4973847910556471. alineknob1997@gmail.com.

${ }^{3}$ Mestre em Zootecnia pela Universidade Federal de Santa Maria. lattes.cnpq.br/2802434607616458. leticialopes.zoot@gmail.com

${ }^{4}$ Pós-doutoranda em Zootecnia pela Universidade Federal de Santa Maria. lattes.cnpq.br/5315093891875912. taidajuliana@yahoo.com.br.

${ }^{5}$ Doutora em Zootecnia pela Universidade Federal do Rio Grande do Sul. Professora do Departamento de Zootecnia da Universidade Federal de Santa Maria. lattes.cnpq.br/9378190351379861. leilapicollidasilva@gmail.com.
} 


\title{
FATORES ANTINUTRICIONAIS DA SEMENTE DE FAVEIRA BENTH Parkia platycephala SOBRE O DESEMPENHO DA TAMBATINGA Colossoma macropomum $\mathbf{x}$ Piaractus brachypomus
}

\author{
Pamella Talita da Silva Melo하 Rafael Carvalho da Silva²; Queila Regina Rodrigues Barbosa de \\ Sousa $^{3}$; Renan Ribeiro e Silva ${ }^{4}$; Leonardo Rocha Vidal Ramos ${ }^{5}$.
}

Parkia platycephala ou faveira é uma árvore que ocorre naturalmente no Nordeste brasileiro, onde suas sementes, contendo de cerca de $13 \%$ de proteína bruta, são utilizadas na suplementação animal. No entanto, um fator importante em seu uso é a presença de fatores antinutricionais, tais como as lectinas por integrarem um grupo de proteína capaz de reconhecer carboidratos, podendo causar respostas adversas aos animais, levando-os a óbito. Esse trabalho teve o objetivo de relatar a presença de lectina no extrato de sementes de $P$. platycephala e avaliar o efeito sobre o desempenho da tambatinga (Colossoma macropomum x Piaractus brachypomus).

As sementes de $P$. platycephala foram coletadas no município de Chapadinha-MA, sendo lavadas e moídas obtendo a farinha. A farinha foi utilizada para preparar o extrato bruto utilizando $\mathrm{NaCl}$ a 0,15 M para extração de proteína; em seguida, o extrato foi submetido ao screen de hemaglutinação para avaliar a presença ou não de lectina. Em seguida, foram realizados testes de desnaturação da lectina em diferentes temperaturas e $\mathrm{pH}$. O delineamento consistiu de quatro tratamentos, dietas isoproteícas e isoenergéticas contendo 0,$0 ; 1,0 ; 2,0$ e 3,0 \% de extrato e cinco repetições. 160 alevinos de tambatinga foram divididos em sistema de recirculação de água, durante 60 dias. Finalizado o experimento foi realizada a biometria dos peixes, sendo avaliados os parâmetros de desempenho zootécnico. Os resultados foram submetidos à Análise de Regressão para comparar as médias e a Análise de Variância (ANOVA) a 5 \%. Utilizou-se o software "R" versão 3.6.2.

Os ensaios de hemaglutinação demonstraram a presença de lectina no extrato bruto das sementes e que essa proteína é termoestável mantendo sua atividade em ampla faixa de temperatura, tendo melhor atividade em pH 6,0 e 7,0. Santos et al. (2019) também observaram que a lectina extraída das sementes de Machaerium acutifolium apresentaram maior atividade em pH 6,0 e 7,0. Neste estudo, ganho de peso e ganho de peso relativo apresentaram efeito linear negativo devido ao aumento da inclusão do extrato de faveira (Tabela 1), sugerindo que a presença de lectina pode ter contribuído neste resultado. Martins et al. (2017), relataram que a lectina da soja pode ter afetado o ganho de peso e a ingestão de alimento em tilápias do Nilo (Oreochromis niloticus).

Tabela 1. Desempenho de alevinos de tambatinga (Colossoma macropomum x Piaractus brachypomus) alimentados com dietas contendo diferentes porcentagens de extrato de $P$. platycephala

\begin{tabular}{|c|c|c|c|c|}
\hline \multicolumn{5}{|c|}{ Dietas (Níveis de adição (\%) } \\
\hline & 0 & 1 & 2 & 3 \\
\hline Ganho de Peso $(\mathrm{g}) * *$ & $32,2 \pm 5,4$ & $30,75 \pm 3,3$ & $27,75 \pm 0,52$ & $26,06 \pm 0,6$ \\
\hline $\begin{array}{l}\text { Ganho de Peso } \\
\text { Relativo }(\%)^{* * *}\end{array}$ & $32,2 \pm 5,4$ & $30,75 \pm 3,3$ & $27,75 \pm 0,52$ & $26,06 \pm 0,6$ \\
\hline $\begin{array}{l}\text { Índice } \\
\text { Hepatosomático\# }\end{array}$ & $1,65 \pm 0,15$ & $1,63 \pm 0,10$ & $1,60 \pm 0,20$ & $1,60 \pm 0,12$ \\
\hline Fator de Condição\# & $1,43 \pm 0,22$ & $1,42 \pm 0,5$ & $1,40 \pm 0.22$ & $1,41 \pm 0,15$ \\
\hline
\end{tabular}

Médias são apresentadas como média; $( \pm)$ Erro padrão. $\left(\mathrm{R}^{2}\right)=$ Coeficiente de determinação. (\#) não significante pela ANOVA e Regressão $(p>0,05)$. ** $\mathrm{Y}=34.546-2.165 \mathrm{X} ; p$ - valor $(0,0166) ; \mathrm{R}^{2} 0,34 ; * * * \mathrm{Y}=302.168-10.240 \mathrm{X} ; p$-valor $(<0,00001) ; R^{2} 0,65$.

A inclusão $P$. platycephala em dietas para alevinos de tambatinga não é recomendado por conter lectina e esta afetar negativamente o desempenho zootécnicos dos animais.

Palavras-chave: Aquicultura. Alimentos alternativos. Fatores antinutricionais.

\footnotetext{
${ }^{1}$ Mestranda em Zootecnia na Universidade Federal Rural do Rio de Janeiro. http://lattes.cnpq.br/9489216956736191

${ }_{2}^{2}$ Mestrando em Zootecnia na Universidade Federal Rural do Rio de Janeiro. http://lattes.cnpq.br/7430442264837095

${ }^{3}$ Mestrando em Zootecnia na Universidade Federal Rural do Rio de Janeiro. http://lattes.cnpq.br/8729385208807595

${ }^{4}$ Mestrando em Zootecnia na Universidade Federal Rural do Rio de Janeiro. http://lattes.cnpq.br/9055533208591092

${ }^{5}$ Professor na Universidade Federal Rural do Rio de Janeiro. http://lattes.cnpq.br/2482064548960947
} 
Algicultura

(Macroalgas e Microalgas) 


\section{EFEITOS DE DIFERENTES MEIOS DE CULTIVO NO TEOR DE PROTEÍNA DA MACROALGA Ulva fasciata}

Andrezza Carvalho Chagas ${ }^{1}$; Estefanny Caroline de França Silva ${ }^{2}$; Tomaz Soligo de Mello Ayres ${ }^{3}$; Mariana Holanda Paes Barboza ${ }^{4}$; Luís Henrique da Silva Poersch ${ }^{5}$; Gamze Turan ${ }^{6}$.

As macroalgas desempenham um papel econômico a partir da extração de subprodutos como ágar e carragenana, importantes para indústria farmacêutica e alimentícia (Alencar et al, 2010). Sua composição muda de acordo com os parâmetros físicos e químicos disponíveis no ambiente (Carneiro, 2007). O presente estudo tem como objetivo avaliar o papel de dois ambientes distintos na concentração proteica no tecido da macroalga Ulva fasciata.

O experimento teve duração de 35 dias, consistindo em seis carboys com volume útil de $3 \mathrm{~L}$, areação constante e fotoperíodo $12 \mathrm{hs}$ claro/escuro. A macroalga teve peso inicial de $6,22 \pm 0,10 \mathrm{~g}$. O delineamento experimental contou com cultivo da $U$. fasciata em dois tratamentos com três réplicas: BFT efluente proveniente da engorda de camarão em sistema de bioflocos; VS solução padrão Von Stosch na concentração de $10 \mathrm{ml} / \mathrm{L}$. As amostras de alga foram colhidas no inicio e ao final do experimento, sendo realizada a secagem em estufa por 24 horas, a $60^{\circ} \mathrm{C}$. Em seguida, a biomassa seca foi moída e a proteína bruta foi determinada pelo método de titulação Kjhedal.

Os resultados mostraram que as macroalgas cultivadas em efluente do cultivo de camarão possuíram maior teor de proteína bruta em seu tecido e coloração mais verde do que aquelas cultivadas em solução Von Stosch (Tabela 1). O efluente do sistema em Bioflocos possui elevada concentração de sólidos suspensos e nitrogênio disponível. Em áreas com menor disponibilidade de luz, as macroalgas tendem a compensar no aumento de pigmentos, assim como o alto teor de nitrogênio na água proporciona um aumento no teor de proteína das algas (Duke et al, 1989).

Foi possível determinar que macroalgas cultivadas em efluente do camarão em sistema de Bioflocos possui um aumento do teor proteico em seu tecido. Mostrando que um sistema sustentável de reutilização de efluentes para cultivo de macroalgas é viável.

Tabela 1 - Teor de proteína encontrado nos tratamentos BFT (Biofloco in natura) e VS (solução Von Stoch) ao final do cultivo. Letras minúsculas diferentes representam diferença significativa $(p<0,05)$ entre os tratamentos após teste $t$ de Student.

\begin{tabular}{cc}
\hline Tratamentos & Teor de proteína (\%) \\
\hline BFT & $21,15 \pm 0,62 \mathrm{a}$ \\
VS & $12,40 \pm 2,73 \mathrm{~b}$ \\
\hline \multicolumn{2}{c}{ Fonte: Autora }
\end{tabular}

Palavras-chave: Macroalgas. Carcinicultura. Bioflocos. Meios de Cultura. Proteína

\footnotetext{
1 Mestranda em Aquicultura pela Universidade Federal de Rio Grande. http://lattes.cnpq.br/1275197981223128. andrezzachagas@hotmail.com.

2 Mestranda em Aquicultura na Universidade Federal do Rio Grande. http://lattes.cnpq.br/2407751108346349. esthefanycfs@gmail.com.

3 Mestrando em Aquicultura na Universidade Federal do Rio Grande. http://lattes.cnpq.br/7110867741970987. tomazayres@hotmail.com

4 Doutora em Aquicultura pela Universidade Federal do Rio Grande. http://lattes.cnpq.br/1352578595965600. mariana.holandalima@gmail.com.

5 Doutor em Aquicultura pela Universidade Federal do Rio Grande. Professor do Instituto de Oceanografia da Universidade Federal do Rio Grande. http://lattes.cnpq.br/2302658488477730. lpoersch@ mikrus.com.br.

${ }^{6}$ Doutora em Aquicultura pela Ege University. Professora visitante do Instituto de Oceanografia da Universidade Federal do Rio Grande. https://orcid.org/0000-0002-3610-6347. gamzeturan2000@ gmail.com.
} 


\title{
MÉTODOS DE SECAGEM DA MACROALGA Kappaphycus alvarezii CULTIVADA EM FLORIANÓPOLIS
}

\author{
Leonardo Pereira Felicidade ${ }^{1}$; Isadora Carminatti da Silva ${ }^{2}$; Sarah de Jesus Cantarino ${ }^{3}$; Leila
}

Hayashi ${ }^{4}$.

As macroalgas destinadas à extração de carragenana, como a espécie Kappaphycus alvarezii Doty (Doty) ex P.C. Silva, possuem relevância social e econômica nos países em que são cultivadas comercialmente. A viabilidade do cultivo em Santa Catarina, foi verificada a partir de pesquisas e cultivos experimentais por Hayashi et al. (2011) e Santos (2014) até a recente liberação de licença para cultivo comercial. A secagem da alga nesses cultivos experimentais foi feita diretamente ao sol, distribuída sobre uma lona. Este método simples não agrega custos à produção, mas pode ter eficiência comprometida dependendo das circunstâncias climáticas. Atualmente, um dos desafios para implementação desta cadeia produtiva é o processo da secagem em larga escala. Diferentes parâmetros como umidade, calor e luz solar em excesso, podem influenciar no rendimento, na qualidade e no valor comercial da carragenana.

O presente trabalho teve como objetivo identificar os possíveis métodos de secagem da macroalga $K$. alvarezii para o cultivo comercial em Florianópolis.

Um levantamento de trabalhos relacionados ao tema foi realizado para proposição do desenvolvimento de uma secadora aplicável às demandas locais e condições ambientais.

De acordo com os métodos descritos por Fudholi et al. (2009) e Ali et al. (2017), as secagens assistidas por energia elétrica ativa e híbrida foram selecionadas como opções mais eficientes. Na secagem por energia elétrica ativa, um fluxo de ar é induzido (convecção forçada) na câmara de secagem. Dois protótipos de secadoras foram desenvolvidos nos últimos anos no Estado utilizando esse princípio para produção em pequena escala. Faria (2012) utilizou uma estufa com circulação e renovação de ar forçado e Carvalho e Nagaoka (2014) adaptaram uma secadora de roupa, com a adição de um controlador de temperatura externo. Ambos os trabalhos apontaram $60^{\circ} \mathrm{C}$ como a melhor temperatura para o rendimento da carragenana. O método híbrido consiste em um sistema auxiliar de armazenamento de energia renovável, para o funcionamento durante a ausência de luz solar. Por exemplo, Ali et al. (2017) desenvolveram na Malásia, uma casa de vegetação com uma estrutura com ranhuras em "V" (V-Groove), para conter o calor em seu interior, sendo até $70 \%$ mais eficiente do que o método de exposição ao sol.

Os métodos de secagem híbridos são possibilidades mais eficientes na pós-colheita da K. alvarezii, pois retém a temperatura ideal e reduz os custos adicionais durante esse processo, mantendo a qualidade final da carragenana.

Palavras-chave: Carragenana. Cultivo comercial. Macroalgas. Pós-colheita. Secagem de algas.

\footnotetext{
1 Graduando em Engenharia de Aquicultura pela Universidade Federal de Santa Catarina. http://lattes.cnpq.br/7068058247094699. leonardopereirafelicidade@gmail.com.

2 Graduanda em Engenharia de Aquicultura pela Universidade Federal de Santa Catarina. http://lattes.cnpq.br/9704746229066114. isacarmn@gmail.com.

${ }^{3}$ Mestre em Biotecnologia Marinha pelo Instituto de Estudos do Mar Almirante Paulo Moreira e pela Universidade Federal Fluminense. Pesquisadora voluntária na Universidade Federal de Santa Catarina. http://lattes.cnpq.br/5433441258204564. s.cantarino@gmail.com.

${ }^{4}$ Doutora em Ciências Biológicas (Botânica) pela Universidade de São Paulo. Professora do Departamento de Aquicultura da UFSC. http://lattes.cnpq.br/0118169228234463. leilahayashi@ hotmail.com.
} 


\title{
ANÁLISES FÍSICO-QUÍMICAS DO ÁGAR DAS MACROALGAS Gracilaria birdiae, G. domingensis e G. intermedia EXTRAÍDO COM USO DE ÁCIDOS E BASES NATURAIS
}

\author{
Andreline Jordana Coelho de Mendonça ${ }^{1}$; Marco Aurélio Pereira Leite ${ }^{2}$; Sandra Helena de \\ Mesquita Pinheiro ${ }^{3}$; Margarida Maria Monteiro Vasconcelos ${ }^{4}$.
}

O gênero de Gracilaria é o recurso mais abundante e promissor de produção de ágar, sendo um grupo de algas de águas quentes tendo aproximadamente mais de 150 espécies, de distribuição cosmopolita principalmente nas regiões temperadas, tropicais e subtropicais. O ágar, advindo das algas, é amplamente utilizado na produção de gelatinas por se tratar de um tipo de fibra que não é digerido e tem propriedade laxativa.

A presente pesquisa teve por objetivo avaliar a extração do ágar obtido das espécies Gracilaria birdiae, G. domingensis e G. intermedia, com uso de ácidos e bases naturais coletadas no litoral piauiense.

As algas foram coletadas na Praia do Coqueiro-PI. Foram utilizadas $5 \mathrm{~g}$ de amostras de alga seca, branqueada triturada e hidratada para cada tratamento. Conforme segue: (T1). Extração água destilada; (T2). Extração química; (T3). Extração com uso de suco de limão; (T4). Extração com uso da casca do limão; (T5). Extração com o uso sumo da folha do cajueiro; (T6). Extração com o uso do sumo do caule de cajueiro. $\mathrm{O}$ ágar obtido através dos tratamentos indicados foram analisados quanto ao rendimento do processo (regra de três simples), umidade (estufa a $75^{\circ} \mathrm{C}$ ) e $\mathrm{pH}$. Todas as análises foram realizadas em triplicata com uma repetição.

Os resultados médios obtidos acerca dos aspectos físico-químico do ágar em G. birdiae, G. domingensis e $G$. intermedia, de acordo com a metodologia de extração, indicaram que os padrões de $\mathrm{pH}$ observados, foram considerados estatisticamente iguais entre as espécies e tratamentos aplicados. Não foram observadas diferenças significativas entre os valores de umidade $\left(\mathrm{g} 100 \mathrm{~g}^{-1}\right)$ nos diversos tratamentos aplicados às espécies algais $G$. birdiae e $G$. domingensis. Entretanto foi verificada diferença nas amostras de ágar extraídas da alga $G$. intermedia, com valores de umidade variando de

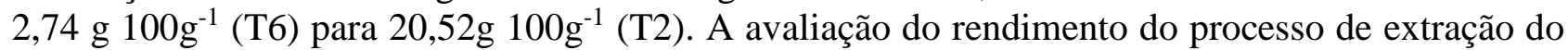
ágar (\%) não evidenciou diferença significativa entre os tratamentos T1 e T3 e nas infusões T4, T5 e T6, aplicados as três espécies de algas estudadas, ficando este parâmetro num intervalo de 30,21\%, no ágar extraído de $G$. birdiae T4 e de 47,65\% T5 na alga $G$. intermedia. No entanto, para as três espécies pesquisadas o T2 reportou diferenças entre os demais tratamentos com valores desde 74,68\% a $89,48 \%$, para $G$. intermedia e $G$. domingensis, respectivamente, sendo este último o maior nível de rendimento do ágar entre os tratamentos aplicados.

O rendimento do ágar nas três algas (Gracilaria birdiae, G. domingensis e G. intermedia) estudadas obtido pelo tratamento alcalino (T2) foi o mais expressivo. O nível de umidade apresentou diferença em função dos tratamentos e das espécies algais, sendo o maior verificado em $G$. intermedia, em T2 (alcalino). $\mathrm{O}$ pH do ágar em todos os tratamentos não variou para as espécies nem para os tratamentos, no entanto apresentaram tendência alcalina.

Palavras-chave: Algas vermelhas. Extração de ágar. Ficocolóide.

\footnotetext{
${ }^{1}$ Doutoranda em Aquicultura pela Universidade Nilton Lins/ Instituto de Pesquisa do Amazônia. http://lattes.cnpq.br/7437413920664181. andrelinecoelho@hotmail.com.

${ }^{2}$ Graduado em Engenharia de Pesca pela Universidade Federal do Piauí. http://lattes.cnpq.br/1884723385237663. aurelioleite44@hotmail.com.

${ }^{3}$ Doutora em Ciência e Tecnologia de Alimentos pela Universidade Federal de Viçosa. http://lattes.cnpq.br/4484097121967936. sandrapinheiro@ufpi.edu.br.

${ }^{4}$ Doutoranda em Ciências de Alimentos pela Université Laval/Québec/ Canada. http://lattes.cnpq.br/8014778607957469. margaridavasconcelos@ufpi.edu.br.
} 


\title{
ACLIMATAÇÃO DA MACROALGA Ulva ohnoi EM DIFERENTES SALINIDADES NO SISTEMA DE BIOFLOCOS
}

\author{
Ana Paula Mariane de Morais ${ }^{1}$; Weverson Ailton da Silva ${ }^{2}$; Julianna Paula do Vale Figueiredo ${ }^{3}$
}

Felipe do Nascimento Vieira ${ }^{4}$.

As macroalgas são comumente utilizadas em sistemas AMTI devido sua capacidade de absorver compostos nitrogenados e fosfato, no entanto é importante avaliar a resistência da ulva em diferentes salinidades aplicadas no sistema bioflocos.

O objetivo do trabalho é aclimatar as macroalgas Ulva onhoi em diferentes salinidades no sistema de bioflocos para integrar em sistema multitrófico.

O delineamento experimental constituiu de quatro tratamentos e três repetições cada, denominados: S15: salinidade $15 \%$; S20: salinidade $20 \%$; S25: salinidade $25 \%$ e S30: salinidade $30 \%$. Com duração de 3 semanas. Para aclimatação foi inserido $25 \%$ de água de bioflocos filtrado (filtro Bag de bidim) e preenchida com água do mar para atingir a salinidade inicial de $30 \%$ para todos os tratamentos e diariamente a salinidade foi diminuída até atingir a salinidade referente a cada tratamentos $\left(30,25,20\right.$ e $15 \%$ ). As macroalgas foram povoadas a uma densidade de $2 \mathrm{~g} \mathrm{~L}^{-1}$, em tanques quadrados com volume útil de 40 litros, pesadas semanalmente para acompanhar o crescimento, quando ultrapassava o peso inicial de $80 \mathrm{~g}$ foi coletado o excedente para ao final do experimento calcular a biomassa final.

Os resultados demostram que não houve diferença significativa no incremento de biomassa das macroalgas entre os tratamentos $(\mathrm{P}>0,05)$ (Figura 01). Assim, as macroalgas se adaptaram nas quatro salinidades testadas sem ocorrer mortalidade e houve um incremento de biomassa em todos os tratamentos, demonstrando que ela pode integrar o sistema multitrófico nas salinidades testadas.

Figura 01: Ganho de biomassa das macroalgas Ulva onhoi aclimatas nas diferentes salinidades no ano de 2020

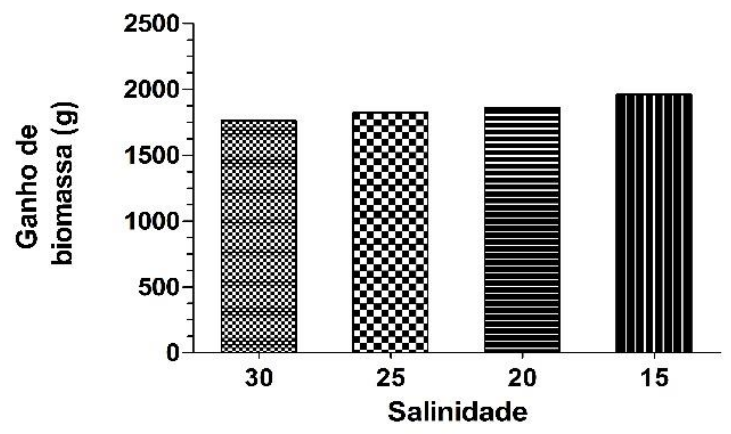

Palavras-chave: Biomassa. Compostos nitrogenados. Sistema multitrófico integrado.

\footnotetext{
${ }^{1}$ Doutoranda em Aquicultura pela Universidade Federal de Santa Catarina. http://lattes.cnpq.br/2538621625115386 paulamariane.morais@gmail.com.

${ }_{2}^{2}$ Mestrando em Aquicultura pela Universidade Federal de Santa Catarina. http://lattes.cnpq.br/8320689687057292 pescailton@gmail.com.

${ }_{3}^{3}$ Doutoranda em Aquicultura pela Universidade Federal de Santa Catarina. http://lattes.cnpq.br/4212230692680889. juliannafigueiredo@hotmail.com

${ }^{4}$ Doutor em Aquicultura pela Universidade Federal de Santa Catarina. Professor da Pós-Graduação em Aquicultura da Universidade Federal de Santa Catarina. http://lattes.cnpq.br/6762840265825292. felipe.vieira@ufsc.br
} 


\section{LEVANTAMENTO QUALITATIVO DO CULTIVO EM TANQUES DA MACROALGA Kappaphycus alvarezii EM FLORIANÓPOLIS}

Pollyanna de França Lima ${ }^{1}$; Sarah de Jesus Cantarino ${ }^{2}$; Leila Hayashi ${ }^{3}$.

A macroalga Kappaphycus alvarezii (Doty) Doty ex P. Silva desenvolve-se bem nos cultivos em Florianópolis $\left(27^{\circ} \mathrm{S}\right)$ durante todo o ano $\left(20^{\circ} \mathrm{C}\right.$ a $\left.32^{\circ} \mathrm{C}\right)$ com exceção do inverno, quando ocorre maiores perdas na produção. Uma opção durante esse período é a manutenção das algas matrizes em cultivo indoor, com condições físico-químicas controladas.

O presente trabalho teve como objetivo identificar os melhores parâmetros para o cultivo em tanques a partir de um levantamento bibliográfico dos trabalhos desenvolvidos na Seção de Macroalgas do Laboratório de Camarões Marinhos (LCM) da UFSC.

Ao todo, 10 trabalhos publicados de 2007 a 2019 foram analisados. Para os experimentos, foram utilizados os tetrasporófitos verde (67\%) e marrom (33\%), cultivados em temperatura de $25 \pm 1^{\circ} \mathrm{C}$, $35 \%$ de salinidade, $\mathrm{pH}$ entre 7,6 e 8,5 e fotoperíodo natural. A aclimatação no escuro antes do período de fertilização assim como alta incidência luminosa com adição de $\mathrm{CO}_{2}$ tiveram resultados promissores. A maioria dos trabalhos analisaram alternativas de fertilização (70\%), destacando-se o uso de bioflocos à $25 \%$ como substituto da solução de Von Stosch 50\%, por apresentar os melhores resultados nas taxas de crescimento, qualidade da carragenana e aumento da força do gel e a viscosidade, Além disso, a fertilização contínua de BFT25 por 4 semanas na densidade de $21 \mathrm{~g} \mathrm{~L}^{-1}$ mostrou-se eficiente como forma de aumentar a taxa de sobrevivência das linhagens quando transplantadas para o mar, além de reduzir custos por ser reuso de efluente de cultivo de camarão. Apenas um trabalho testou diferentes sistemas de circulação de água para melhoria estrutural e outros dois analisaram a transferência da alga do cultivo para o mar.

Tais apontamentos visam nortear futuros estudos para melhor aproveitamento dos recursos e aperfeiçoamento do cultivo em tanques.

Palavras-chave: Manutenção. Inverno. Matrizes. Cultivo em tanques.

\footnotetext{
${ }^{1}$ Mestranda em Aquicultura pela Universidade Federal de Santa Catarina. http://lattes.cnpq.br/9777336243987289. pollyanna.f.lima@ufsc.br.

2 Mestre em Biotecnologia Marinha pelo Instituto de Estudos do Mar Almirante Paulo Moreira e pela Universidade Federal Fluminense. Pesquisadora voluntária na Universidade Federal de Santa Catarina. http://lattes.cnpq.br/5433441258204564. s.cantarino@gmail.com.

3 Professora do curso de graduação em Engenharia de Aquicultura e do programa de pós-graduação em Aquicultura na Universidade Federal de Santa Catarina. http://lattes.cnpq.br/0118169228234463. leila.hayashi@ufsc.br.
} 


\title{
LEVANTAMENTO QUANTITATIVO DA PRODUÇÃO ACADÊMICA RELACIONADA AO CULTIVO DA MACROALGA Kappaphycus alvarezii EM SANTA CATARINA
}

\author{
Thiago César dos Santos ${ }^{1}$; Isadora Carminatti da Silva ${ }^{2}$; Thallis Felipe Boa Ventura ${ }^{3}$; Alex Alves \\ dos Santos ${ }^{4}$; Leila Hayashi ${ }^{5}$.
}

Kappaphycus alvarezii é uma macroalga vermelha originária do sudeste asiático, e foi introduzida em diversos países devido ao seu potencial na produção de carragenana, um ficocolóide com propriedades gelificantes, emulsificantes e estabilizantes. Sua introdução em Santa Catarina teve início com uma solicitação de cultivo experimental em 2007, atendendo a Instrução Normativa IBAMA 165/2007, com o envolvimento da Empresa de Pesquisa Agropecuária e Extensão Rural de Santa Catarina (EPAGRI) e da Universidade Federal de Santa Catarina (UFSC). A viabilidade do cultivo no Estado de Santa Catarina foi verificada pelos estudos e produções acadêmicas de aproximadamente uma década, que embasaram a liberação do cultivo comercial em 2020, pela publicação da Instrução Normativa IBAMA 01/2020.

O objetivo do presente trabalho foi realizar um levantamento das produções acadêmicas da UFSC com temas relacionados ao cultivo da macroalga K. alvarezii desde 2007 até os dias atuais e, demonstrar a o impacto da parceria da Universidade e da EPAGRI na sociedade, em âmbito nacional e internacional.

Para quantificar essa produção acadêmica, foi realizado um levantamento bibliográfico e, posteriormente, os trabalhos foram categorizados por ano de publicação, linha de pesquisa, e por tipo de produção acadêmica, sendo considerados: resumos em anais de Congressos Científicos, artigos de periódicos, capítulos de livros, trabalhos de conclusão de curso, dissertações e teses. Foram analisados a proporção desses trabalhos para cada categoria e a variação temporal na produção desses trabalhos.

Do período de 2007 a 2020, foram produzidos 109 trabalhos acadêmicos com temas relacionados ao cultivo de $K$. alvarezii por autores com algum vínculo com a UFSC, sendo: $22 \%$ artigos publicados em revistas científicas; $52,3 \%$ resumos apresentados em congressos da área; $1,8 \%$ capítulos de livros; $8,3 \%$ TCCs; $13,8 \%$ dissertações de mestrado e, $1,8 \%$ teses de doutorado. Do total de trabalhos, $45,9 \%$ foram publicados em língua estrangeira. Foi observado um aumento gradativo no número de trabalhos no decorrer do período analisado, especialmente daqueles relacionados a finalização de curso.

O levantamento quantitativo dos trabalhos evidenciou o papel pioneiro e fundamental dos profissionais e alunos da UFSC no desenvolvimento de novas técnicas e tecnologias para o cultivo de $K$. alvarezii, tornando a Universidade referência nacional e internacional. Ademais, evidenciou que a parceria com a EPAGRI foi fundamental para o desenvolvimento das atividades. O presente trabalho demonstra a importância de se contabilizar e divulgar a produção acadêmica universitária, cumprindo seu papel de retribuição à sociedade através do conhecimento gerado.

Palavras-chave: Cultivo de macroalgas. Levantamento bibliográfico. Produção técnico-científica.

\footnotetext{
1 Graduando em Engenharia de Aquicultura pela Universidade Federal de Santa Catarina. http://lattes.cnpq.br/7405605295107832.thiago_cesar@outlook.com.br.

2 Graduanda em Engenharia de Aquicultura pela Universidade Federal de Santa Catarina. http://lattes.cnpq.br/9704746229066114. isacarmn@gmail.com.

${ }^{3}$ Mestre em Aquicultura pela Universidade Federal de Santa Catarina. Professor do Ensino Básico, Técnico e Tecnológico do IFC-SFS. http://lattes.cnpq.br/2590246825379859. thallis_omg@ hotmail.com.

4 Doutor em Aquicultura pela Universidade Federal de Santa Catarina. Pesquisador da EPAGRI. http://lattes.cnpq.br/2850994035479133. alex@epagri.sc.gov.br.

${ }^{5}$ Doutora em Ciências Biológicas (Botânica) pela Universidade de São Paulo. Professora do Departamento de Aquicultura da UFSC. http://lattes.cnpq.br/0118169228234463. leilahayashi@ hotmail.com.
} 


\title{
ADIÇÃO DE BICARBONATO DE SÓDIO COMO ESTRATÉGIA DE OTIMIZAÇÃO PARA O CULTIVO indoor DA MACROALGA Kappaphycus alvarezii
}

\author{
Tatiane Beatriz Malinowski Baran; Fernando Zwierzikowski da Silva² ${ }^{2}$ Leila Hayashi ${ }^{3}$.
}

A macroalga Kappaphycus alvarezii possui grande destaque econômico por ser matéria-prima para extração da carragenana kappa, colóide utilizado como agente espessante e estabilizante em diversos ramos da indústria. Em Santa Catarina, o cultivo experimental dessa espécie apresentou taxas de crescimento favoráveis exceto nos períodos de baixa temperatura, época de grande perda biomassa, sendo necessário manter os talos em laboratório. Diversos estudos estão sendo realizados para estabelecer o melhor método de cultivo nesses meses. A suplementação de $\mathrm{CO}_{2}$ tem sido explorada para cultivos em tanques de macroalgas, entretanto seu uso é limitado devido ao elevado custo. $\mathrm{O}$ bicarbonato de sódio poderia ser uma alternativa de suplementação de carbono inorgânico por ser mais simples e econômico.

Com o objetivo de verificar a eficácia da suplementação de bicarbonato de sódio como fonte de carbono para produção de biomassa em laboratório da macroalga de K. alvarezii, segmentos apicais do tetrasporófito proveniente do banco de linhagens da Seção de Macroalgas do Laboratório de Camarões Marinhos (LCM-UFSC), foram aclimatados durante 7 dias antes do início do experimento nas densidades de 7, 14 e $21 \mathrm{~g} \mathrm{~L}^{-1}$ em água do mar esterilizada enriquecida com solução nutritiva de von Stosch 50\%, sob irradiância de $200 \pm 10 \mu \mathrm{mol}$ de fótons $\mathrm{m}^{-2} \mathrm{~s}^{-1}$, fotoperíodo de $12 \mathrm{~h}$, temperatura de $25 \pm 1{ }^{\circ} \mathrm{C}$, salinidade de $35 \%$ e aeração constante. Os talos foram cultivados em triplicatas, nas mesmas condições da aclimatação, sendo adicionado semanalmente concentrações de 1,2 e $3 \mathrm{mM}$ de bicarbonato de sódio $\left(\mathrm{NaHCO}_{3}\right)$. Propágulos cultivados sem a adição de $\mathrm{NaHCO}_{3}$ foram utilizados como controle. Durante 4 semanas, o meio de cultura e o recipiente foram trocados semanalmente com as respectivas concentrações de bicarbonato de sódio, e a taxa de crescimento, $\mathrm{pH}$ e alcalinidade foram registrados. No final da quarta semana, as algas foram cultivadas apenas com água do mar enriquecida por mais 4 semanas, para verificar o desempenho dos talos após os tratamentos com bicarbonato de sódio, simulando a transferência para o mar.

$\mathrm{Na}$ densidade $7 \mathrm{~g} \mathrm{~L}^{-1}$, plantas cultivadas no tratamento de $3 \mathrm{mM}$ apresentaram diferenças significativas na taxa de crescimento apenas na última semana da primeira etapa, sendo observado diminuição do crescimento. A taxa média de crescimento semanal dos propágulos desse tratamento foi de $2,16 \%$ dia $^{-1}$, enquanto o controle apresentou 4,13 \% dia ${ }^{-1}$. Na primeira semana sem adição de bicarbonato, algas desse mesmo tratamento apresentaram um aumento significativo no crescimento de 5,95\% dia ${ }^{-1}$, em comparação com o controle, $4,89 \% \mathrm{dia}^{-1}$. Porém, nas 3 semanas seguintes, as taxas de crescimento de todos os tratamentos se igualaram. Nos tratamentos em densidade de $14 \mathrm{~g} \mathrm{~L}^{-1}$, as taxas médias de crescimento na primeira etapa apresentaram diferenças significativas para as concentrações $2 \mathrm{mM}$ e $3 \mathrm{mM}$ ocorrendo a diminuição do crescimento, e na segunda etapa não houve diferenças nos crescimentos. Algas cultivadas na densidade de $21 \mathrm{~g} \mathrm{~L}^{-1}$ não apresentaram diferenças significativas em nenhuma etapa.

De acordo com os resultados, a concentração de $3 \mathrm{mM}$ de bicarbonato de sódio, na densidade de $7 \mathrm{~g}$ $\mathrm{L}^{-1}$, foi escolhida para o cultivo de $K$. alvarezii em laboratório.

Palavras-chave: Aquicultura. Carragenana. Rhodophyta.

\footnotetext{
${ }_{1}$ Mestranda em Aquicultura pela Universidade Federal de Santa Catarina. http://lattes.cnpq.br/4505909823040492 tatiane.baran@posgrad.ufsc.br

${ }^{2}$ Mestrando em Aquicultura pela Universidade Federal de Santa Catarina. http://lattes.cnpq.br/4747764208601330 fernando.z.s@usfc.br

${ }^{3}$ Doutora em Ciências Biológicas (Botânica) pela Universidade de São Paulo. Professora da Universidade Federal de Santa Catarina. http://lattes.cnpq.br/0118169228234463. leila.hayashi@ufsc.br
} 


\title{
AVALIAÇÃO DO CRESCIMENTO DA MACROALGA Ulva fasciata EM SOLUÇÃO VON- STOSCH E EM EFLUENTE DE CULTIVO DE CAMARÃO MARINHO EM BFT
}

\author{
Esthefany Caroline de França Silva ${ }^{1}$; Andrezza Carvalho Chagas ${ }^{2}$; Mariana Holanda Paes Barboza ${ }^{3}$; \\ Luís Henrique da Silva Poersch ${ }^{4}$; Gamze Turan ${ }^{5}$.
}

No cultivo in vitro de macroalgas, a solução Von-Stosch é bastante utilizada, ela corresponde a um mix de nutrientes, minerais e vitaminas, que são essenciais para o seu desenvolvimento (Edwards, 1970). Seu uso é economicamente inviável para cultivos em grande escala, portanto, se fazem necessários estudos com meios alternativos para produção de macroalgas em maiores escalas. $\mathrm{O}$ efluente do cultivo de camarão marinho em sistema de bioflocos (BFT) é rico em nitrogênio e fósforo, podendo impactar negativamente o meio onde se é descartado (Gaona et al., 2011). Estudos que visem a utilização desse efluente como meio de cultivo são importantes para aumentar a sustentabilidade desse sistema ambientalmente amigável e biosseguro (Wasielesky et al., 2006).

O presente estudo teve como objetivo avaliar o crescimento in vitro da macroalga Ulva fasciata em solução Von-Stosch e no efluente proveniente da engorda de camarão em sistema de bioflocos.

Delineou-se 2 tratamentos com 3 réplicas (2x3): BFT (Biofloco in natura) - cultivo da alga $U$. fasciata em efluente proveniente da engorda de camarão em sistema de bioflocos com $400 \mathrm{mg} / \mathrm{L}$ de sólidos suspensos totais; VS: cultivo da macroalga $U$. fasciata na solução padrão de enriquecimento Von Stoch na concentração de $10 \mathrm{ml} / \mathrm{L}$. O experimento durou 35 dias e foi mantido com aeração constante, um fotoperíodo $12 \mathrm{hs}$ claro/escuro e a temperatura controlada. Foi utilizada uma densidade de $2 \mathrm{~g} / \mathrm{L}$ da macroalga em cada unidade experimental, possuindo média de peso inicial de 6,22 $\pm 0,10 \mathrm{~g}$. Semanalmente foi realizada a pesagem das macroalgas. Os seguintes parâmetros foram monitorados: temperatura, salinidade, $\mathrm{pH}$, oxigênio dissolvido e turbidez.

A temperatura, oxigênio dissolvido, $\mathrm{pH}$ e salinidade foram mantidos em $26^{\circ} \mathrm{C}, 7,6 \mathrm{mg} / \mathrm{L}, 8,3$ e 29 respectivamente em ambos tratamentos. Apenas os valores de turbidez diferiram estatisticamente ( $p>0,05)$, como esperado o tratamento BFT obteve maiores valores. Os valores do peso médio final foram 9,13 $\pm 2,19 \mathrm{~g}$ para o BFT e $8,32 \pm 1,82 \mathrm{~g}$ para VS e a Taxa de Crescimento relativo foi de $1,03 \pm 0,70$ para BFT e 0,76 $\pm 0,64$ para VS, os valores não diferiram estatisticamente ( $p>0,05)$ entre os tratamentos. Os resultados obtidos nesse estudo indicam que a solução Von-Stosch pode ser substituída pelo efluente de cultivo de camarão marinho em BFT para produção da macroalga $U$. fasciata, sendo assim uma alternativa viável para cultivos em larga escala. Além disso, possibilita o aumento da sustentabilidade do sistema BFT através da reutilização do seu efluente. Esse estudo corrobora com os resultados obtidos por Souza (2014) em que a solução Von-Stosch foi substituída com sucesso pelo efluente de BFT no cultivo da macroalga Glacilaria domingensis.

O meio de cultivo alternativo composto pelo efluente da engorda de camarão marinho em sistema de bioflocos se mostrou viável para produção da macroalga $U$. fasciata. Novos estudos a respeito da produção da macroalga em escalas maiores são necessários.

Palavras-chave: Macroalgas. BFT. Solução Von-Stosch. Meios de Cultivo Alternativos.

\footnotetext{
1 Mestranda em Aquicultura na Universidade Federal do Rio Grande. http://lattes.cnpq.br/2407751108346349. esthefanycfs@gmail.com.

2 Mestranda em Aquicultura na Universidade Federal do Rio Grande. http://lattes.cnpq.br/1275197981223128 andrezzachagas@hotmail.com.

3 Doutora em Aquicultura pela Universidade Federal do Rio Grande. http://lattes.cnpq.br/1352578595965600. mariana.holandalima@gmail.com.

4 Doutor em Aquicultura pela Universidade Federal do Rio Grande. Professor do Instituto de Oceanografia da Universidade Federal do Rio Grande. http://lattes.cnpq.br/2302658488477730. lpoersch@ mikrus.com.br.

${ }^{5}$ Doutora em Aquicultura pela Ege University. Professora visitante do Instituto de Oceanografia da Universidade Federal do Rio Grande. https://orcid.org/0000-0002-3610-6347. gamzeturan2000@gmail.com.
} 


\title{
ESTUDO DA BIOMASSA E PERCENTUAL DE COBERTURA ALGAL DAS MACROALGAS VERMELHAS Gracilaria domingensis e G. intermedia, NA PRAIA DO COQUEIRO, LUÍS CORREIA-PI
}

\author{
Andreline Jordana Coelho de Mendonça ${ }^{1}$; Marco Aurélio Pereira Leite ${ }^{2}$; Sandra Helena de \\ Mesquita Pinheiro ${ }^{3}$; Margarida Maria Monteiro Vasconcelos ${ }^{4}$.
}

As algas marinhas estão distribuídas em toda costa brasileira, apresentando a mais diversa abundância de espécies, sendo divididas de acordo com os pigmentos fotossintéticos. Algumas algas são usadas em todo o mundo com um grande campo de aplicações, sendo o uso principal na alimentação humana. O ágar é um ficocolóide encontrado na parede celular das macroalgas do gênero Gracilaria.

O presente trabalho tem por objetivo de realizar estudos acerca da biomassa e percentual de cobertura algal e dos parâmetros ambientais, como forma de compreender os fatores condicionantes para possíveis extrações dos bancos naturais.

A coleta foi realizada manualmente no período de baixa mar (maré de sizígia), identificada com o auxílio da tabua de marés, nos meses de dezembro (2012) e janeiro (2013). Com o uso de GPS, foram marcados 4 (quatro) pontos aleatórios usando-se, para tanto, transectos de $6 \mathrm{~m}^{2}$, onde foram realizadas in loco as determinações de salinidade (salinômetro de campo Marca BIOBRIX,) e temperatura (termômetro INCOTEN, variação de $\pm 0,2^{\circ} \mathrm{C}$ ). As análises de $\mathrm{pH}$ da água foram realizadas no Laboratório de Tecnologia do Pescado/LATEP/UFPI, as algas coletadas foram submetidas a limpeza de sujidades seguidamente, lavadas com água corrente e pesadas em balança eletrônica. Os dados oriundos das pesagens dos exemplares foram utilizados para determinação da biomassa conforme o cálculo da área do transecto baseado na fórmula matemática de um retângulo. Para o cálculo da biomassa foi realizada a correlação da frequência relativa da alga (Frel.), por peso úmido (g) em função da área (A) do transecto $\left(\mathrm{m}^{2}\right)$, sendo utilizada a seguinte fórmula: (Biomassa $\left(\mathrm{gm}^{2}{ }^{2}\right)=$ Frel/A). O percentual de cobertura (\%) foi calculado em função do somatório das biomassas ao longo dos dois meses pesquisados, para cada espécie algal, utilizando-se regra de três simples.

Os valores referentes à biomassa das macroalgas $G$. domingensis e G. intermedia coletadas na Praia do Coqueiro/PI no decorrer dos meses de dezembro (2012) a janeiro (2013), apontaram uma biomassa total de $622,2 \mathrm{gm}^{-2}$ (Dez) e $665,6 \mathrm{gm}^{-2}$ (Jan) respectivas espécies. Percentual de cobertura total de $80,26 \%$ e $67,10 \%$ para as respectivas algas. A $G$. intermedia $\left(356,70 \mathrm{gm}^{-2}\right)$ em dezembro e $G$. domingensis $\left(362,30 \mathrm{gm}^{-2}\right)$ em janeiro apresentaram percentual de cobertura de $46,01 \%$ e $36,52 \%$ respectivamente.

Do presente trabalho pode-se concluir que nos meses de pesquisa as G. domingensis e G. intermedia, coletadas na Praia do Coqueiro/PI, apresentaram abundância nos bancos algais. Verifica-se que os valores de biomassa reportados na presente pesquisa para as algas vermelhas $G$. domingensis e $G$. intermedia, estão de acordo com a vasta distribuição do gênero na costa brasileira.

Palavras-chaves: Macroalga. Gracilaria. Biomassa.

\footnotetext{
${ }^{1}$ Doutoranda em Aquicultura pela Universidade Nilton Lins/ Instituto de Pesquisa do Amazônia. http://lattes.cnpq.br/7437413920664181. andrelinecoelho@ hotmail.com.

${ }^{2}$ Graduado em Engenharia de Pesca pela Universidade Federal do Piauí. http://lattes.cnpq.br/1884723385237663. aurelioleite44@hotmail.com.

${ }^{3}$ Doutora em Ciência e Tecnologia de Alimentos pela Universidade Federal de Viçosa. http://lattes.cnpq.br/4484097121967936.sandra_hmp@yahoo.com.br.

${ }^{4}$ Doutoranda em Ciências de Alimentos pela Université Laval/Québec/ Canada. http://lattes.cnpq.br/8014778607957469. guidamv@ hotmail.com
} 
Sanidade, manejo

$$
\begin{aligned}
& \text { e patologia na } \\
& \text { aquicultura }
\end{aligned}
$$




\section{LETALIDADE DOS SANITIZANTES HIPOCLORITO DE SÓDIO E DICLOROISOCIANURATO DE SÓDIO EM GIRINOS DE RÃ-TOURO (Lithobates catesbeianus)}

Rafael Lucas de Oliveira Silva ${ }^{1}$; Fernando Mazzioli Braga ${ }^{2}$; Híviny Francis de Oliveira Santos ${ }^{3}$; Lucas Sousa de Freitas Santos ${ }^{4}$; Maria Carolina Bastos Amaral ${ }^{5}$; Oswaldo Pinto Ribeiro Filho ${ }^{6}$.

$\mathrm{Na}$ ranicultura, o sistema recebe água captada direto de nascentes e lagos, que podem conter patógenos. Estes patógenos podem ser introduzidos no sistema produtivo caso não haja cuidado com a qualidade da água. Esses organismos patogênicos causam doenças e geram prejuízos econômicos devido à queda no desempenho zootécnico ou o aumento da mortalidade dos animais.

Havendo escassez de estudos sobre o uso de sanitizantes na ranicultura, este trabalho foi realizado com o objetivo de determinar a concentração letal aguda (CL5096h) do hipoclorito de sódio e do dicloroisocianurato de sódio, em girinos de rã-touro (Lithobates catesbeianus).

O experimento foi realizado no Ranário Experimental do Departamento de Biologia Animal da Universidade Federal de Viçosa - MG utilizando 480 girinos na fase 26 de Gosner (1960). Adaptouse a metodologia para teste de toxidade aguda recomendada pela OCDE. Os girinos foram distribuídos em 40 caixas de polietileno contendo 12 litros de água cada, na densidade de um girino por litro. Cada grupo de quatro caixas foi exposto a um tratamento de solução com hipoclorito de sódio, nas concentrações de $0,0 \mathrm{~mL} \mathrm{~L}^{-1}, 1,0 \mathrm{~mL} \mathrm{~L}^{-1}, 0,8 \mathrm{~mL} \mathrm{~L}^{-1}, 0,6 \mathrm{~mL} \mathrm{~L}^{-1}, 0,4 \mathrm{~mL} \mathrm{~L}^{-1} \mathrm{e} 0,2 \mathrm{mg} \mathrm{L}^{-1}$; ou de dicloroisocianurato de sódio nas concentrações de $300 \mathrm{mg} \mathrm{L}^{-1}, 225 \mathrm{mg} \mathrm{L}^{-1}, 150 \mathrm{mg} \mathrm{L}^{-1}, 75 \mathrm{mg}$ $\mathrm{L}^{-1}$ e $0 \mathrm{mg} \mathrm{L}^{-1}$. As unidades experimentais foram mantidas por 24 horas em sala climatizada com $27^{\circ} \mathrm{C}$ e fotoperíodo de 12:12. Os animais mortos foram removidos e incinerados. Os cálculos das concentrações para máxima tolerância, letalidade média e de letalidade total, foram realizados pela obtenção da expressão de probabilidade de letalidade em função da concentração de hipoclorito de sódio e dicloroisocianurato de sódio por meio de regressão logística.

Como resultado obtivemos que em hipoclorito de sódio, $10 \%$ dos animais morreram após 18 horas. Expostos a concentração de $0,4 \mathrm{~mL} \mathrm{~L}^{-1}$; e em $0,6 \mathrm{~mL} \mathrm{~L}^{-1}, 60 \%$ dos animais morreram em 12 horas. E em $0,8 \mathrm{~mL} \mathrm{~L}^{-1}$ todos os animais morrem em menos de 6 horas. Quando expostos a dicloroisocianurato de sódio não há mortalidade até $150 \mathrm{mg} \mathrm{L}^{-1}$. Porém, ocorre $100 \%$ de mortalidade em $300 \mathrm{mg} \mathrm{L}^{-1}$ após 6 horas. Logo a tolerância dos girinos foi menor ao dicloroisocianurato de sódio do que ao hipoclorito de sódio, saltando de 0 a $100 \%$ de mortalidade de um tratamento para o outro.

Concluímos que a concentração máxima tolerada de hidróxido de sódio e do dicloroisocianurato de sódio é de, repectivamente, $0,2 \mathrm{~mL} \mathrm{~L}^{-1}$ e $150 \mathrm{mg} \mathrm{L}^{-1}$; a concentração letal média (CL $\mathrm{CL}_{50} 96 \mathrm{~h}$ ) é de 0,52 $\mathrm{mL} \mathrm{L}^{-1}$ e $225 \mathrm{mg} \mathrm{L}^{-1}$; e a concentração de letalidade total é $0,8 \mathrm{~mL} \mathrm{~L}^{-1}$ e $300 \mathrm{mg} \mathrm{L}^{-1}$.

Palavras-chave: Hipoclorito de Sódio. Dicloroisocianurato de sódio. Girinos. Sanidade.

\footnotetext{
${ }^{1}$ Mestrando em Biologia Animal pela Universidade Federal de Viçosa. http://lattes.cnpq.br/3722552996608105. E-mail: rafaellucas827@gmail.com.

${ }^{2}$ Graduando em Zootecnia pela Universidade Federal de Viçosa. http://lattes.cnpq.br/4971141911286491. E-mail: fernandobragamazzioli@gmail.com.

${ }^{3}$ Graduanda em Biologia pela Universidade Federal de Viçosa. http://lattes.cnpq.br/9436254279195446. E-mail: hivinyf@gmail.com@gmail.com.

${ }^{4}$ Graduando em Zootecnia pela Universidade Federal de Viçosa. http://lattes.cnpq.br/3882781251208847. E-mail: lucas.s.freitas@ufv.com.

${ }^{5}$ Graduanda em Zootecnia pela Universidade Federal de Viçosa. http://lattes.cnpq.br/6715040972239852. E-mail: maria.c.bastos@ufv.com.

${ }^{6}$ Doutor em Zootecnia pela Universidade Federal de Viçosa. Professor do Departamento de Biologia Animal da Universidade Federal de Viçosa. http://lattes.cnpq.br/4470574323962701. E-mail: oribeiroufv@ @otmail.com.
} 


\title{
ANÁLISE DE PREVALÊNCIA, INTENSIDADE E ABUNDÂNCIA DE ECTO E ENDOPARASITOS DO TAMBAQUI Colossoma macropomum NA REGIÃO AMAZÔNICA
}

\author{
Iana Elza Costa Fernandes ${ }^{1}$;Raquel Emilia dos Santos Pereira ${ }^{2}$; Sílvia Umeda Gallani ${ }^{3}$; Gustavo \\ Moraes Ramos Valladão ${ }^{4}$.
}

O tambaqui Colossoma macropomum é o peixe nativo mais produzido em toda a América do Sul. A criação deste pescado tem se intensificado nos últimos anos e, com isso, surgem problemas sanitários que necessitam de soluções emergenciais. Dentre as doenças na aquicultura, destacam-se as parasitoses, que ocasionam um grande impacto na sua produção.

Preliminarmente, o objetivo deste trabalho foi realizar um acompanhamento dos principais parasitos que acometem as pisciculturas do Estado do Amazonas e, a partir disso, detectar e identificar parasitos externos (ectoparasitas) e internos (endoparasitas) no tambaqui.

Ao total, análises de 20 peixes foram realizadas em 12 pisciculturas dentro do Estado. Como procedimento, os animais foram eutanasiados por concussão cerebral e secção da medula, seguindo os critérios estabelecidos pelo Conselho Federal de Medicina Veterinária (CFMV). Posteriormente, coleta de muco, brânquias e intestino para identificação e quantificação dos parasitos foram realizadas. Por fim, foram efetuados cálculos para determinar a prevalência, intensidade média e abundância média dos parasitos. Devido ao grande volume de informação, os dados integrais de parasitismo das 12 pisciculturas serão expostos em detalhes no vídeo de apresentação.

No resultado dos parasitos de pele, foram identificados Piscinoodinium pillulare, mixosporídeos, monogenoides, Ichthyobodo sp., peritríqueos, Argulus sp., Dermocistidium sp., e Trichodina sp., com uma maior prevalência dos mixosporídeos. com uma maior prevalência dos Mixosporídeos.

Nas análises das brânquias foram identificados monogenoides, $P$. pillulare e mixosporídeos, sendo os monogenoides aqueles de maior relevância devido à alta prevalência ( $>95 \%$ em 11 pisciculturas) e à intensidade/abundância média chegando a 9.645 parasitos/peixe. Nos resultados do intestino, foram identificados mixosporídeos, Spironucleus sp., Cryptobia sp., acantocéfalos, larvas plerocercoides, e Procamallanus sp.

Os monogenoides se destacam como os mais prevalentes e encontrados em grandes níveis de intensidade parasitária na produção do tambaqui. O acantocéfalo Neoechinorhynchus buttnerae causa um maior impacto nas criações, pois este parasito não permite o crescimento do animal, o que resulta em grandes perdas produtivas e econômicas. Ainda não existem medicamentos registrados e eficazes para o tratamento de parasitoses em peixes no Brasil, as boas práticas de manejo, o monitoramento sanitário e a adoção de medidas de biosseguridade são as melhores formas de prevenção.

Como conclusão, os parasitos mais importantes na produção de tambaqui do Amazonas foram aqueles da classe Monogenea e do filo Acantocephala. Ambos são conhecidos por afetar o desenvolvimento do animal e/ou causar patologias que podem levar o peixe a morte.

Palavras-chave: Aquicultura. Peixe Nativo. Diagnóstico. Parasitose. Piscicultura. Apoio: CNPq; CAPES; UNINILTONLINS.

\footnotetext{
1 Graduanda em Medicina veterinária pela Universidade Nilton Lins. http://lattes.cnpq.br/1509637905072073. ianasuk19@outlook.com.

2 Graduanda em Medicina veterinária pela Universidade Nilton Lins. http://lattes.cnpq.br/0301759301979701. if.raquelesp@gmail.com.

${ }^{3}$ Doutora em Aquicultura pelo Centro de Aquicultura da Unesp (CAUNESP), Brasil. Professor Adjunto I da Universidade Nilton Lins. http://lattes.cnpq.br/7315530238565999. silviaugallani@gmail.com.

${ }^{4}$ Doutor em Aquicultura pelo Centro de Aquicultura da Unesp (CAUNESP), Brasil. Professor Adjunto I da Universidade Nilton Lins. http://lattes.cnpq.br/3388795761978632. gmrvalladao@gmail.com.
} 


\title{
MONITORAMENTO DE BACTÉRIAS NO TAMBAQUI Colossoma macropomum
}

\begin{abstract}
Aline Baggio Wanderley ${ }^{1}$; Michelle Valério e Silva ${ }^{2}$; Carlos Eduardo Baldin ${ }^{3}$; Ingrid Schifelbein de Oliveira $^{4}$; Guilherme Campos Tavares ${ }^{5}$; Gustavo Moraes Ramos Valladão ${ }^{6}$; Sílvia Umeda Gallani .
\end{abstract}

Na piscicultura, os peixes estão sujeitos a uma variedade de enfermidades, nas quais destacam-se diversas infecções bacterianas, como aquelas causadas por Aeromonas hydrophila, Flavobacterium columnare, Streptococcus agalactiae, Edwardsiella tarda, entre outras. O tambaqui Colossoma macropomum é a espécie nativa mais produzida no país, mesmo assim, são escassas as informações sobre quais enfermidades afetam esta espécie. É possível relacionar fatores de risco de surtos de enfermidades com dados epidemiológicos de potenciais agentes patogênicos. Por isso, neste estudo foi realizado o monitoramento da prevalência de microrganismos presentes em tambaquis sadios, oriundos de criações na região Norte, a maior consumidora e produtora dessa espécie no Brasil. Mensalmente, durante cinco meses, 20 juvenis de pisciculturas comerciais foram examinados microbiologicamente. Fragmentos do cérebro, rim, fígado e baço foram coletados assepticamente, estriados em meio não seletivo de ágar triptona de soja (TSA) e incubados a $28^{\circ} \mathrm{C} / 72 \mathrm{~h}$. Para isolamento específico de $F$.columnare, fragmentos do fígado foram estriados em meio específico ágar Hsu-Shotts (MHS) e incubados a $25^{\circ} \mathrm{C} / 120 \mathrm{~h}$. Após crescimento, as bactérias foram repicadas até purificação, para caracterização do Gram e identificação do gênero e espécie em espectrometria de massas Maldi-Tof. Após identificação, a prevalência das bactérias foi calculada. Na maior parte dos indivíduos analisados (73\%) não houve crescimento bacteriano. No restante, foram identificadas Acinetobacter bereziniae, Aeromonas hydrophila, Aeromonas jandaei, Aeromonas ichthiosmia, Bacillus cereus, Brevibacterium casei, Brevundimonas sp., Cellulosimicrobium cellulans, Chryseobacterium sp., Elizabethkingia meningoseptica, Methylobacterium radiotolerans, Microbacterium natoriense, Microbacterium paraoxydans, Micrococcus luteus, Plesiomonas shigelloides, Pseudomonas aeruginosa, Pseudomonas monteilii, Pseudomonas otitidis, Salmonella sp. e Serratia marcescens. As bactérias mais prevalentes foram Aeromonas spp. (8\%), Pseudomonas sp. (5\%) e Plesiomonas spp. (5\%), que dentre as bactérias identificadas, são as com maiores relatos literários de patogenicidade em peixes. Os demais isolados são na maioria relatados em biofilmes e no ambiente, mas com poucos ou nenhum relato como agente patogênico de peixe. Como muitas bactérias patogênicas de peixes são classificadas como oportunistas, estes dados epidemiológicos nos mostram que os microrganismos isolados podem corresponder a um risco potencial para os tambaquis cultivados no Amazonas. Destacamos também que, como o monitoramento foi realizado em peixes saudáveis, não foi identificado $F$. columnare, e que isso não a descarta como potencial microrganismo patogênico. Neste estudo, foram identificados 15 gêneros bacterianos e os dados fornecidos nos permitem direcionar os estudos sanitários para potenciais patógenos mais prevalentes, favorecendo o desenvolvimento de protocolos sanitários para o cultivo do tambaqui na região Norte.

Palavras-chave: Aquicultura. Doença. Microbiologia. Peixe amazônico. Piscicultura. Apoio: PROCAD

\footnotetext{
${ }^{1}$ Graduanda em Medicina Veterinária pela Universidade Nilton Lins. http://lattes.cnpq.br/2717040848231188

${ }^{2}$ Graduanda em Medicina Veterinária pela Universidade Nilton Lins. http://lattes.cnpq.br/7757521742234510

${ }^{3}$ Graduando em Medicina Veterinária pela Universidade Nilton Lins. carlosbaldin15@gmail.com

${ }^{4}$ Graduanda em Medicina Veterinária pela Universidade Nilton Lins. http://lattes.cnpq.br/0753111460525639

5 Doutor em Ciência Animal pela Escola de Veterinária da Universidade Federal de Minas Gerais. Professor do Departamento de Medicina Veterinária Preventiva da Universidade Federal de Minas Gerais. http://lattes.cnpq.br/0656314462372593 gcamposvet@ hotmail.com

${ }^{6}$ Doutor em Aquicultura pelo Centro de Aquicultura da Universidade Estadual Paulista. Professor do Departamento de Parasitologia e Patologia de Organismos Aquáticos da Universidade Nilton Lins. http://lattes.cnpq.br/3388795761978632 gmrvalladao@gmail.com

${ }^{7}$ Doutora em Aquicultura pelo Centro de Aquicultura da Universidade Estadual Paulista. Professora do Departamento de Microbiologia Aplicada a Organismos Aquáticos da Universidade Nilton Lins. http://lattes.cnpq.br/7315530238565999 silviaugallani@gmail.com
} 


\section{TESTES DE TOXICIDADE AGUDA DE COMPOSTOS ISOLADOS DE PLANTAS EM TAMBAQUIS (Colossoma macropomum)}

\section{Carolina de Souza Pereira ${ }^{1}$; Rebeca Machado do Nascimento ${ }^{2}$; Gustavo Moraes Ramos Valladão ${ }^{3}$.}

O tambaqui (Colossoma macropomum) é a espécie de peixe nativa que nos últimos anos tem ganhado destaque nos setores de piscicultura. Alguns fatores como surtos por infecções parasitárias têm afetado a viabilização da produção deste pescado. $\mathrm{O}$ uso indiscriminado de antiparasitários sintéticos para o tratamento de doenças geram efeitos negativos ao ambiente e ao próprio peixe, logo, a fitoterapia vem sendo abordada como uma medida promissora para tratamento de doenças em peixes. No entanto, há poucos trabalhos relacionados à efeitos adversos de moléculas isoladas de plantas.

Este projeto objetivou o estudo da toxicidade aguda do timol e carvacrol no tambaqui, com a finalidade de determinar uma concentração letal das moléculas testadas e posteriormente disponibilizar resultados que ofereçam suporte a ensaios subsequentes de tratamentos.

O presente ensaio ocorreu de forma inteiramente casualizada com os compostos timol, carvacrol e a associação timol + carvacrol. Avaliou-se quatro concentrações, em duplicata, além dos grupos controles (sem nenhum composto, e com o solvente dimetilsulfóxido). A taxa de mortalidade dos peixes foi quantificada em 24, 48, 72 e 96 h. Realizou-se também observações quanto à ocorrência de sinais clínicos nos indivíduos. Para estimar as diferentes concentrações letais modelos de regressão estabelecidos por Lei \& Sun (2018) foram utilizados. A CL50 foi utilizada para classificação dos compostos carvacrol e timol quanto à sua toxicidade para o tambaqui, estabelecido de acordo com a tabela proposta por Zucker (1985) para organismos aquáticos.

A concentração letal 50\% ( $\mathrm{CL}_{50)}$ após $96 \mathrm{~h}$ dos tratamentos timol, carvacrol e timol+carvacrol foram respectivamente $10,12 \mathrm{mg} / \mathrm{L}, 10,23 \mathrm{mg} / \mathrm{L}$ e $10,65 \mathrm{mg} / \mathrm{L}$. Todos os tratamentos foram classificados como ligeiramente tóxicos para o tambaqui. Quanto à ocorrência de sinais clínicos caracterizaram-se pigmentação escurecida, letargia, espasmos, nado errático e sobrenado. Ocorreu de forma semelhante para todos os tratamentos.

A toxicidade dos dois compostos foi similar, e isto pode estar relacionado ao fato de serem estruturalmente muito semelhantes, no qual a única distinção é a posição de seu grupo hidroxila: timol é 2-Isopropyl-5-methylphenol e o carvacrol é 5-Isopropyl-2-methylphenol. Em estudos aplicados em tambaquis expostos ao óleo de Lippia origanoides, no qual possui moléculas de carvacrol e timol como principais constituintes, apresentou sinais clínicos e a classificação de ligeiramente tóxico semelhantes à este estudo.

Diante dos resultados nota-se que as moléculas timol, carvacrol e timol + carvacrol são promissoras como futuros protocolos terapêuticos para o tratamento e prevenção de doenças em tambaqui, pois estão entre os limites de toxicidade mais baixos observados para a espécie.

Palavras-chave: Moléculas isoladas. Timol. Carvacrol. Toxicidade aguda. tambaqui.

Apoio: CNPq; UNINILTONLINS.

\footnotetext{
1 Graduanda em Medicina Veterinária pela Universidade Nilton Lins. http://lattes.cnpq.br/3850867079054703. karoll.pereira12@gmail.com.

2 Mestranda em Zootecnia pela Universidade Nilton Lins. http://lattes.cnpq.br/7950715419217516. rebeccaklein@ hotmail.com.

${ }^{3}$ Pós - doutorando em Aquicultura pela Universidade Federal de Santa Maria, UFMS, Brasil. Professor Adjunto I da Universidade Nilton Lins. http://lattes.cnpq.br/3388795761978632.gmrvalladao@ gmail.com
} 


\title{
PARÂMETROS IMUNOLÓGICOS DE TILÁPIAS-DO-NILO APÓS SUPLEMENTAÇÃO COM DIFERENTES CONCENTRAÇÕES DO ÁCIDO ORGÂNICO BENZOICO E DESAFIADAS VIA GAVAGEM COM Streptococcus agalactiae
}

\begin{abstract}
Maria Clara Miguel Libanori ${ }^{1}$; Gracienhe Gomes dos Santos ${ }^{2}$; Scheila Anelise Pereira ${ }^{3}$; Matheus Berlofa Ferreira $^{4}$; Marco Shizuo Owatari ${ }^{5 ;}$ Maurício Laterça Martinss ${ }^{6}$; José Luiz Pedreira Mouriño ${ }^{7}$

Streptococcus agalactiae é um dos principais patógenos na piscicultura, já sendo considerado emergente na tilapicultura devido às grandes taxas de mortalidade causada. Para reduzir os impactos gerados por estas enfermidade, os ácidos orgânicos são uma alternativa bioseguras, com propriedades antimicrobianas e nutricionais.
\end{abstract}

O objetivo do estudo foi avaliar o efeito dietético do ácido orgânico benzoico em diferentes concentrações para Oreochromis niloticus sob os parâmetros imunológicos e sobrevivência após desafio bacteriano com Strepetococcus agalactiae.

Para tal, 320 peixes foram divididos em 16 tanques acoplados a um sistema de recirculação, com 20 peixes em cada tanque, em quadruplicata para cada tratamento, sendo eles: grupo controle (sem suplementação); suplementação com $0,1 \%$; suplementação com $0,2 \%$ e suplementação com $0,3 \%$. Os animais foram alimentados durante 54 dias. Após este período, seis peixes por unidade experimental foram coletados para as análises imunológicas. Os demais foram desafiados com $S$. agalactiae via gavagem na concentração de $1 \times 10^{8} \mathrm{UFC} \mathrm{mL}^{-1}$ e monitorados por 15 dias. Para as análises, foi obtido o plasma sanguíneo pré e pós infecção. A proteína total plasmática foi mensurada com o kit comercial Proteína Total (Lab Test ${ }^{\circledR}$ ). Já a concentração de imunoglobulina total plasmática foi realizada segundo Amar et al., (2000).

Os resultados mostraram um aumento nos níveis de proteína e imunoglobulina total plasmática préinfecção, principalmente no grupo suplementado com a concentração de $0,1 \%$ de ácido benzoico, além de maior taxa de sobrevivência deste mesmo grupo após o desafio bacteriano.

Tal fato mostra, que os animais responderam de forma positiva a suplementação, pois houve aumento das proteínas totais plasmáticas e das imunoglobulinas, apontando melhorias na resposta imune adaptativo. Portanto, ambos os parâmetros podem ter colaborado para a maior sobrevivência observada após desafio bacteriano.

Dessa forma, a suplementação dietética do ácido orgânico benzoico para tilapia-do-nilo, principalmente na dose $0,1 \%$, influência positivamente o sistema imunológico inato e adaptativo, além de promover maior resistência a infecção por S. agalactiae.

Palavras-chave: Piscicultura. Sobrevivência. Aditivo Alimentar. Imunologia.

\footnotetext{
1 Mestrando em Aquicultura e Recursos Pesqueiros pela Universidade Federal de Santa Catarina. http://lattes.cnpq.br/3953017521326902

2 Mestrando em Aquicultura e Recursos Pesqueiros pela Universidade Federal de Santa Catarina. http://lattes.cnpq.br/7718764544867000

${ }^{3}$ Doutora em Aquicultura pela Universidade Federal de Santa Catarina. Professora substituta no Departamento de Aquicultura da Universidade Federal de Santa Catarina. http://lattes.cnpq.br/8983368247235457.

4 Graduado em Engenharia de Aquicultura pela Universidade Federal de Santa Catarina. http://lattes.cnpq.br/6582836950838100. matheusaqi@ hotmail.com.

5 Doutorando em Aquicultura e Recursos Pesqueiros pela Universidade Federal de Santa Catarina. http://lattes.cnpq.br/6410822493267136. owatarimarco@ hotmail.com.

${ }^{6}$ Doutor em Aquicultura pelo Centro de Aquicultura da Unesp (CAUNESP). Professor da Universidade Federal de Santa Catarina. http://lattes.cnpq.br/0229235513357607.mauricio.martins@ufsc.br.

${ }^{7}$ Doutor em Aquicultura pela Universidade Federal de Santa Catarina. Professor da Universidade Federal de Santa Catarina. http://lattes.cnpq.br/8824794070182176.jlpmourino@gmail.com.
} 


\title{
USO DO LEVAMISOL CONTRA O ACANTOCÉFALO Neoechinorhynchus buttnerae
}

\author{
Indra Mary Costa Fernandes; Sílvia Umeda Gallani²; Gustavo Moraes Ramos Valladão³.
}

O tambaqui (Colossoma macropomum) é o peixe nativo mais produzido atualmente no Brasil e sua produção tem se intensificado, principalmente na região Norte do país. Juntamente à rápida intensificação, surgem problemas sanitários. Entre os patógenos, os parasitos se destacam como agentes primários de enfermidades em peixes. Muitos são responsáveis por surtos de doenças em peixes, como o acantocéfalo Neoechinorhynchus buttnerae, um endoparasito intestinal que tem afetado de forma significativa o setor produtivo do tambaqui.

Neste trabalho, nosso objetivo foi avaliar o levamisol e sua atividade contra o acantocéfalo, afim de determinar a eficácia da molécula.

O levamisol foi previamente solubilizado em dimetilsulfóxido (DMSO) na proporção de $30 \mathrm{mg}$ de levamisol para $1500 \mu \mathrm{L}$ de DMSO. Para coleta dos parasitos, os peixes foram anestesiados por imersão em solução de benzocaína na dose de $1 \mathrm{~g}$ para cada $10 \mathrm{~L}$ de água. Após aprofundamento anestésico, foi feito a secção da medula para eutanásia. Foram inseridos oito acantocéfalos dentro de cada unidade experimental (pote coletor universal, com capacidade de $60 \mathrm{~mL}$ ) contendo $8 \mathrm{ml}$ de meio de cultura RPMI. Para o teste in vitro, foram definidas quatro concentrações crescentes $(37,5 \mathrm{mg} / \mathrm{L}$, $150 \mathrm{mg} / \mathrm{L}, 225 \mathrm{mg} / \mathrm{L}$ e $300 \mathrm{mg} / \mathrm{L})$ e um grupo controle com DMSO ( $\geq 99,5 \%$ ) na maior concentração testada. Todos os grupos foram avaliados em duplicata. Os recipientes foram armazenados em incubadoras do tipo BOD à $28^{\circ} \mathrm{C}$. A mortalidade dos parasitos foi avaliada após $24 \mathrm{~h}$ de exposição ao fármaco.

$\mathrm{Na}$ concentração mais baixa testada $(37,5 \mathrm{mg} / \mathrm{L})$, observarmos que houve uma mortalidade de $31 \%$ dos parasitos, nos levando a crer que o fármaco tem uma boa eficácia sobre o $N$. buttnerae. Na segunda concentração $(150 \mathrm{mg} / \mathrm{L})$, vimos uma mortalidade de $68,75 \%$ dos parasitos. Na terceira concentração (225 mg/L), verificou-se uma mortalidade de 87,5\% dos acantocéfalos, confirmando que mesmo em concentrações mais baixas o levamisol tem um excelente resultado no controle do $N$. buttnerae. Na concentração mais alta $(300 \mathrm{mg} / \mathrm{L})$, ocorreu uma mortalidade de $100 \%$ dos parasitos. No grupo controle com DMSO foi observado que houve $0 \%$ de mortalidade até o fim das 24 horas de teste. Com relação à estimativa de concentração de eficácia (CE) do levamisol, verificou-se que a concentração de eficácia estimada para mortalidade de 50\% dos parasitos foi em média 67,70 mg/L.

Uma característica importante observada foi que os parasitos demostraram movimentação reduzida após a exposição ao fármaco, comprovando que o levamisol provocou a paralisia do acantocéfalo. A partir dos resultados obtidos, concluímos que o levamisol apresenta efeito anti-acantocéfalo, imobilizando o parasito, se mostrando promissor no controle da doença na criação do tambaqui.

Palavras-chave: Quimioterápico. Doença. Piscicultura. Parasito. Antiparasitário.

Apoio: UNINILTONLINS; CAPES; CNPq.

\footnotetext{
1 Graduanda em Medicina veterinária pela Universidade Nilton Lins. http://lattes.cnpq.br/5366217258042333. indrahwang.18@gmail.com

${ }^{2}$ Doutora em Aquicultura pelo Centro de Aquicultura da Unesp (CAUNESP). Professora Adjunto I da Universidade Nilton Lins. http://lattes.cnpq.br/7315530238565999. silviaugallani@gmail.com.

${ }^{3}$ Doutor em Aquicultura pelo Centro de Aquicultura da Unesp (CAUNESP). Professor Adjunto I da Universidade Nilton Lins. http://lattes.cnpq.br/3388795761978632.gmrvalladao@gmail.com.
} 


\title{
PREVALÊNCIA E POTENCIAL PATOGÊNICO DE BACTÉRIAS DO ACARÁ-DISCO (Symphysodon aequifasciatus) E DO ACARÁ-BANDEIRA (Pterophyllum scalare)
}

\author{
Ingrid Schifelbein de Oliveira ${ }^{1}$; Carlos Eduardo Xavier Baldin²; Aline Baggio Wanderley ${ }^{3}$; \\ Franscisco Yan Tavares Reis ${ }^{4}$; Guilherme Campos Tavares ${ }^{5}$; Gustavo Moraes Ramos Valladão ${ }^{6}$; \\ Sílvia Umeda Gallani?
}

O Brasil é um dos maiores exportadores mundiais de peixes ornamentais. $\mathrm{O}$ acará-bandeira Pterophyllum scalare e o acará-disco Symphysodon aequifasciatus estão entre as espécies mais exportadas e, devido às restrições técnicas de comercialização, se tornam predispostos às infecções. Apesar das doenças bacterianas serem associadas ao impacto negativo na comercialização de peixes ornamentais em todo o mundo, é de nosso conhecimento que não há muitos relatos sobre o monitoramento e confirmação de patogenicidade dos agentes bacterianos em peixes ornamentais amazônicos. Essa lacuna de informações prejudica o desenvolvimento de protocolos sanitários que possam diminuir o impacto econômico decorrente dos surtos de doenças bacterianas. Devido à necessidade e urgência destas informações, neste estudo, realizamos exames microbiológicos em lotes com histórico de surto de mortalidade, oriundos de estabelecimento exportador. Fragmentos do cérebro e rim foram estriados em ágar triptona soja e incubados a $28^{\circ} \mathrm{C} / 48 \mathrm{~h}$. Os isolados puros foram identificados em espectrometria de massas MALDI-ToF. Com a identidade dos isolados, foi possível determinar a prevalência dos agentes bacterianos. Foram identificadas bactérias do Gênero Aeromonas, Chromobacterium e Pandoraea em acarás-bandeira. Nos acarás-disco, além destas, foi constatada a presença de Citrobacter, Chryseobacterium e Edwardsiella. Com base nas cepas suspeitas de maior potencial patogênico, foi selecionada Aeromonas hydrophila para certificação da patogenicidade em ambas espécies, enquanto Aeromonas jandaei, Citrobacter freundii e Edwardsiella tarda foram selecionadas para investigação quanto a patogenicidade apenas no acarádisco. Para o estudo de patogênese, foi realizado o Postulado de Koch, com inoculação intraperitoneal de cada bactéria em 5 indivíduos $\left(0,1 \mathrm{~mL}\right.$ do inóculo a $1 \times 10^{8} \mathrm{UFC} \mathrm{mL}^{-1}$ por indivíduo). Adicionalmente, foi inoculado $0,1 / \mathrm{mL}$ de PBS estéril por indivíduo do grupo controle. Apenas $A$. hydrophila foi re-isolada de acarás-disco que apresentaram sinais clínicos, alterações comportamentais e mortalidade aguda do lote condizentes à septicemia hemorrágica. Apesar das demais cepas não terem causado mortalidade dos animais inoculados, elas não podem ser excluídas como potenciais agentes patogênicos, principalmente devido à diversidade de fatores de virulência dentro de uma espécie de bactéria. Neste estudo, obtivemos como resultado a certificação da patogenicidade de $A$. hydrophila, do qual, é uma das principais bactérias patogênicas de peixes ornamentais como o acará-disco, que é uma das espécies ornamentais mais valiosas e comercializadas no mundo.

Palavras-chave: bacteriose, infecção, patogenia, peixe ornamental.

\footnotetext{
1 Graduanda em Medicina Veterinária pela Universidade Nilton Lins. http://lattes.cnpq.br/0753111460525639 ingrid9999@hotmail.com>

${ }^{2}$ Graduando em Medicina Veterinária pela Universidade Nilton Lins. carlosbaldin15@gmail.com

3 Graduanda em Medicina Veterinária pela Universidade Nilton Lins. http://lattes.cnpq.br/2717040848231188. alinebaggiocw@gmail.com>

${ }^{4}$ Graduado pela Universidade Estadual do Ceará- UECE e mestrando pela Universidade Federal de Minas Gerias- UFMG. http://lattes.cnpq.br/5890312058914513.yan_reis@ @otmail.com>

5 Doutor em Ciência Animal pela Escola de Veterinária da Universidade Federal de Minas Gerais. Professor do Departamento de Medicina Veterinária Preventiva da Universidade Federal de Minas Gerais. http://lattes.cnpq.br/0656314462372593 gcamposvet@ hotmail.com

${ }^{6}$ Doutor em Aquicultura pelo Centro de Aquicultura da Universidade Estadual Paulista. Professor do Departamento de Parasitologia e Patologia de Organismos Aquáticos da Universidade Nilton Lins. http://lattes.cnpq.br/3388795761978632 gmrvalladao@gmail.com

${ }^{7}$ Doutora em Aquicultura pelo Centro de Aquicultura da Universidade Estadual Paulista. Professora do Departamento de Microbiologia Aplicada a Organismos Aquáticos da Universidade Nilton Lins. http://lattes.cnpq.br/7315530238565999 silviaugallani@gmail.com
} 


\section{CONCENTRAÇÃO LETAL MÉDIA (CL5024H) DO PERMANGANATO DE POTÁSSIO EM GIRINOS DE RÃ-TOURO (Lithobates catesbeianus)}

Fernando Mazzioli Braga ${ }^{1}$; Rafael Lucas de Oliveira Silva ${ }^{2}$; Oswaldo Pinto Ribeiro Filho ${ }^{3}$; Híviny
Francis de Oliveira Santos ${ }^{4}$; Lucas Sousa de Freitas Santos ${ }^{5}$; Maria Carolina Bastos Amaral ${ }^{6}$.

$\mathrm{Na}$ aquacultura, a manutenção de animais saudáveis depende diretamente de um ambiente dentro dos padrões higiênicos ideais ao sistema produtivo. O sanitizante permanganato de potássio $\left(\mathrm{KMNO}_{4}\right)$, além de seu baixo custo, é eficaz para a eliminação de fungos e bactérias Gram positivas, responsáveis pela incidência de doenças, como a encefalite, patologia com alta mortalidade que resulta em prejuízos para ranicultura.

Uma vez que há escassez de estudos sobre o uso de sanitizantes na ranicultura, este trabalho foi realizado com o objetivo de determinar a concentração letal aguda ( $\left.\mathrm{CL}_{50} 24 \mathrm{~h}\right)$ do permanganato de potássio, em girinos de rã-touro (Lithobates catesbeianus).

O experimento foi realizado no Ranário Experimental do Departamento de Biologia Animal da Universidade Federal de Viçosa utilizando 576 girinos. Adaptou-se a metodologia para teste de toxidade aguda em peixes recomendada pela OCDE. Os animais foram divididos em dois grupos de acordo com a fase de desenvolvimento. Sendo: fases 25 e 41 de Gosner (1960). Para cada fase os animais eram distribuídos em 24 caixas de polietileno com 12 litros de água cada, na densidade de um girino por litro. Cada grupo de 4 caixas recebeu um tratamento de solução de permanganato de potássio, nas concentrações de $0,0 \mathrm{ppm}, 2 \mathrm{ppm}, 4 \mathrm{ppm}, 6 \mathrm{ppm}, 8 \mathrm{ppm}$ e $10 \mathrm{ppm}$. Utilizou-se o delineamento inteiramente casualizado com 6 tratamentos e 4 repetições para cada uma das 3 fases de desenvolvimento trabalhadas. As unidades experimentais foram mantidas por 24 horas em ambiente climatizado com temperatura de $27^{\circ} \mathrm{C}$ e fotoperíodo de $12: 12$. Os animais mortos foram removidos e incinerados. Os cálculos das concentrações de máxima tolerância, letalidade média e de letalidade total, foram realizados pela obtenção da expressão de probabilidade de letalidade em função da concentração de permanganato de potássio por meio de regressão logística.

Em ambas as fases não houve mortalidade até a concentração de 2 ppm de permanganato de potássio. Na concentração de 4 ppm ocorreu $20 \%$ de mortalidade nos girinos na fase 25 de Gosner (1960), e $48 \%$ de mortalidade nos girinos na fase 41 de Gosner (1960). E 100\% dos animais morreram, em ambas as fases, quando expostos a 6 ppm.

Concluímos que nas fases 25 e 41 a tolerância do girino as concentrações de permanganato de potassio é a mesma. Sendo que a concentração máxima tolerada é 2 ppm; a concentração letal média (CL5024h) é de 4,12 ppm; e a concentração de letalidade total é 6 ppm.

Palavras-chave: Ranicultura. Sanitizante. Ranidae.

\footnotetext{
${ }^{1}$ Graduando em Zootecnia pela Universidade Federal de Viçosa. http://lattes.cnpq.br/4971141911286491. E-mail: fernandobragamazzioli@gmail.com.

${ }^{2}$ Mestrando em Biologia Animal pela Universidade Federal de Viçosa. http://lattes.cnpq.br/3722552996608105 E-mail: rafaellucas827@gmail.com.

${ }^{3}$ Doutor em Zootecnia pela Universidade Federal de Viçosa. Professor do Departamento de Biologia Animal da Universidade Federal de Viçosa. http://lattes.cnpq.br/4470574323962701. E-mail: oribeiroufv@ hotmail.com.

${ }^{4}$ Graduanda em Biologia pela Universidade Federal de Viçosa. http://lattes.cnpq.br/9436254279195446. E-mail: hivinyf@gmail.com.

${ }^{5}$ Graduando em Zootecnia pela Universidade Federal de Viçosa. http://lattes.cnpq.br/3882781251208847. E-mail: lucas.s.freitas@ufv.com.

${ }^{6}$ Graduanda em Zootecnia pela Universidade Federal de Viçosa. http://lattes.cnpq.br/6715040972239852. E-mail: maria.c.bastos@ufv.com.
} 


\section{DIAGNÓSTICO E PREVALÊNCIA DE AGENTES BACTERIANOS EM PEIXES DE PRODUÇÃO NATIVOS DA AMAZÔNIA}

Carlos Eduardo Baldin ${ }^{1}$; Michelle Valério e Silva ${ }^{2}$; Aline Baggio Wanderley ${ }^{3}$; Ingrid Schifelbein de Oliveira $^{4}$; Guilherme Campos Tavares ${ }^{5}$; Gustavo Moraes Ramos Valladão ${ }^{6}$; Sílvia Umeda Gallani ${ }^{7}$.

As doenças bacterianas correspondem a um dos principais obstáculos para o desenvolvimento da aquicultura. Estudos epidemiológicos são importantes para fornecer informações sobre quais potenciais patógenos afetam as espécies de criação, possibilitando a constatação da patogênese e métodos para controle e tratamento. Apesar do matrinxã Brycon amazonicus, pirarucu Arapaima gigas e tambaqui Colossoma macropomum estarem entre as espécies de peixes mais produzidas no Brasil, informações de prevalência de bactérias são escassas ou ausentes. Assim, neste estudo, objetivou-se estabelecer os dados de prevalência de microrganismos isolados dessas três importantes espécies nativas, oriundas de lotes de monitoramento com peixes sadios e de lotes com histórico de surto de mortalidade. Foram examinados 18 matrinxãs, 62 pirarucus e 214 tambaquis, oriundos de 5 municípios do Amazonas. Fragmentos do cérebro, rim, fígado e baço foram estriados em meios não seletivos ágar triptona de soja (TSA) ou infusão de cérebro e coração (BHI) e incubados a $28^{\circ} \mathrm{C}$ por 72 horas para o cultivo das bactérias. Fragmentos teciduais do tambaqui foram adicionalmente estriados em meio específico Hsu Shotts (MHS) e incubados a $25^{\circ} \mathrm{C}$ por 5 dias, para cultivo específico de Flavobacterium columnare. As cepas puras foram identificadas em espectrometria de massas Maldi-Tof, quanto ao gênero e espécie. Após identificação, a prevalência das bactérias foi calculada. Nos matrinxãs doentes, Aeromonas spp. foram as bactérias de maior prevalência, correspondendo a $75 \%$ dos isolados, sendo $A$. jandaei a espécie mais prevalente $(66,67 \%)$. A variabilidade de agentes isolados de pirarucus doentes foi maior, correspondendo a 5 gêneros principais: Plesiomonas shiguelloides (19,35\%), Chryseobacterium spp. (16,13\%), Pseudomonas otitidis (9,68\%), Aeromonas spp. $(9,67 \%)$ e Edwardsiella tarda $(8,06 \%)$. Nos tambaquis de monitoramento e doentes, três gêneros foram mais isolados: P. shiguelloides (15,79\%), Aeromonas spp. $(13,16 \%)$ e E. tarda $(9,21 \%)$. Contudo, exclusivamente nos tambaquis doentes, a bactéria $F$. columnare foi isolada, correspondendo ao microrganismo de maior prevalência $(17,11 \%)$. Desta forma, este estudo traz informações epidemiológicas inéditas das bactérias que afetam as três principais espécies de peixes de produção da região amazônica. Estes dados possibilitaram a criação de um banco de bactérias de espécies de peixes nativas, o qual está sendo utilizada para confirmação da patogenicidade em cada espécie a partir do Postulado de Koch, como também conhecimento necessário para a certificação de potenciais agentes patogênicos, o que permite o desenvolvimento de protocolos sanitários para prevenção e controle de bactérias da matrinxã, pirarucu e tambaqui.

Palavras-chave: Aquicultura. Bactéria. Matrinxã. Pirarucu. Tambaqui.

\footnotetext{
${ }^{1}$ Graduando em Medicina Veterinária pela Universidade Nilton Lins. carlosbaldin15@gmail.com

2 Graduanda em Medicina Veterinária pela Universidade Nilton Lins. http://lattes.cnpq.br/7757521742234510. micariocavalerio@gmail.com

3 Graduanda em Medicina Veterinária pela Universidade Nilton Lins. http://lattes.cnpq.br/2717040848231188. alinebaggiocw@gmail.com

4 Graduanda em Medicina Veterinária pela Universidade Nilton Lins. http://lattes.cnpq.br/0753111460525639 ingrid9999@hotmail.com>

5 Doutor em Ciência Animal pela Escola de Veterinária da Universidade Federal de Minas Gerais. Professor do Departamento de Medicina Veterinária Preventiva da Universidade Federal de Minas Gerais. http://lattes.cnpq.br/0656314462372593 gcamposvet@ hotmail.com

${ }^{6}$ Doutor em Aquicultura pelo Centro de Aquicultura da Universidade Estadual Paulista. Professor do Departamento de Parasitologia e Patologia de Organismos Aquáticos da Universidade Nilton Lins. http://lattes.cnpq.br/3388795761978632 gmrvalladao@gmail.com

${ }^{7}$ Doutora em Aquicultura pelo Centro de Aquicultura da Universidade Estadual Paulista. Professora do Departamento de Microbiologia Aplicada a Organismos Aquáticos da Universidade Nilton Lins. http://lattes.cnpq.br/7315530238565999 silviaugallani@gmail.com
} 


\title{
POTENCIAL ANTIBACTERIANO DO TOMILHO Thymus vulgaris CONTRA Aeromonas jandaei isoladas DO ACARÁ-DISCO Symphysodon spp. E DO ACARÁ-BANDEIRA Pterophyllum scalare
}

\author{
Taísa Freitas Botinelly ${ }^{1}$; Claire Juliana Francisco ${ }^{2}$; Sílvia Umeda Gallani ${ }^{3}$.
}

O objetivo deste estudo é evidenciar o uso do tomilho Thymus vulgaris em cepas de Aeromonas jandaei, isoladas de Pterophyllum scalare (acará-bandeira) e Symphysodon spp. (acará-disco), oriundos de comércios exportadores do Amazonas. O isolamento foi realizado a partir da estriagem de fragmentos do rim e cérebro em meio de cultura ágar triptona soja, os quais foram incubados a $28^{\circ} \mathrm{C}$ por 72 horas. A confirmação da espécie bacteriana foi feita através da identificação das proteínas ribossomais em espectrometria de massas Maldi-Tof.

As concentrações mínimas inibitórias (CMI) e bactericidas (CMB) do óleo essencial (OE) de tomilho foram obtidas para uma cepa de $A$. jandaei de cada espécie ornamental. O teste in vitro foi realizado através do ensaio de microdiluição em placa de ELISA, com $20 \mu \mathrm{l}$ do OE diluído em DMSO, $180 \mu \mathrm{l}$ meio Muller Hinton ajustado em cátions. Após diluição seriada, cada poço foi acrescido de $100 \mu 1$ de solução bacteriana a $1 \times 10^{6} \mathrm{UFC} / \mathrm{mL}$. O fármaco foi testado em triplicata para cada cepa alvo, além do controle negativo do meio de cultura e solução teste, e positivo da bactéria. Posteriormente, as placas foram incubadas a $28^{\circ} \mathrm{C} / 24 \mathrm{~h}$. A concentração mais baixa da solução-teste que não turvou (sem crescimento bacteriano), foi considerada a CMI. Para determinação da CMB, as três menores concentrações que não turvaram, foram plaqueadas em ágar Muller-Hinton e incubadas por $28^{\circ} \mathrm{C} / 24 \mathrm{~h}$.

A menor concentração em que não foi verificado crescimento bacteriano foi considerada a CMB. A relação $\mathrm{CMB} / \mathrm{CMI}$ das concentrações de $\mathrm{OE}$ de tomilho apresentaram resultado 2 para ambas cepas patogênicas, classificando-o como agente bactericida. $\mathrm{O}$ estudo permitiu a certificação do $\mathrm{OE}$ de tomilho como promissor agente bactericida para o desenvolvimento de protocolos sanitários de prevenção e controle de A. jandaei do $P$. scalare e Symphysodon spp., umas das espécies ornamentais mais comercializadas mundialmente.

Palavras-chave: Bacteriose. Infecção. Peixe ornamental. Protocolo sanitário.

\footnotetext{
1 Graduanda em Medicina Veterinária pela Universidade Nilton Lins. http://lattes.cnpq.br/5651162434374881. taisabotinelly@ hotmail.com

${ }^{2}$ Doutora em Biologia pela Universidade do Porto. MBR Technology LTDA. http://lattes.cnpq.br/8864707866294630. aquicultura2005@hotmail.com

${ }^{3}$ Doutora em Aquicultura pelo Centro de Aquicultura da Universidade Estadual Paulista. Professora do Departamento de Microbiologia Aplicada a Organismos Aquáticos da Universidade Nilton Lins. http://lattes.cnpq.br/7315530238565999. silviaugallani@gmail.com
} 


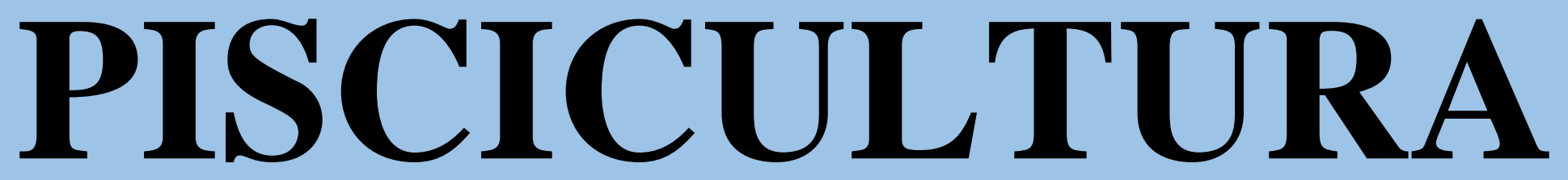




\title{
ISOLAMENTO E IDENTIFICAÇÃO DE BACTÉRIAS ÁCIDO LÁCTICAS NO INTESTINO DE TAMBAQUIS (Colossoma macropomum) COM POTENCIAL PROBIÓTICOS
}

\author{
Deborah Jacob Freire da $\mathrm{Paz}^{1}$; Larissa Salgado da Cunha²; Guilherme Campos Tavares ${ }^{3}$; Rodrigo \\ Yukihiro Gimbo ${ }^{4}$.
}

O uso de probióticos é uma das alternativas para prevenir surtos nas pisciculturas. Sendo o tambaqui (Colossoma macropomum) uma das espécies de maior importância para a Amazônia e para o Brasil. O presente trabalho propõe isolar e identificar bactérias ácidas lácticos no intestino de tambaquis e identificar as cepas que possuam características favoráveis para futuros testes in vivo. Para este fim, 10 juvenis de tambaqui foram mortos em benzocaína (400 mg.L-1), para a retirada do intestino. O conteúdo intestinal foi homogeneizado em solução salina, diluído de forma seriada e incubado em caldo Brain Heart Infusion (BHI). As unidades formadoras de colônia (UFC) foram repicadas e classificadas quanto à coloração gram, teste de hemólise, catalase e oxidase, além da identificação bioquímica por MALDI-TOF. Para que uma BAL (bactérias ácido lácticas) seja considerada para testes in vivo, ela deve conter algumas características favoráveis como a capacidade de colonizar o trato gastrintestinal do hospedeiro, inibir o crescimento de cepas patogênicas de interesse, não sofrer ação das enzimas digestivas e não apresentar potencial hemolítico. As BAL autóctones foram escolhidas por conta das características favoráveis e pelo fato de que os produtos no mercado são provenientes de isolados bacterianos de outras espécies. Neste estudo foram isoladas 16 cepas, sendo 14 com potencial patogênico e apenas 2 apresentaram resultado negativo para o teste de hemólise. Somente as espécies Citrobacter freundi e Clostridium buthirycum, ambos bacilos, apresentaram essas características de interesse, sendo as mesmas selecionadas para submissão, futuramente, de testes de antagonismo e testes in vivo em larvas e juvenis de tambaqui.

Palavras-chave: Aquicultura, autóctone e testes.

\footnotetext{
${ }^{1}$ Acadêmica de medicina veterinária da Universidade Nilton Lins. Avenida Professor Nilton Lins, 3259. Parque das Laranjeiras. CEP 69058-030, Manaus - AM. E-mail: debyjacob@hotmail.com

${ }^{2}$ Acadêmica de mestrado em aquicultura da Universidade Nilton Lins. Avenida Professor Nilton Lins, 3259. Parque das Laranjeiras. CEP 69058-030, Manaus - AM.

${ }^{3}$ Professor Doutor da Universidade Federal de Minas Gerais. Av. Pres. Antônio Carlos, 6627 - Pampulha, CEP 31270 901, Belo Horizonte - MG.

${ }^{4}$ Professor Doutor da Universidade Nilton Lins. Avenida Professor Nilton Lins, 3259. Parque das laranjeiras. CEP 69058 03, Manaus - AM.
} 


\title{
DIAGNÓSTICO DA PISCICULTURA NO DISTRITO FEDERAL E RIDE-DF
}

\author{
Amanda Hellen Soares Alves ${ }^{1}$; Ana Carolina Silva Brandizzi ${ }^{2}$; Eduardo Pickler Schulter ${ }^{3}$; Maria
} Fernando Nince Ferreira ${ }^{4}$.

A piscicultura de água doce se consolidou como principal ramo da aquicultura nacional e se tornou uma interessante alternativa para produção de proteína animal de alta qualidade. A produção de peixes de cultivo no Brasil atingiu cerca de 758 mil toneladas no ano de 2019, representando um crescimento anual de 4,9\%. No Brasil, o consumo médio anual de pescado é de $10 \mathrm{Kg}$ per capita, inferior ao recomendado pela Organização Mundial de Saúde - OMS (12 Kg. /hab./ano). Em contrapartida, no Distrito Federal, o consumo anual per capita em 2019 foi de 14 quilos. Ao se posicionar como um dos principais mercados consumidores do Brasil, o DF possui características únicas em relação ao resto do país. A alta concentração urbana, o elevado poder de compra e as múltiplas origens de sua população proporcionam um mercado consumidor único e diversificado.

Essa revisão de literatura tem como objetivo analisar a produção da piscicultura no Distrito Federal e nos municípios que compõem a RIDE-DF (Região Integrada de Desenvolvimento do Distrito Federal e Entorno).

Foi realizado um levantamento de dados secundários a partir de publicações oficiais e bases de dados de órgãos e instituições ligados ao setor, além de artigos científicos, dissertações, papers, identificados em bases de pesquisas confiáveis.

Dentre os municípios mais participativas na produção de pescado do DF e RIDE, segundo o IBGE, destacam-se Niquelândia (2.365.000 Kg./ano), Água Fria de Goiás (528.700 Kg./ano), Luziânia (425.854 Kg./ano), Cavalcante (330.000 Kg./ano), Brasília (329.670 Kg./ano) e Planaltina do Goiás (328.500 Kg./ano). Nas regiões de Minas Gerais e Goiás que compõem a RIDE, os principais sistemas de produção utilizados são viveiros escavados e tanques-rede. Já no DF, o principal meio são os viveiros escavados, devido à ausência de grandes reservatórios de hidrelétricas. A Tilápia do Nilo (Oreochromis niloticus) é o peixe mais cultivado, sendo que outras espécies como Tambacu, Curimatã, Lambari, Matrinxã, Pacu, Pintado e Piau, todas nativas e as Carpas (exótica) aparecem com potencial comercial na região.

O crescente mercado de consumo do Distrito Federal somado ao potencial hídrico e de terras encontrado na região, poderiam vir a tornar a piscicultura uma atividade agropecuária de sucesso na Região da RIDE, cabendo às instituições públicas e privadas incrementar as políticas públicas, pesquisas e projetos que auxiliem na estruturação desta cadeia produtiva.

Palavras-chave: Agronegócio. Aquicultura. Produção animal.

\footnotetext{
1 Graduanda em Medicina Veterinária do Centro Universitário ICESP de Brasília. http://lattes.cnpq.br/3454972822305374. amanda.soares@souicesp.combr

2 Graduanda em Medicina Veterinária do Centro Universitário ICESP de Brasília. http://lattes.cnpq.br/8308505870256380. ana.brandizzi@ souicesp.com.br

${ }^{3}$ Mestre em Agronegócios pela Universidade de Brasília. Professor coordenador do curso de Medicina Veterinária do Centro Universitário ICESP de Brasília. http://lattes.cnpq.br/1330335333232053. eduardo.schulter@icesp.edu.br

${ }^{4}$ Doutora em Ecologia pela Universidade Federal do Rio de Janeiro. Professora adjunta na Universidade de Brasília. http://lattes.cnpq.br/7553469356320921.mfnince@gmail.com
} 


\title{
DETERMINAÇÃO DA VAZÃO HÍDRICA NECESSÁRIA PARA O SISTEMA DE CULTIVO SEMI-INTENSIVO DE TILÁPIAS DO NILO (Oreochromis niloticus, Linnaeus, 1758), NO SETOR DE AQUICULTURA DO IFES - CAMPUS DE ALEGRE
}

\author{
Samuel Oliveira da Silva ${ }^{1}$; Emanuela Rodrigues Meneghetti ${ }^{2}$; Jéferson Luiz Ferrari ${ }^{3}$.
}

O sistema semi-intensivo de cultivo de tilápias nilótica (Oreochromis niloticus, Linnaeus, 1758) em viveiros escavados é bastante utilizado dentro da piscicultura brasileira e tem proporcionado retorno econômico satisfatório, com um baixo custo de manutenção. Nesse sistema a taxa de renovação de água é de, aproximadamente, 5 a 10\%, o que se torna viável em regiões desprovidas de grande disponibilidade de água. Os viveiros, geralmente, apresentam $2.000 \mathrm{~m}^{2}$ a $15.000 \mathrm{~m}^{2}$ de área alagada, não excedendo $30 \mathrm{~m}$ largura, com profundidades de $1,0 \mathrm{~m}$ na entrada de água e de $1,5 \mathrm{~m}$ a 2,0 $\mathrm{m}$ na saída e com declividade do fundo de 0,2\% 1,0\% (Oliveira et al., 2007). O presente trabalho tem como objetivo determinar a vazão hídrica necessária para o sistema de cultivo semi-intensivo de tilápias nilóticas em um setor de aquicultura que realiza seus cultivos em viveiros escavados. O referido fica localizado no Instituto Federal do Espírito Santo-Campus de Alegre, localizado no município de

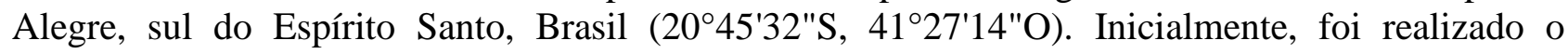
georreferenciamento do limite do setor e a quantificação das áreas de todos os viveiros escavados. Procedimento este realizado em Sistema de Informação Geográfica, o QGIS, versão 8.3 Zanzibar (Sherman et al., 2018), a partir de uma imagem de satélite georreferenciada, de alta resolução espacial (0,45 m). Em seguida, foram obtidos, durante o período de ciclo de cultivo para as tilápias (150 dias), os dados de precipitação pluviométrica e de evapotranspiração da Estação Meteorológica Automática de Alegre (INMET, 2019). De posse desses dados e da área total da lâmina de água dos viveiros, aplicou-se a metodologia da Food and Agriculture Organization of the United Nations (Fao, 1984) para calcular a quantidade de água requerida para a produção aqui citada. Realizou-se uma série de operações matemáticas: que pode ser sintetizada da seguinte forma: $\mathrm{Q}=\left(40.632,18+541,62 \mathrm{~m}^{3}+\right.$ $\left.22,52 \mathrm{~m}^{3}+13,71 \mathrm{~m}^{3}+0 \mathrm{~m}^{3}-23.32 \mathrm{~m}^{3}\right) /(86400 * 150$ dias); encontrando como resultado os valores de $\mathrm{Q}=0,00317 \mathrm{~m} 3 / \mathrm{s}$ ou $3,17 \mathrm{~L} / \mathrm{s}$. Conclui-se que durante um período de produção semi-intensiva de tilápia, nos 42.325,19 $\mathrm{m}^{2}$ de lâmina d'água disponíveis para cultivo no setor de aquicultura do referido campus, haveria um gasto de 3,17 L/s, até o fim do período seriam utilizados 41.083.200 litros de água. Com esses dados, basta acompanhar a previsão da disponibilidade de água na região e na época em que aconteceria a produção para ter tempo de tomar as medidas necessárias em caso de escassez de água, além de ser possível ponderar o aumento ou variação da produção aplicando um sistema mais intenso e adicionando novas espécies, basta reajustar os cálculos para tais condições.

Palavras-chave: Aquicultura. Consumo hídrico. Geoprocessamento. Viveiros escavados.

\footnotetext{
${ }^{1}$ Graduando do Curso de Engenharia em Aquicultura pelo Instituto Federal do Espírito Santo - Campus de Alegre. http://lattes.cnpq.br/2925485868309443. engaquisamuel@gmail.com.

${ }^{2}$ Graduanda do Curso de Engenharia em Aquicultura pelo Instituto Federal do Espírito Santo - Campus de Alegre. http://lattes.cnpq.br/1508497435373344.manu.meneghetti11@gmail.com

${ }^{3}$ Doutor em Produção Vegetal, Área de Concentração Engenharia Agrícola e Economia Rural pela Universidade Estadual Norte Fluminense Darcy Ribeiro. https://orcid.org/0000-0001-5663-6428. ferrarijluiz@ gmail.com.
} 


\section{BEM-ESTAR EM SISTEMAS DE CRIAÇÃO DE PEIXES ORNAMENTAIS E DE PRODUÇÃO}

Ana Luiza Nunes Galdino ${ }^{1}$; Andressa de Sousa Martins²; Brenda Cordeiro Bastos ${ }^{3}$; Diélica da Silva Brandão $^{4}$; Érica Fabiana da Silva Lima ${ }^{5}$ J Juliana Orlando Silva ${ }^{6}$; Lucas Agueiro de Carvalho ${ }^{7}$; Thaís Ágata Veiga Ferreira ${ }^{8}$; Victória Cristina Feitosa de Souza ${ }^{9}$; Tamyres Izarelly Barbosa da Silva ${ }^{10}$.

A criação de peixes exige que boas práticas de bem-estar sejam oferecidas com base em suas necessidades fisiológicas e ecológicas. A manutenção da água e fornecimento de alimentação adequada são ações fundamentais. Além do benefício direto a esses animais, cuja senciência já foi comprovada, práticas de bem-estar na piscicultura geram maiores lucros à cadeira produtiva.

Objetivou-se por meio deste trabalho revisar publicações científicas, indexadas nas principais bases de dados da área, no que tange à implementação de técnicas relativas ao bem-estar na criação de peixes ornamentais e destinados ao sistema de produção.

Foram selecionadas e avaliadas 48 obras nacionais e internacionais que abordaram a temática da criação de peixes ornamentais e de produção, publicadas em periódicos especializados, no período entre 1999 e 2018. Foi possível verificar que apenas 25\% dos trabalhos abordaram a senciência presente nos peixes e $42 \%$ apresentaram alternativas para aprimorar as condições de bem-estar, tais como enriquecimento ambiental, manejo adequado do ambiente em que os animais são acondicionados e preservação da taxa ideal de lotação nestes ambientes. Além disso, a promoção do bem-estar, visando um abate mais humanitário, foi a temática mais abordada pelos autores.

Para discutir o bem-estar dos animais, é essencial entender a senciência, que se trata da capacidade dos seres de terem percepções e sensações de forma consciente. A maioria dos artigos revisados no presente trabalho apresentaram técnicas para aumentar a produtividade, mas não abordavam diretamente sobre como o manejo adequado e bem-estar alavancam a criação de peixes.

Conclui-se, então, que a capacidade sensitiva dos peixes ainda é pouco explorada no meio científico, o que dificulta a atualização e reprodução de técnicas de manejo, que visem proporcionar melhor qualidade de vida a estes animais. Assim, é preciso que alternativas de bem-estar animal sejam amplamente apresentadas no meio científico e estes conhecimentos se estendam à sociedade.

Palavras-chave: Piscicultura. Qualidade de vida. Senciência.

\footnotetext{
${ }^{1}$ Graduanda em Medicina Veterinária pela Universidade Federal do Acre. analuiza.alng@ gmail.com.

${ }^{2}$ Graduanda em Medicina Veterinária pela Universidade Federal do Acre. andressadesm@gmail.com.

${ }^{3}$ Graduanda em Medicina Veterinária pela Universidade Federal do Acre. bbastos836@ gmail.com.

${ }^{4}$ Graduanda em Medicina Veterinária pela Universidade Federal do Acre. dielicadasilvabrandao@gmail.com.

${ }^{5}$ Graduanda em Medicina Veterinária pela Universidade Federal do Acre. ericafabiana8@ gmail.com.

${ }^{6}$ Graduanda em Medicina Veterinária pela Universidade Federal do Acre. julianaorlandos@gmail.com.

${ }^{7}$ Graduando em Medicina Veterinária pela Universidade Federal do Acre. lucasjipa2@ hotmail.com.

${ }^{8}$ Graduanda em Medicina Veterinária pela Universidade Federal do Acre. tveigaferreira@gmail.com.

${ }^{9}$ Graduanda em Medicina Veterinária pela Universidade Federal do Acre. victoriacristina250@ gmail.com.

${ }^{10}$ Professora Adjunta dos Cursos de Graduação e Pós-Graduação em Medicina Veterinária da Universidade Federal do Acre. http://lattes.cnpq.br/4356065151849759. Tamyres_ibs@ hotmail.com.
} 


\title{
ONTOGENIA DA CARPA CAPIM Ctenopharyngodon idellus
}

\author{
Rafael Vieira Da Silva ${ }^{1}$; Erivelto Oliveira De Souza²; Pedro Pierro Mendonça ${ }^{3}$.
}

A carpa capim (Ctenopharyngodon idella) é uma espécie exótica que possui ótimo desempenho na aquicultura (RIBEIRO et al. 2015). Desempenho este que pode ser melhorado ao entendermos os diferentes momentos fisiológicos do desenvolvimento ontogênico do animal (ALVES et al.2016).

O objetivo do presente trabalho foi observar e descrever os estágios de desenvolvimento ontogênico da carpa capim.

O experimento foi realizado no Instituto Federal do Espirito Santo (Ifes) - Campus de Alegre, no setor de aquicultura. Foram selecionadas para indução por hipofisação, 3 fêmeas com média de 4,367士0,13 e 6 machos com média de 3,327 $\pm 0,10$. As fêmeas receberam a primeira dose $(0,5 \mathrm{mg} \mathrm{de} \mathrm{EH} / \mathrm{kg}$ de fêmea) e após 10 horas foi aplicada a segunda dos (5 mg de EH/kg de fêmea) e a aplicação da dose única nos machos ( $1 \mathrm{mg}$ de $\mathrm{EH} / \mathrm{kg}$ de macho). As observações foram realizadas em intervalos de 30 minutos ate a formação do ducto anal, coletando amostras de dez ovos por momento em cada incubadora, posteriormente colocados em placa de petri e observados com microscópio optico, na lente de aumento (40x), e devolvidos após as observações para as incubadoras. Para as análises dos dados coletados, foi utilizado o método estatístico descritivo.

No decorrer do experimento obteve-se valores médios dos parâmetros de qualidade da água dentro dos valores recomendados para produção dessa espécie; temperatura média de 26,3 $\pm 0,4$, pH médio

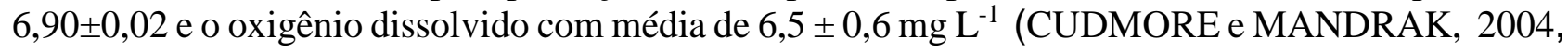
XAVIER, J.A.A, 2008, ARRIGNON, 1979; MAKINOUCHI, 1980). Nos primeiros 30 minutos após a hora zero observou-se a formação da blástula. Com 90 minutos o início da formação da gastrula. Em 210 minutos, a formação de $90 \%$ da gástrula. Com 310 minutos, o fechamento do blastóporo do embrião. Com 340 minutos, diferenciação dos folhetos embrionários. Com 410 minutos, a segmentação somática (formação da cauda e diferenciação da cabeça). Com 510 minutos, a presença dos somitos e formação do procefalo. Em 740 minutos, a diferenciação das vesículas ópiticas. Em 1010 minutos, liberação da cauda. Após 1040 minutos, o alongamento do embrião no eixo céfalo-caudal e visualização externa do tubo digestivo. Em 1210 minutos, a vesícula ótica do animal, 1910 minutos, a pigmentação dos olhos da larva, com 2010 minutos o início da flexão caudal, em 2140 minutos o canal anal do animal.

No presente trabalho foi possível observar e descrever os estágios embrionários do Ctenopharyngodon idellus.

Palavras-chave: Aquicultura. Desenvolvimento embrionário. Ontogenia. Carpa capim. Ctenopharyngodon idellus.

Apoio: Ifes Campus de Alegre e setor de Aquicultura.

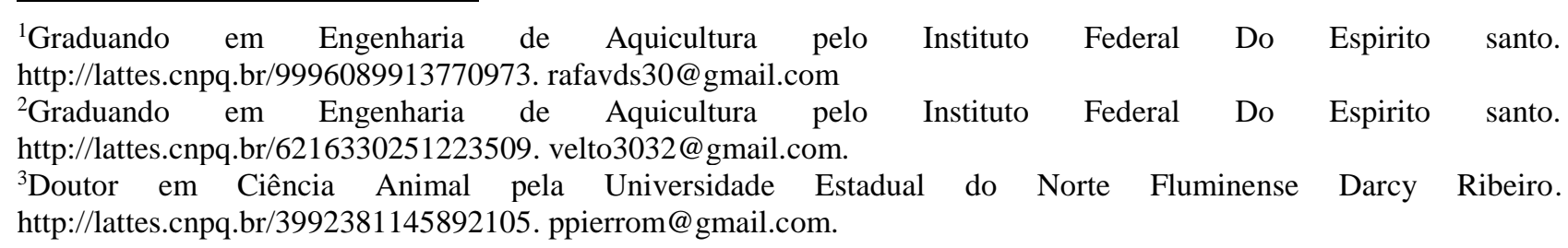




\section{EFEITO DA SALINIDADE NO CRESCIMENTO DE TILÁPIA DO NILO (Oreochromis niloticus) EM SISTEMA DE BIOFLOCOS}

Julianna Paula do Vale Figueiredo ${ }^{1}$; Ana Paula Mariane de Morais ${ }^{2}$; Weverson Ailton da Silva ${ }^{3}$; Ramires Eloíse Queiroz Rafael ${ }^{4}$; Edemar Roberto Andreatta ${ }^{5}$; Frank Belettini ${ }^{6}$; Felipe do Nascimento Vieira ${ }^{7}$.

O sistema de bioflocos tem demonstrado bons resultados nos cultivos de diferentes espécies devido a presença de uma comunidade microbiana que compõem o bioflocos e são responsáveis por manter a qualidade de água e servirem como suplemento alimentar aos organismos cultivados.

Neste sentido, o presente estudo teve como objetivo avaliar o crescimento de tilápia do Nilo (Oreochromis niloticus) em diferentes salinidades no sistema de bioflocos.

Os animais foram divididos em quatro tratamentos com quatro repetições cada, denominados: S02: salinidade $2 \%$; S08: salinidade $8 \%$; S15: salinidade $15 \%$ e S22: salinidade $22 \%$. A aclimatação foi feita utilizando $20 \%$ de água de bioflocos preenchida diariamente com água do mar e/ou doce de forma gradual, até atingir a salinidade de cada tratamento. Os peixes foram estocados em tanques circulares com volume útil com 800 litros, pesando em média 200g. A biometria foi realizada quinzenalmente para ajuste da alimentação de acordo com a biomassa. O experimento teve duração de 60 dias.

Os resultados demostram que não houve diferenças significativas entre os tratamentos de salinidades mais baixas (S02 e S08), o que já era esperado por se tratar de uma espécie de água doce. Os tratamentos S15 e S22 não diferiram entre si e apresentaram sobrevivência menor que os demais de 93,75 e 66,67 respectivamente, enquanto as menores salinidade tiveram sobrevivência de $100 \%$ $(\mathrm{P}>0,05)$ (Tabela 01). Concluiu-se então que o cultivo de tilápia é viável até a salinidade $15 \%$, pois apesar de demonstrar crescimento inferior ao S02 e S08, apresentou sobrevivência maior de $90 \%$.

Tabela 1. Ganho de peso (g) de Tilápia-do-nilo cultivada em diferentes salinidades $(0 \%$, 8\%, $15 \%$ e $22 \%$ ) durante 60 dias. Os dados são apresentados em médios \pm desvio padrão. ${ }^{*}$ Letras diferentes representam diferença significativa pelo teste Tukey $(\mathrm{p}<0,050)$.

\begin{tabular}{|l|l|l|l|l|}
\hline \multirow{2}{*}{ Crescimento } & Tratamento & \multicolumn{5}{|l|}{} \\
\cline { 2 - 5 } & S02 & S08 & S15 & S22 \\
\cline { 2 - 5 } & $242,21 \pm 16,53^{\mathrm{a}}$ & $217,10 \pm 16,27^{\mathrm{a}}$ & $149,74 \pm 22,91^{\mathrm{b}}$ & $122,46 \pm 16,58^{\mathrm{b}}$ \\
\hline
\end{tabular}

Palavras-chave: Cultivo. Tilápia. BFT.

\footnotetext{
${ }^{1}$ Doutoranda em Aquicultura pela Universidade Federal de Santa Catarina. http://lattes.cnpq.br/4212230692680889. juliannafigueiredo@hotmail.com

${ }^{2}$ Doutoranda em Aquicultura pela Universidade Federal de Santa Catarina. http://lattes.cnpq.br/2538621625115386 paulamariane.morais@gmail.com.

${ }_{3}^{3}$ Mestrando em Aquicultura pela Universidade Federal de Santa Catarina. http://lattes.cnpq.br/8320689687057292 pescailton@gmail.com.

${ }^{4}$ Doutoranda em Aquicultura pela Universidade Federal de Santa Catarina. http://lattes.cnpq.br/9814840610085923. Ramires.eloise@gmail.com

${ }^{5}$ Doutor em Ecologia e Recursos Naturais pela Universidade Federal de São Carlos. Professor titular da Universidade Federal de Santa Catarina. http://lattes.cnpq.br/6378294652077378. edemar.andreatta@ufsc.br

${ }^{6}$ Doutor em Aquicultura pela Universidade Federal de Santa Catarina. Professor substituto de graduação em Aquicultura da Universidade Federal de Santa Catarina. http://lattes.cnpq.br/6560339698232288. frank.belettini@ufsc.br

${ }^{7}$ Doutor em Aquicultura pela Universidade Federal de Santa Catarina. Professor da Pós-Graduação em Aquicultura da Universidade Federal de Santa Catarina. http://lattes.cnpq.br/6762840265825292. felipe.vieira@ufsc.br
} 


\title{
BETA-GLUCANOS COMO AGENTE PREBIÓTICO PARA TILÁPIAS: METANÁLISE SOBRE PARÂMETROS DE DESEMPENHO E ATIVIDADE DA LISOZIMA
}

\author{
Aline Neis Knob ${ }^{1}$; Éverton Augusto Kowalski²; Taida Juliana Adorian ${ }^{3}$; Leila Picolli da Silva ${ }^{4}$; \\ Luciana Pötter ${ }^{5}$.
}

Os beta-glucanos são substâncias relacionadas a melhorias na saúde dos animais, tais como aumento na atividade da lisozima sérica, muco epidérmico e ativação do sistema complemento.

A respeito desse aditivo, metanalisou-se os efeitos da utilização, perante ganho de peso, taxa de crescimento específico e atividade da lisozima em tilápias.

Realizou-se revisão bibliográfica sistemática utilizando os termos "prebiótico", "beta-glucano" e "tilápia" em inglês e português. Coletou-se 234 artigos, dois quais, 13 analisou-se estatisticamente com software RStudio, versão 4.0.2. Agrupou-se os dados em planilhas considerando o tratamento controle e um grupo teste. Com auxílio do software Web Ploter Digitizer, obteve-se os valores dispostos em imagens. Padronizou-se todas as medidas de variação em desvio padrão.

Os resultados encontrados indicam que seu uso trouxe efeito negativo para os animais, o que pode estar relacionado ao nível e tempo de utilização ou as altas heterogeneidades apresentadas.

Deve-se conduzir mais estudos para melhor compreensão dos meios de interação desse ingrediente.

Tabela 1. Resultados metanalisados do ganho de peso, taxa de crescimento e atividade da lisozima em tilápias

\begin{tabular}{|c|c|c|c|c|c|}
\hline \multirow{3}{*}{ Variáveis } & \multirow{3}{*}{$\mathrm{T}$} & \multirow{3}{*}{$\mathrm{Nv} \%$} & \multicolumn{3}{|c|}{ Variáveis Observadas } \\
\hline & & & GPd & SGR & $\mathrm{LZ}$ \\
\hline & & & \multicolumn{3}{|l|}{ MD } \\
\hline Tamanho amostral & 13 & 13 & 8 & 8 & 7 \\
\hline Média geral & 40,46 & 0,91 & $-0,10$ & $-0,26$ & $-4,78$ \\
\hline $\mathrm{DP} \pm$ geral & 32,63 & 2,74 & 0,17 & 0,34 & 5,16 \\
\hline Média GPd & 57 & 1,34 & - & - & - \\
\hline Média SGR & 59 & 1,33 & - & - & - \\
\hline Média LZ & 31,42 & 0,24 & - & - & - \\
\hline $\mathrm{DP} \pm \mathrm{GPd}$ & 30,25 & 3,50 & - & - & - \\
\hline $\mathrm{DP} \pm \mathrm{SGR}$ & 27,33 & 3,50 & - & - & - \\
\hline $\mathrm{DP} \pm \mathrm{LZ}$ & 32,79 & 0,35 & - & - & - \\
\hline $\mathrm{I}^{2} \%$ & - & - & 97 & 97 & 92 \\
\hline
\end{tabular}

T: Tempo em dias; Nv\%: Nível de utilização; GPd: Ganho de peso diário g; SGR: Taxa de crescimento especifica em \%; LZ: Atividade da lisozima em $\mu \mathrm{g} / \mathrm{ml}$; MD: Tamanho do efeito; DP \pm : Desvio padrão; $\mathrm{I}^{2} \%$ : Heterogeneidade; Fonte: Elaborado pelos autores.

Palavras-chave: Desempenho. Metanálise. Prebiótico. Peixe. Sistema Imune.

Apoio: PET Zootecnia. CNPq.

\footnotetext{
${ }^{1}$ Graduanda em Zootecnia pela Universidade Federal de Santa Maria. lattes.cnpq.br/4973847910556471. alineknob1997@gmail.com.

${ }^{2}$ Mestrando em Zootecnia pela Universidade Federal de Santa Maria. lattes.cnpq.br/9082839831311729 evertonzootecnia@outlook.com.

3 Pós-doutoranda em Zootecnia pela Universidade Federal de Santa Maria. lattes.cnpq.br/5315093891875912. taidajuliana@yahoo.com.br.

${ }^{4}$ Doutora em Zootecnia pela Universidade Federal do Rio Grande do Sul. Professora do Departamento de Zootecnia da Universidade Federal de Santa Maria. lattes.cnpq.br/9378190351379861. leilapicollidasilva@gmail.com

5 Doutora em Zootecnia pela Universidade Federal de Santa Maria. Professora do Departamento de Zootecnia da Universidade Federal de Santa Maria. lattes.cnpq.br/0683474086643296. potter.luciana@gmail.com
} 


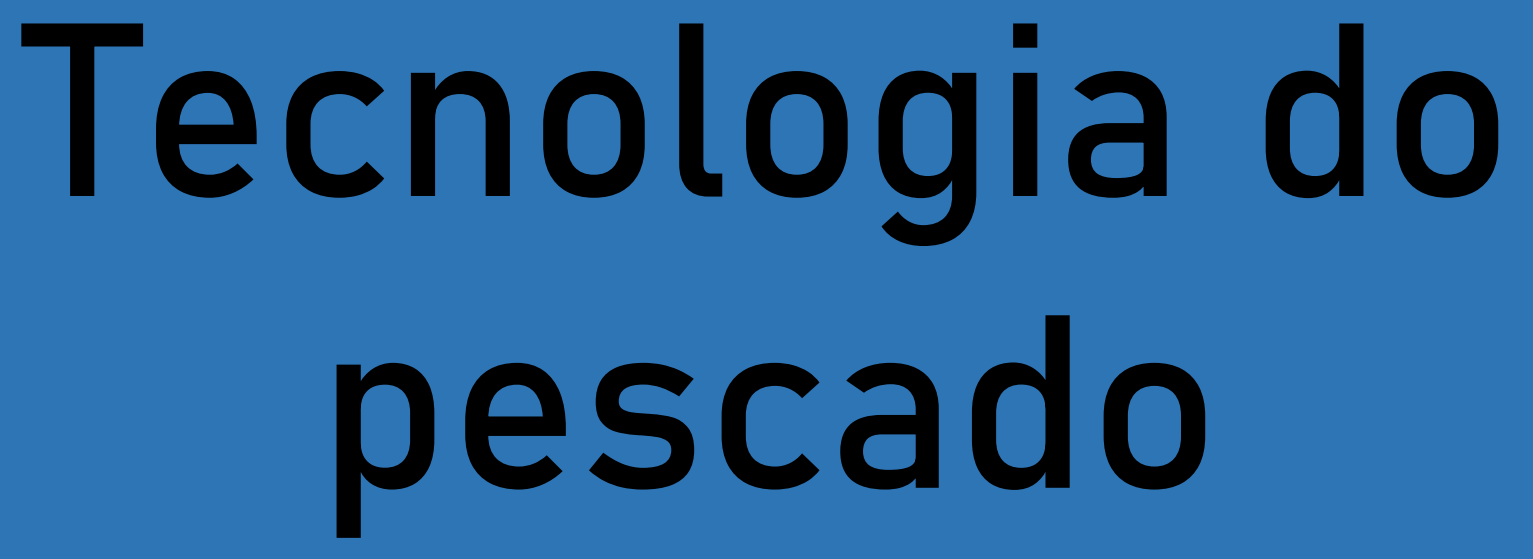




\title{
QUALIDADE FÍSICO QUÍMICA DE FILÉS DE TILÁPIA DO NILO (Oreochromis niloticus)
}

\author{
Guilherme Masteloto da Rosa ${ }^{1}$; Alexandra Pretto ${ }^{2}$; Rejane Sigaran Aguiar ${ }^{3}$; Fernanda R. Goulart \\ Ferrigolo ${ }^{4}$.
}

A Tilápia do Nilo (Oreochromis niloticus) é, atualmente, a espécie de peixe mais produzida no Brasil, sendo o filé a parte preferencialmente consumida. O pescado é considerado um dos alimentos de origem animal com maior valor nutricional, pois é constituído por elevados níveis de proteínas de alto valor biológico, bem como lipídios insaturados, vitaminas e minerais. No entanto, a sua composição, associada ao $\mathrm{pH}$ próximo a neutralidade e elevada atividade da água nos tecidos o tornam altamente perecível. Além disso, más condições de higiene, acondicionamento e refrigeração inadequados intensificam o processo de degradação do pescado.

Diante disso, o presente estudo teve como objetivo avaliar a qualidade físico-químicas de filés de tilápia do Nilo comercializados na cidade de Uruguaiana RS.

O presente estudo foi realizado no Centro de Tecnologia em Pesca e Aquicultura, da Universidade Federal do Pampa, Uruguaiana, RS. As amostras de filé de tilápia foram adquiridas em unidades comerciais na cidade de Uruguaiana, RS e estocadas a $-18^{\circ} \mathrm{C}$ até a realização das análises. Os parâmetros avaliados foram: $\mathrm{pH}$ (n: 2 amostras), com o uso de pHmetro portátil; peróxidos (n: 6 amostras) em amostras de gordura extraída do filé; substâncias reativas ao ácido tiobarbitúrico (TBARS) (n: 6 amostras), através de reação do malondialdeído em meio ácido; e bases nitrogenadas voláteis totais (BNVT) (n: 4 amostras) através da determinação de amônia e aminas voláteis.

As análises do filé de tilápia demonstraram valor médio de $\mathrm{pH}: 6,20 \pm 0,2$ unidades, peróxidos:

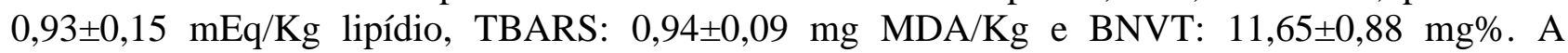
legislação nacional estabelece o limite de $30 \mathrm{mg} \%$ para BNVT e determina que o $\mathrm{pH}$ externo da carne de pescado deve ser inferior a 6,8 e o $\mathrm{pH}$ interno da carne inferior a 6,5. Portanto os valores de $\mathrm{pH} \mathrm{e}$ BNVT observados no filé de tilápia encontram-se dentro do limite desejado. O hidroperóxido, medido como o valor do peróxido, é um dos principais produtos da oxidação de lipídios na carne. Os hidroperóxidos são compostos instáveis e sua degradação gera moléculas voláteis, que alteram, entre outras características, o aroma da carne. De modo geral, os valores de índices de peróxidos variam de 0,2 a 1,1, estando dentro dessa faixa os valores encontrados no presente estudo. De acordo com a legislação, não existem níveis estabelecidos de TBARS indicando se o pescado está próprio para o consumo, porém, quanto menores os valores encontrados na carne de pescado, melhor será a sua qualidade, sendo assim sugere-se que os valores encontrados estão dentro do ideal para o consumo. Conclui-se que a avaliação do frescor do filé de tilápia torna-se de extrema importância, para que se conheça a qualidade dos filés comercializados e consumido na região, já que a espécie é atualmente a mais produzida no Brasil.

Palavras-chave: Pescado. Deterioração. Nutrição.

Apoio: $\mathrm{CNPq}$.

\footnotetext{
${ }^{1}$ Graduando no Curso Superior de Tecnologia em Aquicultura pela Universidade Federal do Pampa de Uruguaiana. http://lattes.cnpq.br/5326492598968808.guilherme.aluno@unipampa.edu.br.

${ }^{2}$ Doutora em Zootecnia pela Universidade Federal de Santa Maria. Técnica administrativa. Universidade Federal do Pampa. http://lattes.cnpq.br/0608992134648028. alexandrapretto@unipampa.edu.br.

${ }^{3}$ Graduanda do curso Superior de Tecnologia em Aquicultura pela Universidade Federal do Pampa de Uruguaiana. http://lattes.cnpq.br/7615199306659328.rejaneaguiar.aluno@unipampa.edu.br.

${ }^{4}$ Doutora em Zootecnia pela Universidade Federal de Santa Maria. Docente. Universidade Federal do Pampa. http://lattes.cnpq.br/2498444513148760. fernandaferrigolo@unipampa.edu.br.
} 


\title{
ESTUDO DE CASO DE RENDIMENTO PIRAPITINGA (Piaractus brachypomus), TAMBATINGA (Colossoma macropomum $X$ Piaractus brachypomus) EVISCERADO FRESCO EM FAIXAS DE PESO COMERCIAL
}

\author{
Shadai Mendes Silva ${ }^{1}$; Juan Rafael Ramirez Buitrago²; Shekinah Mendes Silva ${ }^{3}$.
}

O estudo de rendimento de pescado eviscerado fresco, é determinante para o planejamento das pisciculturas sobre a quantidade de peixes, qual peso deveria chegar a espécie para realizar o abate. Importante para a produtor como para a indústria de pescado, e em consequência lucro para o setor. A pirapitinga e tambatinga, tem aumentado o consumo no mercado internacional como Bolívia e Peru, por serem peixes claros e pequenos, para realizar pratos locais. Com isso a produção destes dois peixes está aumentando na região de Rondônia.

Objetivo do estudo é avaliar o rendimento das faixas de peso pirapitinga (Piaractus brachypomus), tambatinga (Colossoma macropomum X Piaractus brachypomus) eviscerado fresco, para o comercio internacional.

O presente trabalho é um estudo de caso de uma agroindústria que eviscera pescado fresco na região amazônica. Durante os meses de maio a agosto de 2020, foram coletados dados de rendimento das faixas $01(1,000 \mathrm{~kg}$ a $1,500 \mathrm{Kg})$, faixa $02(1,500$ a 2,000Kg) da pirapitinga, e da tambatinga. Tais faixas são os tamanhos comercial de venda. Sendo processado 59 toneladas de pirapitinga, e 69 toneladas de tambatinga neste período. Após a separação por balança, os peixes foram processados pela linha de produção. E logo registrados o peso eviscerado. Foi realizado analise de mínimos quadrados para rendimento com intervalos de confiança de 95,0\%. Logo analises de Variância, em seguida soma do quadrados e comparações multiplex para rendimento por tamanho.

Rendimentos do peixe inteiro eviscerado é a forma mais comercializada nas regiões andinas e amazônicas do Peru. Sendo de grande interesse que a espécie tenha um elevado rendimento para atender as exigências do mercado internacional. A faixa 01 e 02 da pirapitinga não teve diferenças entre si, sendo $81 \%$ o rendimento do peso total. A faixa 01 e 02 da tambatinga, não teve diferenças entre essas faixas, mas obteve um menor rendimento $79 \%$ do peso total, comparando com a pirapitinga.

A pirapitinga tem grande aceitabilidade em Cuzco, Peru, por ser um peixe prateado, obteve um bom rendimento para as faixas em estudo. A tambatinga tem melhor preferência que o tambaqui na região andina, por possui uma cabeça pequena. O rendimento desta espécie é um coeficiente baixo comparando com outras espécies amazônicas. Sendo de grande interesse para a indústria de pescado e piscicultores da região produzir a pirapitinga, para o mercado internacional.

Palavras-chave: Rendimento de carcaça. Peixe fresco. Indústria de pescado.

\footnotetext{
${ }^{1}$ Mestre em aquicultura pela Universidade Federal de Rio Grande. Gerente de controle e Qualidade de Entreposto de Pescado/RO. http://lattes.cnpq.br/1486422468909924 . shaddaimendes@ gmail.com

${ }^{2}$ Doutorando em aquicultura pela Universidade Federal de Rio Grande. http://lattes.cnpq.br/2723607251014015. juanrafaelb25@gmail.com

3 Graduado em Engenharia de Alimentos pela Universidade Federal de Rondônia. http://lattes.cnpq.br/2274453204680443.skymsro@gmail.com
} 


\title{
PROCEDÊNCIA E TECNOLOGIAS DE CONSERVAÇÃO APLICADAS NO PESCADO COMERCIALIZADO EM FEIRA DO MUNICÍPIO DE HUMBERTO DE CAMPOS-MA.
}

\author{
Hugo Moreira Gomes ${ }^{1}$; Henrique Chaves Silva ${ }^{2}$; Lucilia Silva Conceição ${ }^{3}$; Laila Freitas Oliveira de \\ Assis $^{4}$
}

Os mercados ou feiras livres, instalados em bairros de grandes cidades, exercem uma função importante gerando emprego e renda para os moradores destes centros, que vendem a varejo vários produtos em diversos locais e, também para pequenos e grandes produtores, que são a base da cadeia produtiva. Esse tipo de mercado sofre interferência diretamente da culinária local, custo e produto. E tendo o consumidor como seu principal cliente, colabora na alimentação de diversas famílias e auxilia no complemento da renda desses feirantes. $\mathrm{O}$ referente estudo teve por finalidade caracterizar a procedência e tecnologias de acondicionamento utilizados no pescado comercializado na feira do município de Humberto de Campos - MA.

O estudo foi realizado no município de Humberto de Campos - Maranhão. Para a realização do trabalho foram aplicados questionários semiestruturados junto aos feirantes deste município, com questões que geraram informações qualitativas e quantitativas. As coletas dessas informações foram através de entrevistas com perguntas do tipo: tempo de profissão, preferência dos clientes, origem, exposição à venda, tempo de estocagem do pescado e o que é feito com o peixe não comercializado.

De acordo com os dados obtidos, a comercialização dos pescados em feiras é a única fonte de renda dos entrevistados, destes eram predominantemente do sexo masculino, com idade média de 35 anos. O tempo de profissão está entre 2 a 44 anos e o valor de investimento para a venda do pescado variou de $\mathrm{R} \$ 500,00$ a $\mathrm{R} \$ 3.000,00$ reais mensalmente. Do peixe comercializado na feira $80 \%$ é oriundo da pesca extrativista local e apenas $2 \%$ provenientes de pisciculturas. Referente a preferência do tipo de pescado, os entrevistados relataram que os consumidores tem preferência por peixes marinhos, o que justifica a baixa comercialização de peixes procedentes de pisciculturas. Em relação a forma de exposição e conservação, os peixes são expostos em caixas de isopor com ou sem gelo, $80 \%$ conservam em caixas de isopor com gelo e $2 \%$ em freezer. Para o tempo de armazenamento até ser vendido, o pescado fica estocado de 3 a 4 dias e quando não é vendido nesse período $100 \%$ dos feirantes relataram que submetem os peixes ao processo de salmoura para serem comercializados na forma de "peixe seco".

Baseado nos resultados, foi possível observar que a comercialização do pescado é a principal fonte de renda dos feirantes no município de Humberto de Campos. É preciso que haja conscientização a respeito das boas práticas e manipulação do pescado, uma vez que o manipulador é quem faz o recebimento do dinheiro, como também a necessidade de mobilização da classe trabalhista e dos órgãos públicos competentes do município no sentido de fortalecer a organização social, garantindo aos feirantes melhores condições de infraestrutura e trabalho, além de investimentos em recursos humanos por meio da oferta constante de cursos e palestras.

Palavras-chave: Conservação. Manipulação. Peixe.

\footnotetext{
${ }^{1}$ Mestrando em Aquicultura pela Universidade Federal de Santa Catarina. http://lattes.cnpq.br/1057679857841026. moreirahugo32@gmail.com.

${ }^{2}$ Graduando em Engenharia de Pesca pela Universidade Estadual do Maranhão. http://lattes.cnpq.br/2623210524440728. hchaves65@gmail.com.

${ }^{3}$ Graduanda em Administração pela Universidade Estadual do Maranhão. http://lattes.cnpq.br/1004967224527177. luuh.sylva8@gmail.com

${ }^{4}$ Mestranda em Aquicultura pela Universidade Federal de Santa Catarina. http://lattes.cnpq.br/9115421412242095. laila.ufsc@gmail.com.
} 


\title{
CARACTERIZAÇÃO NUTRICIONAL DE FILÉS DE PEIXES COMERCIALIZADOS NA CIDADE DE URUGUAIANA-RS
}

\author{
Rejane Sigaran de Aguiar ${ }^{1}$; Alexandra Pretto $^{2}$; Guilherme Masteloto da Rosa ${ }^{3}$; Fernanda Goulart \\ Rodrigues Ferrigolo ${ }^{4}$.
}

O pescado é considerado uma excelente fonte de nutrientes, pois é constituído por proteínas de alto valor biológico, elevados níveis de ácidos graxos das séries n-3 e n-6, além de vitaminas e minerais. Sua composição é variável quanto à espécie, idade, sistema de cultivo, alimentação, peso, entre outros fatores. No Brasil, a tilápia-do-nilo (Oreochromis niloticus) e o panga (Pangasius hypothalmus) tem se destacado quanto a popularidade no mercado de pescados, visto que apresentam elevado valor nutricional, ausência de espinhas intramusculares e características sensoriais desejáveis. Considerando que a composição nutricional do pescado é variável em função de vários aspectos, a caracterização química do produto é de extrema importância a fim de viabilizar e equilibrar os nutrientes consumidos.

O objetivo do presente estudo foi avaliar a composição nutricional de filés de Panga (Pangasius hypophthalmus) e Tilápia (Oreochromis niloticus) comercializados na cidade de Uruguaiana.

Os filés foram adquiridos em comércio local da cidade de Uruguaiana-RS e encaminhadas ao Centro de Tecnologia de Pesca e Aquicultura da Universidade Federal do Pampa, Campus Uruguaiana, RS, e congelados a $-18^{\circ} \mathrm{C}$ até o momento da realização das análises. As amostras de filés de tilápia e panga foram analisadas quanto aos teores de umidade $\left(105^{\circ} \mathrm{C} / 24 \mathrm{~h}\right)$, cinzas $\left(500^{\circ} \mathrm{C} / 4 \mathrm{~h}\right)$, proteína bruta $(\mathrm{N} \mathrm{x}$ 6,25) pelo método micro-Kjeldahl. A gordura foi extraída e quantificada pelo método a frio utilizando os solventes metanol e clorofórmio. Foram analisadas 3 amostras de filé de cada espécie. Os resultados foram submetidos à análise de variância e as médias comparadas pelo teste de Tukey, em nível de 5\% de significância.

No filé de panga foram encontrados teores de $72,9 \%$ de umidade; $15,2 \%$ de proteína bruta e $0,9 \%$ de cinzas, e nos filés de tilápia $77,9 \%$ de umidade; $16,3 \%$ de proteína bruta e $0,88 \%$ de cinzas, não havendo diferença significativa entre as duas espécies analisadas. Porém, o conteúdo de lipídios no panga foi significativamente maior $(4,9 \%)$ comparado a tilápia $(1,4 \%)$. Esse nutriente é o componente mais sujeito a alteração, podendo variar em função da espécie, dieta fornecida, idade, tamanho dos peixes, parte do corpo, entre outros fatores. Conforme a literatura, as espécies de peixes analisadas no presente estudo enquadram-se entre peixes magros ( $<5 \%$ de gordura). Conclui-se que os dados obtidos contribuirão para expandir o consumo de tilápia e panga em razão da elevada quantidade de nutrientes encontrados nos filés analisados.

Palavras-chave: Qualidade do pescado. Frescor. Nutrição.

Apoio: UNIPAMPA.

\footnotetext{
${ }^{1}$ Graduanda no Curso Superior de Tecnologia em Aquicultura pela Universidade Federal do Pampa de Uruguaiana. http://lattes.cnpq.br/7615199306659328. rejaneaguiar.aluno@unipampa.edu.br

${ }^{2}$ Doutora em Zootecnia pela Universidade Federal de Santa Maria. Técnica administrativa. Universidade Federal do Pampa. http://lattes.cnpq.br/0608992134648028. alexandrapretto@unipampa.edu.br

${ }^{3}$ Graduando no curso Superior de Tecnologia em Aquicultura pela Universidade Federal do Pampa de Uruguaiana. http://lattes.cnpq.br/5326492598968808. guilhermerosa.aluno@unipampa.edu.br.

${ }^{4}$ Doutora em Zootecnia pela Universidade Federal de Santa Maria. Docente. Universidade Federal do Pampa. http://lattes.cnpq.br/2498444513148760. fernandaferrigolo@unipampa.edu.br.
} 


\title{
ESTUDO DE CASO DE RENDIMENTO DE TAMBAQUI (Colossoma macropomum) EVISCERADO FRESCO EM FAIXAS DE TAMANHO COMERCIAL
}

\author{
Shadai Mendes Silvaㄹ; Juan Rafael Ramirez Buitrago²; Shekinah Mendes Silva ${ }^{3}$.
}

Há poucos estudos sobre rendimento de carcaças de peixes amazônicos. O rendimento da carcaça, ajuda no planejamento da quantidade de peixes, e em qual peso deveria chegar aquela espécie para realizar a despesca. Sendo característica determinante no desempenho, produção, industrialização e lucratividade para o setor.

Objetivo do estudo é avaliar a faixa de tamanho do tambaqui (Colossoma macropomum), que obtêm maior rendimento eviscerado fresco.

O presente trabalho é um estudo de caso de uma agroindústria que eviscera pescado fresco na região amazônica. Durante os meses de maio a agosto de 2020, foram coletados dados de rendimento das faixas $1(1,600 \mathrm{~kg}$ a 2,299 Kg), faixa $02(2,300$ a 3,000Kg), faixa $03(3,000$ a 4,000 Kg) e faixa 04 (acima de $4 \mathrm{Kg}$ ). Tais faixas são os tamanhos comercial de venda. Sendo processado 80 toneladas neste período. Após a separação por balança, os peixes foram processados pela linha de produção. E logo registrados o peso eviscerado. Foi realizado analise de mínimos quadrados para rendimento com intervalos de confiança de 95,0\%. Logo analises de Variância, em seguida soma do quadrados e comparações multiplex para rendimento por tamanho.

Rendimentos do peixe inteiro eviscerado é a forma mais comercializada em Rondônia, Acre, Mato grosso e Amazonas. Sendo de grande interesse que a espécie tenha um elevado rendimento para atender as exigências do mercado regional. A faixa 02 e 03 não teve diferenças, sendo $82 \%$ o rendimento do peso total. A faixa 01 foi o que obteve o menor rendimento $68,9 \%$ do peso total. A faixa 04 apresentou $81,79 \%$ do peso total.

A faixa 02 e 03, representa o melhor rendimento, sendo de grande interesse para o fornecedor e para a indústria, que o cultivo de tambaqui ganhe um peso tão elevado. E para a indústria não convêm adquirir peixe com a faixa 01 .

Palavras-chave: Rendimento de carcaça. Peixe fresco. Indústria de pescado.

\footnotetext{
${ }^{1}$ Mestre em aquicultura pela Universidade Federal de Rio Grande. Gerente de controle e Qualidade de Entreposto de Pescado/RO http://lattes.cnpq.br/1486422468909924 . shaddaimendes@gmail.com

${ }^{2}$ Doutorando em aquicultura pela Universidade Federal de Rio Grande. http://lattes.cnpq.br/2723607251014015. juanrafaelb25@gmail.com

3 Graduado em Engenharia de Alimentos pela Universidade Federal de Rondônia. http://lattes.cnpq.br/2274453204680443.skymsro@gmail.com
} 
Carcinicultura 


\title{
EFEITO DA ADIÇÃO DE ALGAS PARDAS NA DIETA PARA O CAMARÃO BRANCO- DO-PACÍFICO CRIADO EM SISTEMA DE BIOFLOCOS
}

\author{
Camilla Souza Miranda ${ }^{1}$; Priscila Costa Rezende ${ }^{2}$; Felipe do Nascimento Vieira ${ }^{3}$.
}

O cultivo em sistema de bioflocos, permite o cultivo em áreas menores, com maior biossegurança e maior densidade de estocagem. Porém, precisa estar muito bem equilibrado para não levar a consequências negativas, como multiplicação de bactérias patogênicas, como as do gênero Vibrio que causam mortalidade. Contudo, diversos estudos relacionados com suplementação de camarões com macroalgas marinhas relataram excelente sobrevivência, melhora nos parâmetros de hematoimunológicos, menor concentração de Vibrio spp. e maior sobrevivência após a infecção com o vírus da mancha branca.

Nesse sentido, o objetivo deste trabalho foi avaliar o uso combinado da biomassa seca das algas pardas Sargassum filipendula e Undaria pinnatifida como aditivo alimentar para o camarão marinho Litopenaeus vannamei na engorda, cultivado em bioflocos nos parâmetros zootécnicos, resistência ao choque térmico e microbiota bacteriana intestinal.

Para isso foram avaliados três tratamentos durante 5 semanas: i) 1S:2U: $1 \%$ de $S$. filipendula e $2 \%$ de $U$. pinnatifida; ii) $1 \mathrm{~S}: 4 \mathrm{U}: 1 \%$ de $S$. filipendula e $4 \%$ de $U$. pinnatifida; e iii) Controle: sem suplementação com macroalgas, em quadruplicata, totalizando 12 unidades experimentais. Foram avaliados os parâmetros de qualidade de água, parâmetros zootécnicos, análise da microbiota do trato intestinal e a resistência ao choque térmico.

Nenhum parâmetro de qualidade de água e zootécnico apresentou diferença significativa e se mantiveram dentro dos padrões esperados para a espécie. As adições combinadas de 1S:2U e 1S:4U reduziram a concentração de vibrionáceas no trato intestinal do L. vannamei. O tratamento $1 \mathrm{~S}: 2 \mathrm{U}$ reduziu a mortalidade quando os camarões foram submetidos a quedas bruscas de temperatura, resultando em uma maior resistência ao estresse térmico.

Em conclusão foi possível observar que o uso combinado da biomassa seca das macroalgas $S$. filipendula e U. pinnatifida inseridas na ração do camarão Litopenaeus vannamei, apresenta potencial benéfico mesmo quando cultivos em sistema de bioflocos. A inserção de $1 \mathrm{~S}: 2 \mathrm{U}$ e $1 \mathrm{~S}: 4 \mathrm{U}$ podem reduzir a concentração de vibrionáceas no trato intestinal e a adição de $1 \mathrm{~S}: 2 \mathrm{U}$ das respectivas algas pode aumentar a sobrevivência dos camarões após estresse térmico, sem prejudicar os parâmetros de qualidade de água e índices zootécnicos dos camarões.

Palavras-chave: bioflocos. Litopenaeus vannamei. Sargassum filipendula. Undaria pinnatifida.

Apoio: $\mathrm{CNPq}$

\footnotetext{
1 Graduanda em Engenharia de Aquicultura pela Universidade Federal de Santa Catarina. http://lattes.cnpq.br/5497343830923390.camillasouzamiranda@hotmail.com

2 Doutoranda em Aquicultura e Recursos Pesqueiros pela Universidade Federal de Santa Catarina. http://lattes.cnpq.br/7052318292631232. Priscila.pesca.ufa@hotmail.com

3 Doutor em Aquicultura pela Universidade Federal de Santa Catarina. http://lattes.cnpq.br/6762840265825292. felipe.vieira@ufsc.br
} 


\title{
ALGAS PARDAS COMO ADITIVO ALIMENTAR PARA CAMARÃO BRANCO PACÍFICO, CULTIVADO EM SISTEMA DE BIOFLOCOS, MELHORA A RESISTÊNCIA AO ESTRESSE TÉRMICO E AO VÍRUS DA SÍNDROME DA MANCHA BRANCA
}

\author{
Priscila Costa Rezende ${ }^{1}$; Norha Constanza Bolívar Ramíre ${ }^{2}$; Felipe do Nascimento Vieira ${ }^{3}$.
}

O processo de intensificação dos sistemas de produção de camarões marinhos ao longo do tempo, levou a um incremento expressivo da produtividade das fazendas de cultivo. Com o aumento das densidades de estocagem e do input de ração nos sistemas produtivos houve um incremento da descarga de nitrogênio e outros potenciais poluentes nos ambientes aquáticos, além de aumentar o potencial de disseminação de enfermidades. O objetivo do trabalho foi avaliar o uso combinado da biomassa seca das algas pardas Sargassum filipendula (S) e Undaria pinnatifida (U) como aditivo alimentar na engorda do camarão-branco-do-pacífico cultivado em sistema de bioflocos, e seu efeito sobre o desempenho zootécnico, contagem bacteriana do trato digestivo, parâmetros hematoimunológicos, resistência ao estresse térmico agudo (choque térmico) e à infecção com vírus da Síndrome da Mancha Branca (WSSV) em associação com flutuação térmica. Foram avaliadas duas dietas contendo combinações da biomassa seca das algas pardas 1\%:2\% e 1\%:4\% (S:U) e uma controle, sem a adição das algas, em quadruplicata, totalizando 12 unidades experimentais. Os camarões foram cultivados por cinco semanas (de 3,8 $\pm 0,04 \mathrm{~g}$ até $10,9 \pm 0,06 \mathrm{~g}$ ) em tanques de polietileno de $400 \mathrm{~L}$, na densidade de 300 camarões $\mathrm{m}^{-3}$, e alimentados 4 vezes ao dia. Os tanques experimentais foram preenchidos inicialmente com $40 \%$ de água proveniente de um tanque matriz de bioflocos maduro, para promover o rápido estabelecimento da comunidade microbiana da água. Ao final do experimento, não foi observada diferença significativa entre os tratamentos quanto ao desempenho zootécnico e à contagem total de bactérias heterotróficas no intestino dos camarões. No entanto, a contagem de vibrionáceas foi significativamente menor no intestino dos camarões alimentados com as dietas experimentais em relação à controle. Quanto aos parâmetros hematoimunológicos, apenas os animais alimentados com a dieta $1 \mathrm{~S}: 4 \mathrm{U}$ apresentaram um incremento significativo em relação aos do grupo controle, exceto na contagem total de hemócitos. Para o choque térmico, os animais foram transferidos dos tanques experimentais, contendo água à $28{ }^{\circ} \mathrm{C}$, para tanques com água à $12,5^{\circ} \mathrm{C}$, após $1 \mathrm{~h}$, foram transferidos novamente para os tanques experimentais $\left(28^{\circ} \mathrm{C}\right)$. A mortalidade cumulativa foi registrada por $48 \mathrm{~h}$, e o tratamento $1 \mathrm{~S}: 2 \mathrm{U}$ apresentou menor mortalidade (27\%) em comparação aos demais tratamentos (controle: 50\%; 1S:4U 48\%). O desafio com WSSV + flutuação térmica teve duração de cinco dias, sendo os dias 1,4 e 5 realizados com a água à $28^{\circ} \mathrm{C}$, e os dias 2 e 3 com água à $18^{\circ} \mathrm{C}$. Os tratamentos com adição das algas (1S:2U e $\left.1 \mathrm{~S}: 4 \mathrm{U}\right)$ apresentaram menor mortalidade cumulativa ( $26 \%$ e $34 \%$, respectivamente) que o controle $(68 \%)$. Portanto, o uso combinado de $S$. filipendula e $U$. pinnatifida na dieta causou diversos efeitos fisiológicos benéficos para $L$. vannamei, sem prejudicar seu desempenho zootécnico, revelando enorme potencial para utilização em regiões subtropicais com incidência da doença da Mancha Branca.

Palavras-chaves: Litopenaeus vannamei, Sargassum filipendula, Undaria pinnatifida, Resistência ao choque térmico, Resistência ao WSSV.

Apoio: Capes e CNPq.

\footnotetext{
1 Doutoranda em Aquicultura pela Universidade Federal de Santa Catarina. LATTES: http://lattes.cnpq.br/7052318292631232. priscila.pesca.ufal28@gmail.com.
Doutora em Aquicultura pela Universidade Federal de Santa Catarina. LATTES: http://lattes.cnpq.br/8904527298357492.norhabolivar@yahoo.com.

${ }^{3}$ Doutor em Aquicultura pela Universidade Federal de Santa Catarina. Professor do Departamento de Pós-Graduação em Aquicultura da Universidade Federal de Santa Catarina. LATTES: http://lattes.cnpq.br/6762840265825292. YYY@gmail.com.
} 


\title{
AVALIAÇÃO DE PROBIÓTICOS COMERCIAIS DURANTE A FASE DE BERÇÁRIO DE Litopenaeus vannamei (BOONE, 1934) EM SISTEMA DE BIOFLOCOS
}

\author{
Laís de Lima ${ }^{1}$; Caio Henrique do Nascimento Ferreira ${ }^{2}$; Fabrício Martins Dutra ${ }^{3}$; Willian Favetta \\ Eduardo Luis Cupertino Ballester ${ }^{5}$.
}

O camarão marinho Litopenaeus vannamei é o mais produzido mundialmente. Em função da intensificação da atividade e da redução do uso de água, a utilização de probióticos é fundamental para atingir resultados positivos durante sua criação.

O objetivo deste trabalho foi avaliar o desempenho zootécnico do L. vannamei comparando o uso de um probiótico comercial em pó e o TCP (tecnologia de consórcio de probiótico).

Para a realização dos bioensaios foram utilizadas 12 unidades com volume de 70 litros em sistema de bioflocos e estático. Em cada unidade foram estocadas pós-larvas $(n=75 ; 0,0126 \pm 0,004 \mathrm{~g})$ durante 32 dias. O delineamento foi inteiramente casualizado contendo três repetições e quatro tratamentos, i.e., T1) sem adição de probiótico; T2) adição do probiótico comercial em pó; T3) probiótico TCP concentração recomendada pelo fabricante; T4) probiótico TCP - dobro da concentração recomendada pelo fabricante. As pós-larvas foram alimentadas quatro vezes ao dia. A taxa de arraçoamento utilizada foi calculada projetando crescimento dos animais em um grama em 30 dias. A ração foi ajustada semanalmente de acordo com as biometrias. Ao final do experimento os animais foram pesados, medidos e contabilizados para determinação do peso final, comprimento, sobrevivência, biomassa e conversão alimentar aparente. Os resultados de desempenho zootécnico foram submetidos a ANOVA e as comparações das médias ao teste Tukey $(\alpha=0,05)$.

Não houve significância ( $\mathrm{p}>0,05)$ para sobrevivência entre os tratamentos. As demais variáveis, comprimento total, peso, biomassa e conversão alimentar aparente apresentaram resultados significativamente superiores para T3 e T4 $(\mathrm{p}<0,05)$. Os valores estão sumarizados na tabela 1.

Tabela 1: Valores médios ( \pm E.P.) das variáveis de desempenho zootécnicos de pós larvas de Litopenaeus vannamei com aplicação de probiótico no sistema de produtivo em bioflocos.

\begin{tabular}{lllll}
\hline Variáveis & $\mathrm{T} 1$ & $\mathrm{~T} 2$ & $\mathrm{~T} 3$ & $\mathrm{~T} 4$ \\
\hline Sobrevivência $(\%)$ & $96 \pm 0.77$ & $92 \pm 0.45$ & $95 \pm 2.03$ & $96 \pm 2.04$ \\
Comprimento total $(\mathrm{cm})$ & $5,57 \pm 0,07^{\mathrm{b}}$ & $5,61 \pm 0,07^{\mathrm{b}}$ & $5,75 \pm 0,06^{\mathrm{ab}}$ & $5,88 \pm 0,06^{\mathrm{a}}$ \\
Peso $(\mathrm{g})$ & $1,15 \pm 0,03^{\mathrm{c}}$ & $1,18 \pm 0,04^{\mathrm{bc}}$ & $1,29 \pm 0,03^{\mathrm{ab}}$ & $1,37 \pm 0,04^{\mathrm{a}}$ \\
Biomassa $(\mathrm{g})$ & $82,74 \pm 4,09^{\mathrm{b}}$ & $81,69 \pm 3,84^{\mathrm{b}}$ & $90,50 \pm 1,64^{\mathrm{ab}}$ & $97,37 \pm 2,60^{\mathrm{a}}$ \\
Conversão alimentar aparente $(\mathrm{g} / \mathrm{g})$ & $1,16 \pm 0,06^{\mathrm{a}}$ & $1,18 \pm 0,05^{\mathrm{a}}$ & $1,06 \pm 0,02^{\mathrm{ab}}$ & $0,98 \pm 0,03^{\mathrm{b}}$ \\
\hline
\end{tabular}

Letras diferentes na mesma linha significam diferença estatística $(\alpha=0,05)$. Fonte: Elaborado pelos autores

Conclui-se que o tratamento T4 apresenta os melhores resultados em desempenho zootécnico, mas por ser o dobro da concentração recomendada pelo fabricante, pode não ser economicamente viável. Portanto, recomendamos o tratamento T3 por não apresentar diferença significativa em comparação com o T4, bem como pela variação observada nos resultados de desempenho zootécnico ser irrisória.

Palavras-chave: Carcinicultura, camarão-branco do pacífico, sistema intensivo.

\footnotetext{
${ }^{1}$ Graduanda em Engenharia de Aquicultura pela UFPR. Lattes: http://lattes.cnpq.br/6659755209393799

${ }^{2}$ Mestrando em Aquicultura e Desenvolvimento Sustentável pela UFPR. Lattes:http://lattes.cnpq.br/6386461991949867

${ }^{3}$ Pós-Doutorando em Aquicultura e Desenvolvimento Sustentável pela UFPR. Lattes: http://lattes.cnpq.br/1117229830675578.

${ }^{4}$ Graduado em Engenharia de Aquicultura pela UFPR. Lattes: http://lattes.cnpq.br/2808612355253826

${ }^{5}$ Doutor em Oceanografia Biológica pela Universidade Federal do Rio Grande. Professor da Universidade Federal do

Paraná. Lattes: http://lattes.cnpq.br/7710902249475122.
} 


\title{
AVALIAÇÃO DO USO DE PROBIÓTICOS COMERCIAIS NO BEM-ESTAR DE PÓS- LARVA Litopenaeus vannamei (BOONE, 1931) EM SISTEMA DE BIOFLOCOS
}

\author{
Caio Henrique do Nascimento Ferreira ${ }^{1}$;Laís de Lima $^{2}$; Fabrício Martins Dutra ${ }^{3}$; Ademir Heldt $^{4}$; \\ Eduardo Luis Cupertino Ballester 5 .
}

A carcinicultura vem se intensificando ao longo dos anos, e com esse crescimento o bem-estar animal tem se tornado uma preocupação, os probióticos vêm apresentando potencial de melhoria de bemestar nos sistemas intensivos de produção.

O objetivo deste trabalho foi avaliar o bem-estar do camarão Litopenaeus vannamei comparando o probiótico comercial em pó e o TCP (tecnologia de consórcio de probiótico).

Para a realização dos experimentos foram utilizadas 12 unidades com volume de 70 litros em sistema de bioflocos e estático. Em cada unidade foram estocadas pós-larvas $(\mathrm{n}=75 ; 0,0126 \pm 0,004 \mathrm{~g})$ durante 32 dias. $\mathrm{O}$ delineamento foi inteiramente casualizado contendo três repetições e quatro tratamentos, i.e., T1) sem adição de probiótico; T2) adição do probiótico comercial em pó; T3) probiótico TCP - concentração recomendada pelo fabricante; T4) probiótico TCP - dobro da concentração recomendada pelo fabricante. As pós-larvas foram alimentadas quatro vezes ao dia. A taxa de arraçoamento utilizada foi calculada projetando crescimento dos animais em um grama em 30 dias e ajustada semanalmente com base nas biometrias. Ao final do experimento foi determinado o comprimento da antena. Os animais também foram medidos e pesados para determinar o Índice Escalonado de Massa (IEM; Peig e Green $2009^{6}$ ). Os resultados foram submetidos a ANOVA e comparação de média pelo teste Tukey $(\alpha=0,05)$.

Foi observado aumento significativo no comprimento da antena em todos os tratamentos com uso de probióticos $(\mathrm{p}<0,05)$, para o IEM foi determinada diferença significativa $(\mathrm{p}<0,05)$ para os tratamentos com TCP, sendo que no tratamento com o dobro da dose o resultado foi superior em relação aos outros tratamentos. Isto revela que o uso do probiótico TCP melhorou as condições de bem-estar das pós-larvas em sistemas de bioflocos. Os resultados apresentados na tabela 1.

Tabela 1. Valores médio ( \pm E.P.) do Comprimento da Antena e IEM para pós-larvas de Litopenaeus vannamei em sistemas de bioflocos com uso de probióticos comerciais.

\begin{tabular}{lllll}
\hline Variáveis & $\mathrm{T} 1$ & $\mathrm{~T} 2$ & $\mathrm{~T} 3$ & $\mathrm{~T} 4$ \\
\hline Comprimento da antena $(\mathrm{cm})$ & $4,80 \pm 0,12^{\mathrm{b}}$ & $5,48 \pm 0,14^{\mathrm{a}}$ & $5,47 \pm 0,14^{\mathrm{a}}$ & $5,54 \pm 0,15^{\mathrm{a}}$ \\
& $1,10 \pm 9,1.10^{-3 \mathrm{c}}$ & $1,12 \pm 0,01^{\mathrm{c}}$ & $1,26 \pm 9,3.10^{-3}$ & $1,36 \pm 0,01^{\mathrm{a}}$ \\
\hline
\end{tabular}

Letras apresentam significância. Fonte do autor.

Conclui-se, que o tratamento com o dobro da concentração recomendada do probiótico TCP (T4) indicou melhores condições de bem-estar para pós-larvas de Litopenaeus vannamei em sistema de bioflocos.

Palavras-chave: Carcinicultura marina, camarão branco do pacífico, sistema intensivo.

\footnotetext{
${ }^{1}$ Mestrando em Aquicultura e Desenvolvimento Sustentável pela UFPR. Lattes: http://lattes.cnpq.br/6386461991949867 ${ }^{2}$ Graduanda em Engenharia de Aquicultura pela UFPR. Lattes: http://lattes.cnpq.br/6659755209393799

${ }^{3}$ Pós-Doutorando em Aquicultura e Desenvolvimento Sustentável pela UFPR. Lattes: http://lattes.cnpq.br/1117229830675578.

${ }^{4}$ Mestrado em Aquicultura e Desenvolvimento Sustentável pela UFPR. Técnico da UFPR. Lattes: http://lattes.cnpq.br/3131935273946116

${ }^{5}$ Doutor em Oceanografia Biológica pela FURG. Professor da UFPR. Lattes: http://lattes.cnpq.br/7710902249475122
} 


\title{
UTILIZAÇÃO DE CARVACROL COMO ALTERNATIVA AOS ANTIBIÓTICOS NO CONTROLE DE ENFERMIDADES BACTERIANAS NA CARCINICULTURA
}

\author{
Jaqueline da Rosa Coelho ${ }^{1}$; Karolina Victória Rosa ${ }^{2}$; Jamilly Sousa Rocha ${ }^{3}$; Norha Constanza \\ Bolívar Ramírez ${ }^{4}$; Felipe do Nascimento Vieira ${ }^{5}$.
}

As doenças são consideradas um dos principais fatores limitantes para a aquicultura e dentre estas estão as causadas por bactérias Gram-negativas do gênero Vibrio. Em busca de solucionar este problema utiliza-se antibióticos nos cultivos. Entretanto, o seu uso indiscriminado pode causar resistência bacteriana, deixar resíduos nos alimentos e no meio ambiente. Dessa forma, há um crescente interesse em substituir quimioterápicos por fitoterápicos e dentre estes está o carvacrol, um composto fenólico encontrado em óleos essenciais extraídos de plantas, na qual possui atividades antimicrobianas, antifúngicas e antioxidantes. Produtos derivados das plantas, como o carvacrol, possuem uma série de vantagens em relação aos antibióticos, pois não apresentam risco ao meio ambiente e a saúde humana, demonstrando assim uma fonte promissora, segura e sustentável para ser empregada na aquicultura. Com isso, o objetivo do presente estudo foi testar o carvacrol (em nanoemulsão) na dieta do camarão Litopenaeus vannamei. Para isso foi avaliado a microbiota intestinal, parâmetros imunológicos e zootécnicos dos animais. O estudo foi realizado no Laboratório de Camarões Marinhos (LCM) e os tratamentos utilizados foram: a) Controle negativo (ração sem carvacrol), b) Ração $+1 \mathrm{mg} / \mathrm{mL}$ de carvacrol, c) Ração $+3 \mathrm{mg} / \mathrm{mL}$ de carvacrol d) Ração $+4 \mathrm{mg} / \mathrm{mL}$ de carvacrol e e) Ração $+6 \mathrm{mg} / \mathrm{mL}$ de carvacrol. Os tratamentos foram realizados em triplicatas ( $\mathrm{n}=15 /$ tanques), os animais foram alimentados quatro vezes ao dia por quatro semanas e mantidos em ambiente totalmente controlado. Para avaliação da microbiota intestinal foram extirpados os tratos digestivos dos camarões ( $\mathrm{n}=10 /$ tanque). Em seguida estes foram homogeneizados, diluídos seriamente em solução salina (0\% e 3\%), semeados em meio de cultura Agar Marinho e TCBS (para contagem de bactérias heterotróficas totais e vibrios, respectivamente) e incubados em estufa a $30^{\circ} \mathrm{C}$ por 24 horas. Para a avaliação dos parâmetros imunológicos foi coletado a hemolinfa de camarões ( $\mathrm{n}=10 /$ tanque) para posterior contagem total de hemócitos (THC), concentração total de proteína na hemolinfa, atividade da fenoloxidase (PO) e título aglutinante do soro. Ao final do experimento foi avaliado o desempenho zootécnico dos animais, como ganho de peso semanal (GPS), peso final, fator de conversão alimentar (FCA) e a sobrevivência. Nos resultados obtidos não foram observadas diferenças significativas em nenhum dos parâmetros avaliados. Sendo assim, conclui-se que as concentrações de carvacrol utilizadas na alimentação de $L$. vannamei do presente estudo não afetaram o desempenho zootécnico, imunológico e a microbiota intestinal dos animais.

Palavras-chave: Aquicultura. Litopenaeus vannamei. Óleo essencial. Aditivo alimentar. Vibrios. Apoio: CNPq, FAPESC.

\footnotetext{
${ }^{1}$ Doutoranda em Aquicultura pela Universidade Federal de Santa Catarina. http://lattes.cnpq.br/2534940759927950. jaquesombrio@gmail.com.

2 Graduanda em Engenharia de Aquicultura pela Universidade Federal de Santa Catarina. http://lattes.cnpq.br/5205773308062565. Karolina.vrosa@gmail.com.

${ }^{3}$ Doutoranda em Aquicultura pela Universidade Federal de Santa Catarina. http://lattes.cnpq.br/4428418005740904. jamillysr@hotmail.com.

${ }^{4}$ Doutorado em Aquicultura pela Universidade Federal de Santa Catarina. http://lattes.cnpq.br/8904527298357492. norhabolivar@yahoo.com.

${ }^{5}$ Doutorado em Aquicultura pela Universidade Federal de Santa Catarina. http://lattes.cnpq.br/6762840265825292. felipe.vieira@ufsc.br.
} 


\title{
Nannochloropsis sp. COMO ADITIVO ALIMENTAR NA DIETA DO CAMARÃO- BRANCO-DO-PACÍFICO: EFEITOS NA MICROBIOLOGIA DO INTESTINO, RESISTÊNCIA AO ESTRESSE TÉRMICO E IMUNOLOGIA
}

\author{
Ariane Martins Guimarães ${ }^{1}$; Jaqueline da Rosa Coelho ${ }^{2}$; Priscila Costa Rezende ${ }^{3}$; Renata Oselame \\ Nóbrega $^{4}$; Felipe do Nascimento Vieira ${ }^{5}$.
}

O objetivo deste trabalho foi avaliar a farinha de Nannochloropsis sp. como aditivo alimentar para o camarão-branco-do-pacífico e os efeitos sobre sua microbiota intestinal, resistência ao choque térmico e parâmetros imunológicos.

Inicialmente, foi determinado o coeficiente de digestibilidade aparente do ingrediente. A digestibilidade da farinha da microalga foi total para alguns ácidos graxos importantes e para proteína; e bem alta para lipídeos em geral $(78,88 \%)$ e ácido graxo eicosapentahenóico $(73,86 \%)$. Posteriormente, a Nannochloropsis sp. foi incluída na dieta dos camarões em quatro níveis de adição $(0,0,5,1$ e $2 \%)$. Foi realizado o cultivo em sistema de água clara, com 20 camarões por tanque de $500 \mathrm{~L}$, com peso inicial de 6,05 $\pm 0,06 \mathrm{~g}$, alimentados quatro vezes ao dia de acordo com conversão alimentar programada. Os tratamentos foram realizados em quadruplicata, e cada tanque continha sistema de aeração constante, aquecimento e a água dos tanques foi renovada $80 \%$ ao dia. Após 15 dias, foram avaliados os parâmetros microbiológicos, realizado o choque térmico em baixa temperatura e os parâmetros imunológicos.

Os camarões alimentados com dieta suplementada com Nannochloropsis sp. (0,5 e 2\%) apresentaram diferença significativa com maior resistência ao teste de estresse térmico, em relação ao grupo controle (sem adição) e ao grupo com $1 \%$ de inclusão. Foi observada diferença estatística significativa nas espécies reativas de oxigênio, onde pode-se observar que nos níveis 1 e $2 \%$ de inclusão os animais estavam mais imunoestimulados que os demais tratamentos, sendo capazes de produzir mais moléculas altamente reativas (EROs). Não houve diferença estatística entre os tratamentos nos parâmetros imunológicos com relação a contagem total de hemócitos, atividade da fenoloxidase, título aglutinante e concentração proteica, assim como para microbiologia do trato intestinal. Desta forma, fica evidenciado que a adição de Nannochloropsis sp. na dieta de camarões $(0,5 \%$ e $2 \%)$ aumenta sua resistência ao choque térmico e sua capacidade em produzir EROs (1 e 2\%).

Palavras-chave: Litopenaeus vannamei. EPA. Choque térmico em baixa temperatura. Parâmetros imunológicos. Espécies reativas de oxigênio.

\footnotetext{
1 Doutoranda em Aquicultura e Recursos Pesqueiros pela Universidade Federal de Santa Catarina. http://lattes.cnpq.br/3090658263821449. ARIANEUFSC@ gmail.com.

2 Doutoranda em Aquicultura e Recursos Pesqueiros pela Universidade Estadual de Santa Catarina. http://lattes.cnpq.br/2534940759927950.JAQUESOMBRIO@gmail.com.

3 Doutoranda em Aquicultura e Recursos Pesqueiros pela Universidade Federal de Santa Catarina. http://lattes.cnpq.br/7052318292631232. PRISCILA.PESCA.UFAL@ hotmail.com.

4 Doutora em Aquicultura e Recursos Pesqueiros pela Universidade Federal de Santa Catarina. http://lattes.cnpq.br/4655592442446055. RENATA.OSELAMENOBREGA@gmail.com.

${ }^{5}$ Doutor em Aquicultura pela Universidade Federal de Santa Catarina. Coordenador do grupo de pesquisa do Laboratório de Camarões Marinhos - Universidade Federal de Santa Catarina. http://lattes.cnpq.br/6762840265825292. FELIPE.VIEIRA@ufsc.com.
} 
Legislação 


\title{
OS MARCOS REGULATÓRIOS ESTADUAIS E SEUS EFEITOS SOBRE A TILAPICULTURA NA REGIÃO HIDROGRÁFICA TOCANTINS-ARAGUAIA
}

\author{
Rafael Ramos Correa ${ }^{1}$; Marcos Ferreira Brabo ${ }^{2}$.
}

A Região Hidrográfica Tocantins-Araguaia integra, pelo menos parcialmente, seis unidades federativas do Norte, Nordeste e Centro-Oeste do Brasil, são elas: Tocantins, Goiás, Pará, Maranhão, Mato Grosso e Distrito Federal. Neste contexto, cada uma conta com um marco regulatório com critérios próprios para a prática da aquicultura, inclusive no que tange a espécies exóticas, como é o caso da tilápia Oreochromis niloticus. Este estudo objetivou analisar os marcos regulatórios estaduais e seus efeitos sobre a tilapicultura na Região Hidrográfica Tocantins-Araguaia. Efetuou-se um levantamento das normas jurídicas, nas plataformas oficiais de divulgação de cada unidade federativa. E também o levantamento da produção de tilápia do Censo Agropecuário 2017 por unidade federativa, através da Plataforma SIDRA, no site do Instituto Brasileiro de Geografia e Estatística. Visando assim, evidenciar os mecanismos de mitigação de impactos ambientais adotados e seus efeitos sobre o desenvolvimento da atividade. Desta forma, foram catalogadas e analisadas 13 legislações estaduais referente ao uso de espécies exóticas de peixes na Bacia Tocantins-Araguaia. Os critérios e medidas adotadas pelas legislações foram distintas. $\mathrm{O}$ estado com maior produção de tilápia foi Goiás (9291,5 t), o qual pode refletir sobre sua legislação, onde solicita apenas 2 medidas físicas de contenção. A segunda e quarta maiores produções foram das unidades geográficas que não tinham medidas restritivas expressas nas legislações, Maranhão (2440,7 t) e Distrito Federal (1162,7 t), respectivamente. O $3^{\circ}$ maior produtor foi o Mato Grosso $(1709,2)$, onde solicita apenas medidas físicas de contenção. E os estados com menores produções de tilápia, Pará (262,8 t) e Tocantins (30,8 t), possuíam as legislações com critérios mais restritivos. Os únicos que exigiam medidas biológicas, reversão sexual da espécie, mais critérios físicos de contenção. Destacando ainda que para o PA a produção em sistema aberto é caracterizada como atividade ilegal, o único com esta característica. Ressalta-se porém que as outras unidades federativas permitem essas modalidades com base nas

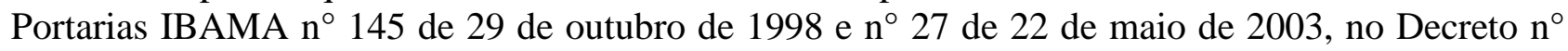
4.895 de 25 de novembro de 2003 e na Resolução CONAMA n ${ }^{\circ} 413$ de 26 de junho de 2009. Assim, o rigor do marco regulatório paraense tem influência direta sobre a baixa produção de tilápia em seu território, mas é ineficiente na tentativa de evitar possíveis impactos ambientais promovidos pela espécie, devendo ser revisto de forma conjunta com os demais integrantes da Região Hidrográfica Tocantins-Araguaia.

Palavras-chave: Tilapicultura. Espécies exóticas. Legislação aquícola. Piscicultura.

\footnotetext{
${ }^{1}$ Mestrando em Aquicultura pela Universidade Federal de Santa Catarina. http://lattes.cnpq.br/6585733841145026. Correarrafael@gmail.com.

2 Doutor em Ciência Animal pela Universidade Federal do Pará. Professor do Curso de Engenharia de Pesca, da Universidade Federal do Pará. http://lattes.cnpq.br/4274389612082613.m.brabo@ufpa.br
} 


\title{
LICENCIAMENTO AMBIENTAL AQUÍCOLA E A NOVA ÉTICA DO ANTROPOCENO
}

\author{
Luciana Guzella ${ }^{1}$; Poliana Ribeiro dos Santos²; Anita Rademaker Valença ${ }^{3}$.
}

O licenciamento ambiental é um excelente instrumento de gestão instituído pela Política Nacional do Meio Ambiente, Lei $\mathrm{n}^{\circ} 6.938$ de 31 de agosto de 1981; no qual busca regularizar atividades e empreendimentos que utilizem recursos naturais e/ou possam causar degradação ambiental onde tiverem instalados. O Licenciamento Ambiental atende o Princípio da Precaução, e tem como objetivos: 1) proporcionar segurança ambiental evitando o assoreamento ecológico dos ecossistemas; 2) democratizar o uso dos recursos naturais a todos os organismos vivos conforme previsto no Art. 225 da Constituição da República Federativa do Brasil de 1988. Desta forma, a Licença Ambiental representa ao Poder Público e a Sociedade, que a implantação e operação de empreendimentos utilizadores de recursos naturais e/ou potencialmente causadores de degradação ambiental adotem medidas necessárias que garantam a sustentabilidade sob o ponto de vista ambiental.

Se tratando de empreendimentos Aquícolas, todos são passíveis de Licença ou Autorização Ambiental por utilizarem recursos naturais e serem potencialmente causadores de impacto ambiental, conforme previsto nas Resoluções do CONAMA n ${ }^{\circ} 237$ de 19 de dezembro de 1997, $\mathrm{n}^{\circ} 312$ de 10 de outubro de 2002, n 413 de 26 de julho de 2009. Dentre alguns impactos ambientais inerentes à empreendimentos aquícolas podemos considerar afugentamento de fauna, supressão de vegetação, remoção das camadas férteis do solo e escavação do terreno, acondicionamento de água, produção de efluentes e resíduos sólidos, uso indiscriminado de quimioterápicos e fuga de espécimes; os quais variam de acordo com o tipo, porte do empreendimento e severidade da espécie cultivada, sendo necessário programas ambientais que visem minimizar os impactos ambientais apontados no Estudo Ambiental.

Entretanto, quase quarenta anos após a criação da Política Nacional do Meio Ambiente, o licenciamento ambiental ainda é muito mal interpretado, sendo avaliado muitas vezes como um entrave ao desenvolvimento econômico, deturpando completamente o conceito de desenvolvimento sustentável, criado para a preocupação ser o meio ambiente. Dados demonstram redução da população mundial de animais em 68\% entre os anos de 1970 e 2016, sendo que $94 \%$ deste total ocorreram em regiões tropicais da América Latina. No Brasil, $77 \%$ da perda de biodiversidade está relacionada com a degradação do habitat. Aproximadamente $12 \%$ dos recursos hídricos superficiais do planeta, encontram-se em território nacional, onde cerca $10 \%$ das espécies de peixes continentais estão sob risco de extinção e $64 \%$ das áreas úmidas já sofreram perturbações ambientais severas. (WWF e Plataforma Brasileira de Biodiversidade e Serviços Ecossistêmicos).

Esses dados demonstram o relapso às questões ambientais, afetando diretamente o equilíbrio ecológico, os serviços ecossistêmicos, o bem-estar e a saúde humana, sem qualquer contribuição social e econômica. Por isso, é imprescindível parar imediatamente o desmatamento, não reproduzir mais modelos sociais e econômicos insustentáveis que visam o comportamento consumista, a escravização e o uso direto e irresponsável dos recursos naturais. É necessário desenvolver tecnologias cujas economias sejam agroecológicas, circulares e de baixo carbono, valorar os serviços ecossistêmicos, recuperar as áreas degradadas e improdutivas, respeitar e valorizar os pequenos produtores, os povos originários e as comunidades tradicionais e fazer uso adequado das licenças ambientais sem provocar o desmonte das políticas ambientais.

Palavras-chave: Legislação Ambiental. Impacto Ambiental. Aquicultura.

\footnotetext{
${ }^{1}$ Mestre em Aquicultura, pela Universidade Federal de Santa Catarina. Graduanda em Engenharia de Aquicultura UFSC.

${ }^{2}$ Mestre em Direito, pela Universidade Federal de Santa Catarina. Graduanda em Engenharia de Aquicultura UFSC.

3 Professora do Departamento de Aquicultura da Universidade Federal de Santa Catarina. http://lattes.cnpq.br/1111981506079801. anita.valenca@ufsc.br
} 


\title{
AS COTAS DE RESERVA AMBIENTAL (CRA) COMO FERRAMENTA ECONÔMICA PARA O PISCICULTOR CATARINENSE
}

\author{
Bruna Roque Loureiroํㅜ Darci Pitton Filho²; Alex Pires de Oliveira Nuñer ${ }^{3}$.
}

Em maio de 2012, entrou em vigor a Lei Federal n 12.651/2012, que institui o "novo" Código Florestal Brasileiro. Dentre os principais mecanismos implantados na nova legislação, destaca-se o Cadastro Ambiental Rural (CAR), como principal ferramenta para apoiar na regularização ambiental dos imóveis rurais. A piscicultura continental é enquadrada como atividade passível de licenciamento ambiental e para que tal procedimento seja autorizado a regularização ambiental envolve o cumprimento de todo o arcabouço legal voltado à área florestal. Isso ocorre porque as áreas destinadas a produção estão intimamente associadas aos corpos hídricos naturais, como os cursos d'água e nascentes e o imóvel rural como um todo tem a obrigatoriedade de possuir uma área de vegetação nativa protegida, conhecida como Reserva Legal. Outro ponto de interface do piscicultor no cumprimento das leis florestais é que a atual resolução do Banco central, Resolução nº 4.838 , de 21 de julho de 2020, dispõe novos critérios ao acesso a crédito rural e este só será viabilizado se o piscicultor possuir o CAR. Além dos aspectos ambientais, o novo código prevê instrumentos econômicos e financeiros para o alcance de seus objetivos. O imóvel rural que possui um passivo ambiental, tem a possibilidade de recuperar essa área com déficit de vegetação nativa por meio da compensação ambiental. Nessa opção, como uma das alternativas à modalidade, poderá ser por meio da compra de cotas de reserva ambiental (CRA) em outras propriedades. A compensação será feita da seguinte forma: um produtor que tenha, em sua propriedade, reserva excedente ao estabelecido pela lei, pode gerar cotas $(1$ cota $=1$ hectare $)$ e disponibilizar para venda. As Cotas de Reserva Ambiental (CRAs), portanto são títulos representativos de cobertura vegetal que podem ser usados para cumprir a obrigação de Reserva Legal em outra propriedade. Alguns estados já possuem um mercado regulamentado por meio de um modelo de cotação de bolsa de valores de um mercado verde, onde as ações são as reservas legais disponíveis. Com isso um produtor que possui déficit de reserva legal compra essas cotas de um piscicultor que possui excedente a ser disponibilizado nesse mercado. Na prática, um produtor paga para outro preservar sua reserva. $\mathrm{O}$ trabalho analisou as matérias e seus dispositivos legais referentes à recuperação de Áreas de preservação permanente, reserva legal e compensação via CRA. Considera-se como cenário positivo para o Estado de Santa Catarina, esse instrumento econômico, pois o estado em seu perfil apresenta a economia voltada ao setor produtivo rural e não apenas os piscicultores, assim como todos que possuem imóveis rurais vão precisar regularizar seus passivos ambientais. De acordo com os dados publicados da Atlas da Mata Atlântica no período de 2017-2018, o estado possui 28,8\% da vegetação natural (INPE, 2019). Apesar de parecer um percentual baixo, este pode ser considerado relevante quando comparado a outros estados que integram esse bioma. No entanto, verificou-se um aumento no desmatamento em Santa Catarina, que comparado ao período anterior, foi de $52 \%$. Com isso, o mercado das CRAs assumirá um importante papel de compensação aqueles que preservam sua área verde e necessário para aqueles que desmataram e que irão precisar regularizar essas infrações. Uma forma de valorar economicamente o proprietário do imóvel, com isso, espera-se que aqueles produtores que mesmo produzindo peixes, preservaram suas áreas verdes, venham a se beneficiar agregando uma fonte de renda por meio das vendas das cotas.

Palavras-chave: Piscicultura continental, Adequação ambiental, Cota de reserva ambiental e serviços ecossistêmicos.

Apoio: CAPES, EPAGRI.

\footnotetext{
${ }^{1}$ Doutoranda do programa de Pós-graduação em Aquicultura pela Universidade Federal de Santa Catarina. Lattes: http://lattes.cnpq.br/1791678705458246. brunaroqueloureiro@gmail.com

2 Extensionista rural da Empresa de Pesquisa Agropecuária e Extensão Rural de Santa Catarina, EPAGRI. Lattes: http://lattes.cnpq.br/1123342344267662.ddarcifilho@epagri.sc.gov.br

3 Professor do programa de Pós-graduação em Aquicultura pela Universidade Federal de Santa Catarina. http://lattes.cnpq.br/5156937542968631. alex.nuner@ufsc.br
} 


\title{
LICENÇA AMBIENTAL DE PISCICULTURA EM SANTA CATARINA
}

\author{
Anita Rademaker Valença ${ }^{1}$; Poliana Ribeiro dos Santos $^{2}$; Luciana Guzella ${ }^{3}$; Eduardo Gomes \\ Sanches ${ }^{4}$.
}

O licenciamento ambiental é um dos instrumentos da Lei 6.938, de 31 de agosto de 1981 (Política Nacional do Meio Ambiente - PNMA), sendo um procedimento administrativo para obtenção da licença ambiental de uma atividade ou empreendimento utilizador de recurso ambiental, efetiva ou potencialmente poluidora ou capaz, sob qualquer forma de causar degradação ambiental (LC 140/2011 e CONAMA 237/97). A lista de atividades potencialmente poluidoras e utilizadoras de recursos ambientais encontra-se no anexo VIII da PNMA, e no anexo I da Instrução Normativa do IBAMA n $^{\circ}$ 6, de 15 de março de 2013, em ambas a aquicultura está listada na categoria 20 - Uso de recursos naturais, código 20-54 Exploração de recursos aquáticos vivos. Todas as atividades listadas nessas normativas são obrigadas ao processo de licenciamento ambiental e a inclusão no Cadastro Técnico Federal (CTF) do IBAMA.

No estado de Santa Catarina a Lei $\mathrm{n}^{\circ}$ 15.736, de 11 de janeiro de 2012 (alterada pela Lei $\mathrm{n}^{\circ} \underline{17.622 / 18}$ ) dispõe, define e disciplina a piscicultura de águas continentais. Nela os piscicultores são classificados quanto ao objetivo de sua produção em: produtor de formas jovens, produtor de peixes ornamentais, produtor terminador, produtor de matrizes e reprodutores, produtor de iscas aquáticas e piscicultor de pesque-pague. Ainda no artigo $4^{\circ}$ da lei as pisciculturas são classificadas em: Sistema I: unidade de produção de peixes em viveiros, Sistema II: truticultura, Sistema III: unidade de produção de peixes em tanques-rede e IV - Laboratório de Produção de Alevinos. E estes sistemas de produção podem ser classificados como de porte pequeno, médio ou grande.

De acordo com a lei $\mathrm{n}^{\circ}$ 15.736, em seu artigo 11, o licenciamento ambiental de piscicultura se dará mediante emissão de Licença Ambiental Prévia (LAP), Licença Ambiental de Instalação (LAI) e Licença Ambiental de Operação (LAO), porém no $§ 1^{\circ}$, do mesmo artigo, são excetuadas as atividades de piscicultura classificadas nos Sistemas I, II e III, quando de porte pequeno, as quais serão autorizadas por meio da emissão de Autorização Ambiental (AuA).

Um dos maiores empecilhos do piscicultor catarinense para obtenção da licença ambiental é a localização de seus empreendimentos em Áreas de Preservação Permanente (APP). Porém a Lei $\mathrm{n}^{\circ} 15.736$ autoriza a implantação e manutenção da atividade de piscicultura em APP, desde que de acordo com o disposto no art. 120-E da Lei estadual $n^{\circ} \underline{14.675}$, de 13 de abril de 2009 , e no $\S 6^{\circ}$ do art. $4^{\circ}$ da Lei federal $n^{\circ} 12.651$, de 25 de maio de 2012 (Código Florestal). Os artigos acima mencionados declaram que nos imóveis rurais com até quinze módulos fiscais, é admitida, em algumas áreas de APP, a prática da aquicultura e a infraestrutura física diretamente a ela associada, desde que: sejam adotadas práticas sustentáveis de manejo de solo e água e de recursos hídricos, garantindo sua qualidade e quantidade, de acordo com norma dos Conselhos Estaduais de Meio Ambiente; esteja de acordo com os respectivos planos de bacia ou planos de gestão de recursos hídricos; seja realizado o licenciamento pelo órgão ambiental competente; o imóvel esteja inscrito no Cadastro Ambiental Rural - CAR e não implique novas supressões de vegetação nativa.

Palavras-chave: Regularização ambiental. Licenciamento ambiental. Licença ambiental. IMA.

\footnotetext{
1 Professora do Departamento de Aquicultura da Universidade Federal de Santa Catarina. http://lattes.cnpq.br/1111981506079801. anita.valenca@ufsc.br

${ }^{2}$ Mestre em Direito, pela Universidade Federal de Santa Catarina. Graduanda em Engenharia de Aquicultura UFSC.

${ }^{3}$ Mestre em Aquicultura pela Universidade Federal de Santa Catarina. Graduanda em Engenharia de Aquicultura UFSC.

${ }^{4}$ Pesquisador do Instituto de Pesca/SP. http://lattes.cnpq.br/7293090235151230, eduardo.sanches2005@ gmail.com.
} 
Genética, biologia, reprodução e fisiologia de espécies aquáticas 


\title{
ASPECTOS DA LARVICULTURA E ASSENTAMENTO DE BERBIGÕES Anomalocardia brasiliana EM FLORIANÓPOLIS/SC
}

\author{
João Guzenski ${ }^{1}$; Francisco Carlos da Silva ${ }^{2}$.
}

O berbigão Anomalocardia brasiliana (Gmelin,1791) é uma espécie nativa de molusco bivalve que vive coberto em substrato areno-lodoso, em planícies de maré de águas rasas, sendo sua distribuição desde Antilhas, Bahamas, Suriname, ocorrendo em toda a Costa Brasileira até o Uruguai, de acordo com Rios (1994).Este molusco apresenta uma elevada importância socioeconômica para os países da América Latina, constituindo fonte de renda e subsistência para as comunidades artesanais (CASTILLA \& DEFEO 2001). Segundo Barreira \& Araújo (2005), pesquisas sobre reprodução de bivalves são vistas como base para a criação de programas de manejo, pois podem auxiliar na manutenção dos estoques naturais e contribuir para o desenvolvimento de atividades extrativistas e de maricultura.

O presente trabalho objetivou produzir larvas e sementes de Anomalocardia brasiliana para atender os estudos de campo da EPAGRI com a espécie, na região da Grande Florianópolis.

Para a produção das sementes de Anomalocardia brasiliana, foi realizada a desova, criação de larvas e o assentamento dos spats no Laboratório de Moluscos Marinhos da UFSC, localizado na Barra da Lagoa, município de Florianópolis, Santa Catarina, em maio de 2019. A reprodução foi realizada a partir de 307 exemplares adultos, com um peso de 13,93 $\pm 3,19 \mathrm{~g}$ e comprimento de $32,75 \pm 2,31 \mathrm{~mm}$, mantidos em seco por 12 horas, higienizados e colocados para desova em recipiente com água do mar filtrada em $1 \mu$ e esterilizada por ultravioleta, a temperatura de $25^{\circ} \mathrm{C}$, para indução a desova por choque térmico. À medida que iniciava o processo de expulsão de gametas, os machos eram retirados, mantendo-se apenas as fêmeas. Após 2 horas os gametas foram transferidos para um tanque de 6000 1. A larvicultura durou um período de 10 dias, com a temperatura da água do mar mantida em 21,84 $\pm 0,65{ }^{\circ} \mathrm{C}$, sendo realizada a troca de água total a cada 24 horas a partir do segundo dia. A contagem das larvas foi estimada em $7.13 \times 10^{6}$ larvas $\mathrm{D}$, que foram inicialmente alimentadas diariamente com uma concentração de $2 \times 10^{4}$ cél $/ \mathrm{ml}$ de $I$. galbana e P.lutheri em igual proporção, e a partir do quarto dia foi incrementada a dieta para $5 \times 10^{4} \mathrm{cél} / \mathrm{ml}$, com a introdução de C.muelleri. Aos nove dias foram identificadas as primeiras larvas pé-de-veliger e a contagem indicou $4.8 \times 10^{6}$ larvas viáveis. Aos dez dias de idade as larvas foram transferidas para um tanque de assentamento com sistema downwelling, com capacidade total de 1500 litros e dividas em 3 cilindros com diâmetro de $0,7 \mathrm{~m}$ e malha de 80 micras no fundo. Foi realizada troca de água total do sistema a cada 24 horas. O alimento nesta fase foi ministrado em uma dose diária, com uma concentração inicial de $7 \times 10^{4}$ cél $/ \mathrm{ml}$ de um mix de I. galbana, P. lutheri e C. muelleri, com $50 \%$ da ração diária sendo composta de C. muelleri. À medida que os spats cresciam, estes eram separados por tamanho (maiores ou iguais e menores que 180 micras) e distribuídos nos três cilindros do sistema. Com 28 dias de assentamento foi realizada a troca dos cilindros para tela de fundo de 200 micras e aumentada a alimentação para $10 \times 10^{4}$ cél $/ \mathrm{ml}$. Neste sistema foram mantidas por um período de 72 dias. Ao final do período de assentamento cerca de $5 \%$ das sementes oriundas da larvicultura foram transferidas em lotes para o mar.

Os resultados do presente estudo indicam que a larvicultura em baixa densidade, com troca total da água a cada $24 \mathrm{~h}$, e o uso da dieta com três microalgas pode ser recomendada para a produção de larvas e sementes de Anomalocardia brasiliana.

Palavras chave: Anomalocardia. Berbigão. Reprodução de bivalves.

\footnotetext{
${ }^{1}$ Doutor em Geografia pela Universidade Federal de Santa Catarina. Pesquisador em Aquicultura da EPAGRI/SC. http://lattes.cnpq.br/7638069535941192. guzenski@epagri.sc.gov.br.

${ }^{2}$ Mestre em Aquicultura pela Universidade Federal de Santa Catarina. http://lattes.cnpq.br/4556356537085532. Tecnico do Laboratório de Moluscos Marinhos da UFSC. francisco.cs@ufsc.br.
} 


\title{
AVALIAÇÃO MORFOMÉTRICA DO TECIDO HEPATOPANCREÁTICO DE ZEBRAFISH (Danio rerio) COM OBESIDADE INDUZIDA POR DIETA
}

\author{
Bárbara do Carmo Rodrigues Virote ${ }^{1}$; Amanda Maria Siqueira Moreira ${ }^{2}$; Isabela Miranda \\ Guimarães ${ }^{3}$; André Rodrigues da Cunha Barreto Vianna ${ }^{4}$; Luis David Solis Murgas ${ }^{5}$.
}

O zebrafish, (Danio rerio) tem se destacado como um excelente modelo experimental para o estudo de distúrbios metabólicos, como a obesidade, o que auxilia no entendimento das vias de sinalização atreladas a essa condição. Entretanto, os eventos fisiopatológicos envolvidos nessa condição ainda precisam ser elucidados.

Dessa forma, o objetivo do trabalho foi avaliar as alterações histológicas do pâncreas de zebrafish com obesidade induzida pela dieta. Este estudo foi aprovado sob o número 084/2017 pelo Comitê de Ética Animal.

Durante o experimento foram estudados 90 animais, com idade média de 5 meses, de ambos sexos, separados em dois grupos: grupo controle (GC) e grupo obeso (GO). Durante 8 semanas o GC foi alimentado de acordo com o preconizado para a espécie. Por outro lado, o GO foi superalimentado, recebendo seis vezes mais ração que o GC. Nas semanas 0,4 e 8 foi realizada eutanásia de 8 machos e 10 fêmeas de cada grupo. O hepatopâncreas foi processado para análise histológica, sendo fixado, diafanizado, e confeccionado lâminas, que foram coradas com hematoxilina e eosina. Com auxílio de microscópio, foi calculado o diâmetro médio das ilhotas pancreáticas, utilizando o software ImagePro Plus ${ }^{\circledR}$ versão 7.01. Com os dados obtidos, foi realizado o teste de normalidade Shapiro Wilk, seguido pela análise de variância (ANOVA).

Os resultados indicaram que na quarta e oitava semana de indução à obesidade, houve o aumento significativo no diâmetro das ilhotas pancreáticas do GO em relação ao GC $(\mathrm{P}<0,05)$, tanto em machos, quanto em fêmeas. Esta modificação estrutural é típica de indivíduos que apresentam resistência à insulina, com aumento compensatório das ilhotas pancreáticas. Dessa forma, este modelo de obesidade induzida por dieta utilizando zebrafish causou, a partir da quarta semana, modificações estruturais compensatórias no hepatopâncreas.

Palavras-chave: Alterações histológicas. Distúrbio metabólico. Ilhotas pancreáticas.

Apoio: Rede Mineira de Bioterismo-FAPEMIG, CNPq e CAPES.

\footnotetext{
${ }^{1}$ Doutoranda em Medicina Veterinária pela Universidade Federal de Lavras. http://lattes.cnpq.br/8466553707499960. barbara-crv@hotmail.com.

${ }^{2}$ Mestranda em Biologia Celular pela Universidade Federal de Minas Gerais. http://lattes.cnpq.br/1603667508290425. amandamsmoreira@outlook.com.

3 Graduanda em Zootecnia pela Universidade Federal de Lavras. lattes.cnpq.br/7586627138157709. Isabelamiranda095@gmail.com.

4 Doutor, Professor Adjunto do Departamento de Biociências, Universidade Federal do Paraná. http://lattes.cnpq.br/4686710449601127. andre.vianna@ufpr.br.

5 Doutor, Professor Titular do Departamento de Medicina Veterinária da Universidade Federal de Lavras. http://lattes.cnpq.br/9261836492596804. 1smurgas@ufla.br.
} 


\title{
UTILIZAÇÃO DO DILUENTE TRIS PARA PRESERVAÇÃO DE AMOSTRAS DE SANGUE DO Arapaima gigas SUBMETIDAS A PROTOCOLO DE EXTRAÇÃO DE DNA
}

\author{
Hélen Clarice Chaves Costa ${ }^{1}$; Carlos Riedel Porto Carreiro².
}

O pirarucu (Arapaima gigas) é um dos organismos de água doce mais valorizados do país (FREITAS et al., 2007), destacando-se pelo desenvolvimento e rusticidade (IMBIRA, 2001). No entanto, a execução de estudos para determinar a variabilidade genética de populações da espécie ainda é escasso, afetando a produtividade das criações. Nesse contexto, protocolos de biologia molecular podem ser ajustados, sendo necessários, portanto, estudos básicos para otimização da extração de DNA e coleta de amostra de boa qualidade (SOLLÉRO et al., 2004).

O presente trabalho teve como objetivo testar três diferentes protocolos de conservação de amostras de sangue em cinco exemplares de pirarucu, Arapaima gigas, utilizando o diluente e criopreservador TRIS, solução de TRIS adicionada de soro fisiológico a 5\% e, para controle, sem adição de TRIS. E identificar o tratamento que obtenha maior concentração de DNA genômico.

As amostras de sangue foram coletadas com agulha e seringa de insulina estéreis com perfuração no arco branquial póstero lateral esquerdo, de cinco exemplares de pirarucu (em fase juvenil e adulto, com peso médio de $20 \mathrm{~kg}$ ), de uma fazenda particular localizada no município de Alto Alegre do Pindaré, estado do Maranhão. O sangue coletado foi colocado em tubos eppendorfs contendo: 1) solução de TRIS (TP), 2) Solução de TRIS + soro fisiológico (TD) e 3) controle (SP). Armazenadas em caixa térmica resfriada e enviadas ao Laboratório de Genética e Biologia Molecular Professor Warwick Estevam Kerr da Universidade Estadual do Maranhão para a realização da extração e quantificação do DNA das amostras. A extração de DNA genômico das amostras foi baseada na metodologia adaptada da técnica descrita por Sambrook et al. (1989), de Fenol:Clorfórmio. A determinação da pureza e estimativa de concentração, após a extração, foi feita por espectrofotometria em Nanodrop FEMTO modelo 48.

A média da concentração de DNA extraído obtida das 10 amostras totalizadas, é mostrada na Tabela 1. Com base nessas concentrações obtêm-se melhores rendimentos na quantidade de DNA com a não utilização do tris para a conservação das amostras de sangue. A pureza da amostra foi avaliada pela relação espectrofotométrica A260/A280. O resultado obtido variou entre 1,7 e 2,0. Uma vez que soluções puras de DNA apresentam uma razão entre 1,8 a 2,0, a pureza da solução analisada de DNA foi considerada aceitável. Valores fora deste intervalo, podem indicar contaminação por proteínas ou por RNA (Turner et al., 1997).

Tabela 1 - Média da concentração de DNA obtida nas amostras com os métodos de conservação.

Fonte: Elaborado pelos autores.

\begin{tabular}{l|l}
\hline Forma de conservação & Quantidade de DNA $(\mathrm{ng} / \mu \mathrm{L})$ \\
\hline Tris puro (TP) & 7 \\
\hline Tris + soro fisiológico (TD) & 33 \\
\hline Controle (SP) & 48 \\
\hline
\end{tabular}

Pode-se optar, portanto, pela não utilização do diluente TRIS (grupo controle) nas amostras, visto que se encontra quantidade satisfatória de DNA e pureza aceitável. O presente estudo é preliminar e visa otimizar o protocolo de armazenamento, para extração do DNA no Arapaima gigas.

Palavras-chave: Pirarucu. Biologia molecular. Melhoramento genético.

\footnotetext{
${ }^{1}$ Graduanda em Medicina Veterinária pela Universidade Estadual do Maranhão. http://lattes.cnpq.br/1341231628168488. helencosta633@gmail.com.

${ }^{2}$ Doutor em Engenharia de Pesca pela Universidade Federal do Ceará. Professor do Departamento de Engenharia de Pesca da Universidade Estadual do Maranhão. http://lattes.cnpq.br/4030738283655295. carlosriedelporto@gmail.com.
} 


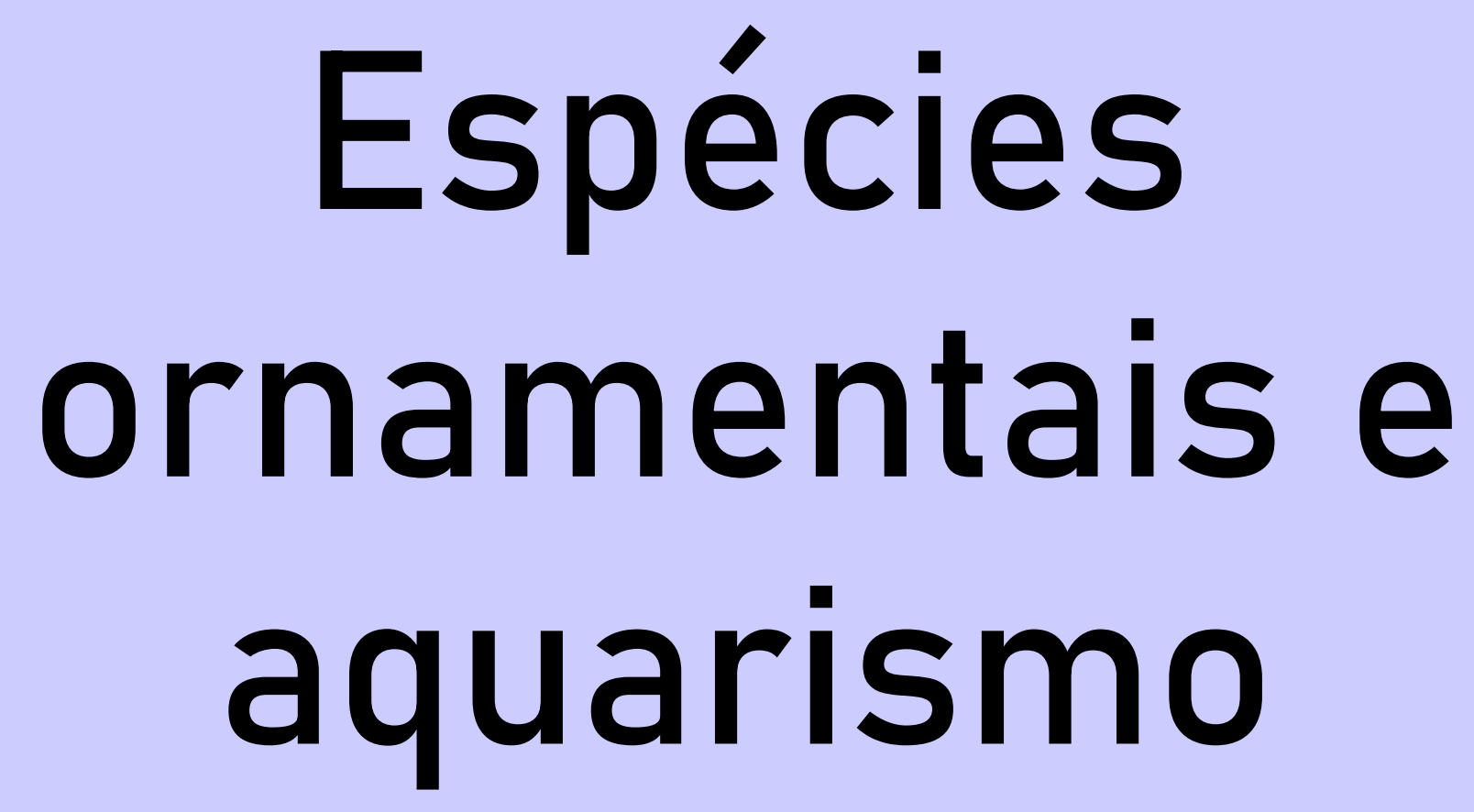




\title{
COMO REGULARIZAR UMA PISCICULTURA ORNAMENTAL
}

\author{
Anita Rademaker Valença ${ }^{1}$; Poliana Ribeiro dos Santos²; Luciana Guzella ${ }^{3}$; Eduardo Gomes
}

Sanches ${ }^{4}$.

A regularização de uma piscicultura ornamental passa por três órgãos governamentais, são eles o Ministério da Agricultura Pecuária e Abastecimento (MAPA), o Instituto Brasileiro do Meio Ambiente e dos Recursos Naturais Renováveis (IBAMA) e o Órgão Estadual do Meio Ambiente (OEMA) do estado onde se localiza o empreendimento. No MAPA o piscicultor irá protocolar o seu Registro e licença de aquicultor (Instrução Normativa MPA No 06, de 19 de maio de 2011). O processo de registro tem duas etapas: a primeira é solicitar o registro no seguinte link:https://sistemasweb.agricultura.gov.br/rgp//web/index.php/registro_aquicultor_solicitar/registro Aquicultor, a próxima etapa é a emissão da licença de aquicultor, esta depende do piscicultor já ter obtido a sua licença ambiental, e pode ser solicitada no link: https://sistemasweb.agricultura.gov.br/rgp/web/index.php/licenca_aquicultor_solicitar/licencaAquic ultor

O próximo passo é o Cadastro Técnico Federal (CTF) no IBAMA, todas as atividades que constam como potencialmente poluidoras ou utilizadoras de recursos ambientais no anexo I da Instrução Normativa $\mathrm{n}^{\circ}$ 6, de 15 de março de 2013, devem se cadastrar. A aquicultura está listada na categoria 20 - Uso de recursos naturais, código 20-54 Exploração de recursos aquáticos vivos. O piscicultor deverá emitir o Certificado de Regularidade cuja validade é de três meses. O link para inscrição de pessoa física no CTF https://servicos.ibama.gov.br/ctf/cadastroInicialPessoaFisica.php e o link para $\begin{array}{lllll}\text { inscrição de } & \text { pessoa } & \text { jurídica } & \text { no } & \text { CTF }\end{array}$ https://servicos.ibama.gov.br/ctf/cadastroInicialPessoaJuridica.php

O processo de licenciamento ambiental para obtenção de licença ambiental deve ser solicitado no Órgão ambiental do estado onde está localizada a piscicultura. Caso o empreendimento seja de pequeno porte, e seu potencial poluidor também seja considerado pequeno, este pode ser dispensado de estudo ambiental e licenciado através da emissão de Autorização Ambiental, processo mais simples e rápido. A maioria das piscicultoras ornamentais são passíveis de Autorização Ambiental devido a apresentarem o somatório das áreas cobertas pelas lâminas d'água menor ou igual a cinco hectares, limite imposto para emissão de autorização ambiental em Santa Catarina.

Outro passo importante é a outorga da água, porém como o volume de água captado, assim como o lançamento de efluentes de pisciculturas ornamentais é pequeno, se considerado insignificante pelo órgão outorgante, será emitida uma declaração de regularidade de usos da água. Em cada região, o comitê de bacia hidrográfica deve definir quais usos não serão sujeitos à outorga.

O transporte de peixes ornamentais sempre deve ser acompanhado da nota fiscal para fins de fiscalização ambiental e da Guia de Transporte Animal - GTA para fins de fiscalização sanitária.

Estes são os principais passos para a produção legalizada de peixes ornamentais no Brasil.

Palavras-chave: Peixe ornamental. Regularização ambiental. CTF. RGP. GTA.

\footnotetext{
1 Professora do Departamento de Aquicultura da Universidade Federal de Santa Catarina. http://lattes.cnpq.br/1111981506079801.anita.valenca@ufsc.br

${ }^{2}$ Mestre em Direito, pela Universidade Federal de Santa Catarina. Graduanda em Engenharia de Aquicultura UFSC.

${ }^{3}$ Mestre em Aquicultura, pela Universidade Federal de Santa Catarina. Graduanda em Engenharia de Aquicultura UFSC.

${ }^{4}$ Pesquisador do Instituto de Pesca/SP. http://lattes.cnpq.br/7293090235151230, eduardo.sanches2005@ gmail.com.
} 


\title{
FREQUÊNCIA INCUBATÓRIA DE FÊMEAS DE CAMARÃO ORNAMENTAL Neocaridina davidi
}

\author{
Gilson Bueno Júnior ${ }^{1}$; Wilson Alessandro Moura²; Jean de Araújo Schneider³; Bruno Estevão de \\ Souza ${ }^{4}$.
}

O Neocaridina davidi é uma espécie de pequenos camarões de água doce, popular entre aquaristas devido à variedade de coloração, com preço médio de três dólares por indivíduo. Para que essa atividade se desenvolva de maneira rentável é necessário aumentar a quantidade de informações acerca da biologia reprodutiva dos camarões $N$. davidi.

Assim, o objetivo do trabalho foi verificar aspectos da biologia reprodutiva de fêmeas desta espécie, buscando verificar a frequência de incubatória de fêmeas de $N$. davidi.

Para isso foram distribuídos 48 machos adultos $(1,0 \pm 0,3 \mathrm{~cm})$ e 16 fêmeas adultas $(1,7 \pm 0,2 \mathrm{~cm})$ em 16 unidades experimentais na proporção de 3 machos por fêmea. Cada U.E consistia em aquários com volume útil de 35 litros, contendo termostato, filtro biológico tipo esponja e uma porção de Taxiphyllum barbieri. Os aquários estavam acondicionados em uma sala climatizada e com fotoperíodo controlado (10 horas de luz/ 14 horas no escuro). No Laboratório de Ornamentais do Instituto Federal do Paraná - IFPR, Campus de Foz do Iguaçu, Paraná. A alimentação foi realizada uma vez ao dia com ração em flocos para peixes ornamentais com $49 \%$ de proteína bruta, semanalmente era realizada troca parcial d'água de $50 \%$. Os parâmetros físicos de água foram monitorados diariamente. Durante o período experimental de 30 dias foram observados, número de incubações, número de ecdises das fêmeas, tempo de incubação intervalo entre ecdises, prole média, dos quais foram obtidas médias e desvio padrão.

Os parâmetros de físicos de qualidade de água foram de $25^{\circ} \mathrm{C} \pm 0,6$ para temperatura, $7,6 \pm 0,5$ para $\mathrm{pH}, 6,5 \pm 02 \mathrm{mg} / \mathrm{L}$ para oxigênio dissolvido. Na tabela 1 estão apresentados os resultados dos parâmetros reprodutivos avaliados. A fecundação ocorre logo após a ecdise, por isso a proximidade nos valores entre essas frequências, já a incubação ocorre horas após a fecundação. Portanto, a incubação é um parâmetro mais preciso que as cópulas porque alguns machos podem ser estéreis. A frequência de incubação ocorre uma vez a cada 15 dias, seguido de uma nova ecdise. Concluímos que as fêmeas de Neocaridina davidi podem incubar ovos em média 1,54 vezes a cada 30 dias obtendo entre 13 a 15 juvenis por incubação.

Tabela 1-Médias e desvio padrão dos parâmetros reprodutivos de fêmeas de Neocaridina davidi

Fonte: Elaborado pelos autores.

\begin{tabular}{lll}
\hline Desempenho reprodutivo & Média & Desvio padrão \\
\hline Incubação (vezes) & 1,54 & 0,64 \\
Ecdise (vezes) & 1,64 & 0,5 \\
Incubação (dias) & 15 & 2,1 \\
Intervalo entre ecdises (dias) & 14,20 & 3,0 \\
Prole (juvenis/fêmea) & 13 & 2,3 \\
\hline
\end{tabular}

Palavras-chave: Aquicultura ornamental. Aquariologia. Carcinicultura ornamental.

\footnotetext{
1 Graduando em Engenharia de Aquicultura pelo Instituto Federal do Paraná. Lattes. http://lattes.cnpq.br/7534889903338677.gilsonjbueno@yahoo.com.br

${ }^{2}$ Graduando em Engenharia de Aquicultura pelo Instituto Federal do Paraná. :http://lattes.cnpq.br/9940817830945294. wilsonifprfoz@gmail.com

${ }^{3}$ Graduando em Engenharia de Aquicultura pelo Instituto Federal do Paraná. http://lattes.cnpq.br/9789790984387817. jeanschneider12@gmail.com

${ }^{4}$ Doutor em Aquicultura pela Universidade Estadual do Oeste Paulista. Lattes http://lattes.cnpq.br/2052979528507209. bruno.souza@ifpr.edu.br
} 


\section{DISSEMINANDO O CONHECIMENTO CIENTÍFICO SOBRE O ACARÁ DISCO (Symphysodon spp., Chiclidae)}

Anita Rademaker Valença ${ }^{1}$; Gabriel Henrique de Mendonça Cardoso ${ }^{2}$; Poliana Ribeiro dos Santos ${ }^{3}$; Luciana Guzella ${ }^{4}$; Eduardo Gomes Sanches ${ }^{5}$.

No intuito de disseminar informações sobre o peixe acará disco foi realizada uma "live" no dia 30 de outubro de 2020 (https://youtu.be/wSWEbWFz9o0 ). Dentre os peixes mais usados para o aquarismo, o acará disco vem se destacando desde a sua descoberta nas águas dos afluentes do Rio Amazonas no Brasil, Colômbia e Peru. Os peixes mais coloridos e estriados são os mais valorizados no mercado internacional. Estudos moleculares identificaram cinco espécies de acarás-disco na bacia amazônica: a espécie Symphysodon discus Heckel 1840, que ocorre principalmente em regiões de água negra; Symphysodon tarzoo Lyons, 1959, espécie que ocorre no limite oeste, confirmando os resultados encontrados por Ready; Symphysodon aequifasciatus Pellegrin, 1904; Symphysodon sp. 1, fenótipo azul da Amazônia central, ocorre nos rios Purus, Quari e baixo Solimões; e Symphysodon sp. 2 com distribuição do extremo leste da bacia amazônica é encontrada no Rio Xingu (AMADO, FARIAS, HRBEK, 2011).

Os criadores passam por diversos problemas na aquicultura do Acará-disco: a manutenção das raças sem que ocorra a perda de variabilidade genética, sabendo que naturalmente os peixes se hibridizam, e como melhor utilizar a genética das matrizes selvagens para o incremento da variabilidade na aquicultura. Esses problemas passam por diversas questões, tais como a determinação das linhagens selvagens e quais características devem ser utilizadas na criação para a seleção genética. Koh et al. (1999) ao avaliarem algumas variedades de híbridos de acará disco desenvolvidas em cativeiro, o turquesa, o pigeon, o ghost, o cobalto e o red royal, descobriram que a contribuição genética é muito maior dos S. aequifasciatus do que do grupo dos S. discus. Degani (2003) constatou uma expressiva perda de variabilidade genética nos híbridos cultivados. A busca por maior conhecimento genético dos discos é um dos grandes desafios na aquicultura, pois quando se perde variabilidade genética as consequências são reduções na fecundidade, na fertilidade, redução na produção de larvas, aparecem deformidades esqueléticas, redução de crescimento, e principalmente, os animais passam a ter uma maior susceptibilidade a doenças, com redução no seu tempo de vida.

$\mathrm{Na}$ natureza os peixes acará disco hibridizam-se naturalmente, assim como mais de cem variedades de híbridos foram desenvolvidos por cruzamentos selecionados pelo homem, estes dois fatos evidenciam a enorme variabilidade genética apresentada por este gênero. Infelizmente, o Brasil está inserido no mercado internacional apenas como um fornecedor de variabilidade genética para criadores estrangeiros, ainda não dominamos a tecnologia de produção de híbridos de alto valor, estamos muito longe disso. Para alcançarmos este patamar competitivo precisamos de mais políticas públicas, formação de pessoal capacitado, desenvolvimento de tecnologias. A aquicultura ornamental no resto do mundo se fortaleceu devido a um forte papel e incentivo do estado.

Palavras-chave: Aquário. Aquicultura ornamental. Peixe ornamental. Amazônia. Híbridos.

\footnotetext{
1 Professora do Departamento de Aquicultura da Universidade Federal de Santa Catarina. http://lattes.cnpq.br/1111981506079801. anita.valenca@ufsc.br

2 Mestre em Biologia de água doce e pesca interior/ Instituto Nacional de Pesquisas da Amazônia. http://lattes.cnpq.br/1690821140209924. gabaohe@gmail.com

${ }^{3}$ Mestre em Direito, pela Universidade Federal de Santa Catarina. Graduanda em Engenharia de Aquicultura UFSC.

${ }^{4}$ Mestre em Aquicultura pela Universidade Federal de Santa Catarina. Graduanda em Engenharia de Aquicultura UFSC.

${ }^{5}$ Pesquisador do Instituto de Pesca/SP. http://lattes.cnpq.br/7293090235151230. eduardo.sanches2005@gmail.com.
} 


\section{DESAFIOS NA CRIAÇÃO COMERCIAL DO ACARÁ DISCO (Symphysodon spp., Chiclidae)}

Anita Rademaker Valença ${ }^{1}$; Gabriel Henrique de Mendonça Cardoso ${ }^{2}$; Poliana Ribeiro dos Santos ${ }^{3}$; Luciana Guzella ${ }^{4}$; Eduardo Gomes Sanches ${ }^{5}$.

No intuito de disseminar informações sobre o peixe acará disco foi realizada uma "live" no dia 30 de outubro de 2020 (https://youtu.be/wSWEbWFz9o0). Dentre os vários assuntos discutidos, foi falado sobre a questão do manejo alimentar na criação e manutenção do peixe acará disco em aquários. Foi ressaltado o pouco conhecimento científico que se produziu sobre esse tema e a importância de mais estudos sobre a alimentação do disco na natureza, mais estudos que contemplem o ciclo hidrológico inteiro, ou seja, como o animal está se alimentando na estação seca e na estação cheia na Amazônia, e a dificuldade de pesquisa, principalmente em relação a época de cheias, quando é mais difícil capturar os animais e também a quantidade necessária para se ter uma amostragem para validar essa avaliação. Perguntas como: será que ficam quatro meses sem se alimentar, será que isso faz parte do ciclo de vida da espécie, quando começa a se alimentar inicia o desenvolvimento das gônadas, a alimentação é um gatilho para o comportamento reprodutivo, para o pareamento, talvez incorporem mais proteína em uma estação para aproveitamento na outra, todas essas questões ainda geram muitas incertezas sobre a biologia alimentar desse gênero.

O acará disco é um peixe detritívoro que se alimenta de pequenos invertebrados, de adultos e larvas de insetos, de pequenos crustáceos e suas larvas. Exibem o comportamento de forragear o fundo do rio, "assoprando esse fundo", como observamos em aquários ou no tanque de criação.

Alguns autores, poucos ainda, se debruçaram sobre a questão do alimento do disco. Chong et al. (2000) analisaram qual a melhor taxa de proteína bruta na ração do acará disco. Avaliaram cinco quantidades de proteína bruta (PB) na ração: 35\%, 40\%, 45\%, 50\% e 55\% de PB em indivíduos com peso médio inicial de 4,40 $\pm 4,65 \mathrm{~g}$ e encontraram que o ideal foi de $50 \%$ de $\mathrm{PB}$.

Outro trabalho de Wen et al. (2018) avaliaram uma questão muito interessante, pois vemos muitos criadores e aquaristas usando esse ingrediente na confecção de "patês" artesanais para alimentarem seus discos. Nesse trabalho, os autores analisaram dez dietas onde incorporaram diferentes proporções de coração de boi e de camarão. Os resultados demonstraram que quanto mais coração de boi na dieta, melhor o desempenho dos animais avaliados em relação a sobrevivência, ganho de peso e crescimento, ou seja, colocar camarão na dieta do acará disco não é tão necessário quanto os criadores acreditam.

Ainda temos muitas questões para serem respondidas e melhor compreendidas em relação ao manejo alimentar destes peixes tão valorizados no mercado do aquarismo. Precisamos de mais estudos sobre o comportamento alimentar, frequência de alimentação, quantidade, alimentação no período reprodutivo, digestibilidade, nutrientes mais importantes, enzimas, enfim, todo um rol da nutrição desses animais precisa ser mais explorado pela ciência.

Palavras-chave: Manejo alimentar. Alimentação. Peixe ornamental. Amazônia.

\footnotetext{
1 Professora do Departamento de Aquicultura da Universidade Federal de Santa Catarina. http://lattes.cnpq.br/1111981506079801.anita.valenca@ufsc.br

2 Mestre em Biologia de água doce e pesca interior/ Instituto Nacional de Pesquisas da Amazônia. http://lattes.cnpq.br/1690821140209924, gabaohe@gmail.com

${ }^{3}$ Mestre em Direito, pela Universidade Federal de Santa Catarina. Graduanda em Engenharia de Aquicultura UFSC.

${ }^{4}$ Mestre em Aquicultura pela Universidade Federal de Santa Catarina. Graduanda em Engenharia de Aquicultura UFSC.

${ }^{5}$ Pesquisador do Instituto de Pesca/SP. http://lattes.cnpq.br/7293090235151230, eduardo.sanches2005@ gmail.com.
} 
Malacocultura 


\title{
ANÁLISE DO CULTIVO DE BERBIGÕES Anomalocardia brasiliana EM SISTEMA SUSPENSO FLUTUANTE
}

\author{
João Guzenski ${ }^{1}$.
}

A extração de berbigões Anomalocardia brasiliana (Gmelin,1791) é uma atividade pesqueira tradicional na região da Grande Florianópolis. Este molusco está inserido na cultura e gastronomia. Durante décadas abasteceu os mercados local e regional. $\mathrm{O}$ esforço de pesca excessivo e a falta de um plano de manejo resultaram na sobreexplotação da espécie, ameaçando sua sustentabilidade. Estudos indicaram que a quantidade de berbigões remanescentes pode não ser suficiente para permitir uma recuperação natural do estoque (PEZZUTO et al, 2010). A introdução em cultivo da espécie poderá contribuir a recuperação desta atividade, com benefícios sociais, econômicos e ambientais. Embora seja uma atividade estabelecida e economicamente importante em diversos países, a técnica de cultivo empregada nestes locais precisa ser testada e adaptada para a Anomalocardia brasiliana, antes de ser utilizada como opção na malacocultura.

Este trabalho tem como objetivo geral analisar a viabilidade do cultivo de berbigões em um sistema suspenso flutuante e como objetivos específicos observar o comportamento dos indivíduos e verificar o crescimento e sobrevivência da espécie em cultivo.

Neste estudo se utilizou sementes com três meses de idade e tamanho médio de $1.78 \mathrm{~mm}$ de $A$. brasiliana produzidas em laboratório, introduzidas em agosto de 2019 na localidade de Santo Antônio de Lisboa, Ilha de Santa Catarina, (27³0'35.78'S e 48 31'10.17’O). As sementes foram mantidas em um sistema suspenso flutuante, do tipo berçário, de forma cilíndrica, passando por um processo de trocas de estruturas à medida que cresciam, iniciando com abertura de malha de $300 \mu$ e manejo diário para a limpeza da tela, passando após 20 dias para outro com malha de $500 \mu$, e manejo semanal por limpeza com jato de água nas telas. Após 30 dias foram transportados para bandejas com malha de $1 \mathrm{~mm}$, depois por 160 dias para bandejas com malha de $2.5 \mathrm{~mm}$ e manejo mensal. Finalmente por um período de 120 dias para um sistema de caixas teladas com área aproximada de $0.17 \mathrm{~m}^{2}$, mantendo uma densidade equivalente a 1000 indivíduos $/ \mathrm{m}^{2}$. Foram colhidas mensalmente informações sobre o crescimento, incidência de fouling, competidores, presença de predadores, sobrevivência, taxa de crescimento, sex-ratio, além das medidas de salinidade e temperatura da água por um período de um ano em cultivo no mar.

Os resultados indicaram que os espécimes em cultivo atingiram um comprimento de $24,30 \pm 1,14 \mathrm{~mm}$ e um peso de $5,17 \pm 0,79 \mathrm{~g}$, em um ano de cultivo em campo, sendo observados indivíduos sexualmente maturos, com uma proporção maior de machos durante a maior parte do período de observação, a exceção dos meses de inverno em que ocorreu maior número de fêmeas nas amostras. A temperatura variou de 16 a $28,5^{\circ} \mathrm{C}$ e a salinidade de 33 a 37 na área do cultivo.

O presente trabalho demonstra que existe um bom crescimento dos berbigões A. brasiliana criados em sistema suspenso flutuante, com os indivíduos atingindo o tamanho mínimo de captura com 300 dias de cultivo. A taxa de sobrevivência foi bastante elevada, de $94 \%$. Isso pode ser devido a pequena quantidade de indivíduos e o manejo utilizado. Na cultura de moluscos, a taxa de sobrevivência é conhecida por variar amplamente em uma faixa de 30 a 75\%, e $94 \%$ é considerado muito satisfatório (CHEN, 1976).

Palavras-chave: Maricultura. Berbigões. Anomalocardia brasiliana.

\footnotetext{
${ }^{1}$ Doutor em Geografia pela Universidade Federal de Santa Catarina. Pesquisador em Aquicultura da EPAGRI/SC. http://lattes.cnpq.br/7638069535941192.guzenski@epagri.sc.gov.br.
} 


\section{AVALIAÇÃO ECONÔMICA DO CULTIVO DE OSTRAS Crassostrea gigas EM FLORIANÓPOLIS/SC}

Felipe Matarazzo Suplicy ${ }^{1}$

A lucratividade do cultivo de ostras varia entre regiões e local de cultivo, espécies cultivadas, sistema de cultivo empregados e escala de produção. Cada fazenda marinha possui uma infraestrutura, produção, marketing e finanças diferentes, de forma que cada situação deve ser analisada individualmente, considerando as circunstâncias locais. No entanto, informações financeiras sobre o cultivo de ostras são escassas na literatura nacional.

Com o intuito de fornecer uma informação atualizada sobre o assunto, foi realizada uma análise de quatro produtores de Florianópolis, os quais, além de possuírem escala de produção distintas, empregam diferentes estratégias para processar as ostras com inspeção sanitária, e utilizam diferentes canais de comercialização. Na análise do custo operacional e lucratividade, foram utilizados os indicadores econômicos empregados pela Epagri para análise de todo agronegócio catarinense. Os resultados desta análise são apresentados de forma resumida no Quadro 1.

Quadro 1 - Característica gerais dos empreendimentos e indicadores econômicos calculados para quatro fazendas de ostras Crassostrea gigas em Florianópolis, SC.

\begin{tabular}{|c|c|c|c|c|c|c|c|c|}
\hline & \multicolumn{2}{|c|}{ Produtor 1} & \multicolumn{2}{|c|}{ Produtor 2} & \multicolumn{2}{|c|}{ Produtor 3} & \multicolumn{2}{|c|}{ Produtor 4} \\
\hline Volume anual de ostras (dz.) & \multicolumn{2}{|r|}{200.000} & \multicolumn{2}{|r|}{100.000} & \multicolumn{2}{|r|}{15.000} & \multicolumn{2}{|r|}{100.000} \\
\hline Volume anual de sementes & \multicolumn{2}{|r|}{5.000 .000} & \multicolumn{2}{|r|}{3.000 .000} & \multicolumn{2}{|c|}{400.000} & \multicolumn{2}{|r|}{4.000 .000} \\
\hline Número de funcionários & \multicolumn{2}{|r|}{14} & \multicolumn{2}{|r|}{8} & \multicolumn{2}{|r|}{-} & \multicolumn{2}{|r|}{7} \\
\hline Inspeção sanitária & \multicolumn{2}{|r|}{ Própria } & \multicolumn{2}{|c|}{ Terceirizada } & \multicolumn{2}{|c|}{ Terceirizada } & \multicolumn{2}{|c|}{ Terceirizada } \\
\hline Preço de venda & $\mathrm{R} \$$ & 12,00 & $\mathrm{R} \$$ & 6,28 & $\mathrm{R} \$$ & 10,00 & $\mathrm{R} \$$ & 10,00 \\
\hline Custo Operacional Total & $\mathrm{R} \$$ & $1.667 .836,67$ & $\mathrm{R} \$$ & $594.006,00$ & $\mathrm{R} \$$ & $96.764,97$ & $\mathrm{R} \$$ & $602.878,83$ \\
\hline Receita Bruta & $\mathrm{R} \$$ & $2.400 .000,00$ & $\mathrm{R} \$$ & $628.000,00$ & $\mathrm{R} \$$ & $150.000,00$ & $\mathrm{R} \$$ & $1.000 .000,00$ \\
\hline Lucro Operacional & $\mathrm{R} \$$ & $732.163,33$ & $\mathrm{R} \$$ & $33.994,00$ & $\mathrm{R} \$$ & $53.235,03$ & $\mathrm{R} \$$ & $397.121,17$ \\
\hline Margem Líquida & \multicolumn{2}{|r|}{$30,5 \%$} & \multicolumn{2}{|r|}{$5,0 \%$} & \multicolumn{2}{|r|}{$35,5 \%$} & \multicolumn{2}{|r|}{$40 \%$} \\
\hline Produtividade de Nivelamento (dz.) & \multicolumn{2}{|r|}{138.986} & \multicolumn{2}{|r|}{89.869} & \multicolumn{2}{|r|}{9.676} & \multicolumn{2}{|r|}{60.288} \\
\hline Custo de produção por dúzia & $\mathrm{R} \$$ & 8,34 & $\mathrm{R} \$$ & 5,94 & $\mathrm{R} \$$ & 6,45 & $\mathrm{R} \$$ & 6,03 \\
\hline
\end{tabular}

Fonte: Elaborado pelo autor.

Os resultados permitem identificar que o custo médio de produção nas fazendas analisadas foi de $\mathrm{R} \$$ 6,69/dz., sendo que o principal componente do custo de produção foi a mão de obra, que chega a representar $47 \%$ do custo operacional efetivo. A diluição e redução do custo decorrente de um aumento no volume de produção é relativa, pois esta diluição é neutralizada em parte por um aumento nas despesas com de mão de obra, a menos que um maior nível de mecanização do manejo seja adotado. Apesar do Produtor 4 ter um aproveitamento médio inferior das sementes (30\%), sua margem de lucro foi a mais alta entre as fazendas analisadas, no entanto, se o Produtor 2 adotasse o preço médio de mercado, sua fazenda seria a de maior lucratividade entre os quatro. O processamento das ostras em um estabelecimento próprio com inspeção sanitária, só é recomendável para volumes de produção acima de 150.000 dúzias por ano, sendo mais indicada uma inspeção sanitária terceirizada para volumes inferiores a este. Para os produtores sem inspeção sanitária própria e volume de produção anual de até 100.000 dúzias, a opção de manter o empreendimento como produtor rural ao invés de abrir uma microempresa, permite uma expressiva redução da carga tributária incidente na comercialização das ostras.

Palavras-chave: Maricultura. Ostreicultura. Análise econômica.

\footnotetext{
${ }^{1} \mathrm{Ph}$. D. em Aquicultura pela University of Tasmania. Pesquisador do Centro de Desenvolvimento em Aquicultura e Pesca (Epagri/Cedap). http://lattes.cnpq.br/8889816208837356. felipesuplicy@epagri.sc.gov.br
} 
Ecologia e meio ambiente aplicados a aquicultura e/ou biologia aquática 


\title{
CULTIVO DO COPEPODA Acartia tonsa COM DIETA BIALGAL SUPLEMENTADA COM BACTÉRIA PROBIÓTICA
}

\author{
Marcia Vanacor Barrosoํㅜ Raoní Gonçalves de Souza ${ }^{2}$; Bárbara Pereira Storck ${ }^{3}$; Luiz Fernando \\ Loureiro Fernandes ${ }^{4}$; Flávia Regina Spago ${ }^{5}$.
}

Os copépodes têm grande importância ecológica como fonte nutricional, pois metabolizam os nutrientes absorvidos através da ingestão do fitoplâncton e os transferem na cadeia trófica à níveis superiores. Como são filtradores, tem a capacidade de bioencapsular probióticos e outras substâncias que possam melhorar os cultivos aquícolas, principalmente larviculturas de peixes marinhos que ainda tem indicadores de sobrevivência larval muito baixos.

O objetivo deste trabalho foi cultivar Acartia tonsa com dieta bialgal composta das famílias Isochrysidaceae e Bacillariophyceae suplementadas com bactéria probiótica, visando obter a melhor população para uso em larviculturas de peixes marinhos.

Neste estudo foram utilizados copépodes da espécie Acartia tonsa cultivados em laboratório há 150 gerações. A unidade experimental utilizou 12 recipientes de $10 \mathrm{~L}$ numa densidade inicial de 0,5 copépode $/ \mathrm{mL}$ e renovação diária de água de $5 \%$, em quatro tratamentos e três repetições, alimentados com 150.000 cels/espécie/dia. O tratamento controle (Iso+Chae) utilizou microalgas Isochrysis galbana (Iso) e Chaetoceros muelleri (Chae). Os demais tratamentos foram: Iso+Chae+P (bactéria probiótica); Iso+Phaeo (Phaeodactylum tricornutum); Iso+Phaeo+P. A bactéria probiótica MGO (P) isolada em cultivos aquícolas no Espírito Santo foi utilizada na concentração 1 x $10^{\wedge} 6$ e $1 \mathrm{~mL} / \mathrm{L}$ do volume experimental. $\mathrm{O}$ experimento teve duração de oito dias, para possibilitar um ciclo de vida completo.

Verificou-se que não houve diferença significativa na população final de copépode/mL entre os tratamentos (Iso+Chae $=0,93 \pm 0,33$; Iso+Chae+P $=1,26 \pm 0,36$; Iso+Phaeo $=1,32 \pm 0,22$; Iso+Phaeo+P $=1,46 \pm 0,30$ ). Estes resultados foram considerados positivos com relação a dieta bialgal, pois a microalga Chaetoceros muelleri pode ser substituída por Phaeodactylum tricornutum sem prejuízos no crescimento populacional dos copépodes. No entanto, observou-se que o acréscimo da bactéria probiótica MGO não gerou resultados significativos ao cultivo. Os parâmetros de qualidade de água obtidos neste estudo (Temperatura 23,95 $\pm 0,05^{\circ} \mathrm{C}$; Salinidade 25,68 \pm 0,49 psu; Oxigênio dissolvido 5,33 $\pm 0,35 \mathrm{mg} / \mathrm{L} ; \mathrm{pH} 8,27 \pm 0,06$ ) estão dentro dos padrões para o cultivo de copépodos.

Palavras-chave: Fitoplâncton. Zooplâncton. Bioencapsulação.

Apoio: FAPES.

\footnotetext{
1 Doutora em Aquicultura pela Universidade Federal de Santa Catarina. Servidora pública do INCAPER/ES. http://lattes.cnpq.br/6731356421528391. marciavanacor@hotmail.com.

${ }^{2}$ Mestrando em Recursos Pesqueiros e Engenharia de Pesca pela Universidade Estadual do Oeste do Paraná - Campus Toledo. http://lattes.cnpq.br/5032820137501249. raonigs@live.com

${ }^{3}$ Graduanda em Química Industrial pelo Instituto Federal de Educação, Ciência e Tecnologia do ES - Campus Aracruz. http://lattes.cnpq.br/9198429047784198. barbara.storck@hotmail.com.

${ }^{4}$ Doutor em Oceanografia pela Texas A\&M University. Professor do Departamento de Oceanografia e Ecologia da Universidade Federal do Espírito Santo. http://lattes.cnpq.br/9962754750741990. luiz.ufes@ gmail.com.

${ }^{5}$ Doutora em Microbiologia pela Universidade Estadual de Londrina. Professora do Instituto Federal de Educação, Ciência e Tecnologia do ES - Campus Piúma. http://lattes.cnpq.br/8366003861921452. flavia.goncalves@ifes.edu.br.
} 


\section{Tratamento de}

$$
\text { efluente e }
$$

qualidade de água aplicados a

aquicultura e/ou biologia aquática 


\title{
CARACTERIZAÇÃO DAS VARIÁVEIS LIMNOLÓGICAS DE TRÊS PISCICULTURAS PERTENCENTES A REGIÃO DO VALE DO GUAPORÉ-MT
}

\author{
Bruno Mendes Visoni ${ }^{1}$; Tatiani Botini Pires ${ }^{2}$.
}

Estudos limnológicos são de grande importância para as pisciculturas uma vez que a produção de peixe está diretamente correlacionada com a qualidade da água. Vale ressaltar que a qualidade da água não só contribui para o desenvolvimento do peixe, mas é um fator primordial nos indicadores econômicos. Então, teve-se como objetivo identificar as características limnológicas em três piscicultura da região do Vale do Guaporé, afim de caracterizar o padrão de qualidade da água.

O estudo ocorreu em três pisciculturas, uma localizada em Vila Bela da Santíssima Trindade, duas localizada no município de Pontes e Lacerda, foi ocorrido entre o período de dezembro de 2014 a dezembro de 2015, com coleta mensal, 6:30 às 9:30 da manhã, as variáveis acompanhadas foram, temperatura da água, Pressão, Oxigênio Saturado, Oxigênio Dissolvido (O.D), Condutividade específica, Condutividade, Coeficiente de Atenuação Vertical da Radiação (k) e potencial hidrogeniônico. Todas as coletas dos parâmetros limnológicos foram in loco utilizando aparelho Multiparâmetro YSI Professional Plus, todos os viveiros são escavados com sistema de abastecimento de água caracterizado como sistema cascata com baixa renovação, abastecidos por água de minas localizados próximo a elas.

Tabela 1 Comparativo dos valores médios do período, seguidos dos valores de desvio padrão, obtidos para às variáveis limnológicas nas três pisciculturas da região do Vale do Guaporé-MT.

\begin{tabular}{l|l|l|l}
\hline Variáveis Limnológicas & Piscicultura 1 & Piscicultura 2 & Piscicultura 3 \\
\hline Pressão Atmosférica (mmHg) & $739,5 \pm 1,22$ & $736,3 \pm 1,67$ & $737,27 \pm 1,46$ \\
Temperatura $\left({ }^{\circ} \mathrm{C}\right)$ & $29,2 \pm 1,35$ & $28,61 \pm 1,54$ & $28,95 \pm 2,26$ \\
Oxigênio Saturado (\%) & $56,49 \pm 18,58$ & $51,85 \pm 20,15$ & $51,68 \pm 26,88$ \\
Oxigênio Dissolvido (mg/L) & $4,18 \pm 1,29$ & $3,81 \pm 1,53$ & $3,83 \pm 2,03$ \\
Condutividade específica & $120,11 \pm 20,63$ & $87,39 \pm 7,94$ & $20,37 \pm 25,12$ \\
Condutividade & $129,61 \pm 23,22$ & $93,56 \pm 8,52$ & $21,9 \pm 27,43$ \\
Coeficiente de Radiação & $8,04 \pm 1,59$ & $11,91 \pm 17,43$ & $51,36 \pm 4,58$ \\
pH & $7,38 \pm 0,50$ & $6,79 \pm 0,45$ & $5,92 \pm 0,51$ \\
\hline
\end{tabular}

Fonte: Elaborado pelo autor

Os resultados obtidos o O.D está fora dos valores estipulados pela resolução do CONAMA $\mathrm{n}^{\circ}$ $357 / 2005$ no que tange as classes 1 e 2 de águas doce. Este resultado pode estar correlacionado com aumento de produção de peixes dentro dos viveiros, tal como Silva e Keppeler (2019), relataram pela menor quantidade de oxigênio nos viveiros que possuíam cultivo. Esteves e Furtado (2011) relatam que o nível de oxigênio tem uma variação nictimeral, apresentando quedas e aumentos conforme o horário. O k este está dentro dos padrões estabelecidos por Kubitza (2009). Sobre a condutividade de acordo com Esteves; Barros; Petrucio, (2011), as águas naturais apresentam teores de condutividade na faixa de 10 a $100 \mu \mathrm{S} \mathrm{cm}-1$, de modo que os resultados obtidos no presente trabalho fixam-se neste caso na faixa ideal para produção. A piscicultura 1 apresentou melhores condições limnológicas para o cultivo de peixe, fato relacionado aos melhores parâmetros limnológicos encontrados. Conclui-se que a região do Vale do Guaporé em Mato Grosso apresenta todas as condições propícias para o cultivo de peixes nativos e os problemas encontrados representam possíveis falhas na prática de manejo e não da condição do recurso hídrico disponível.

Palavra-chave: Tanque escavado. Viveiro. Qualidade dá água. Aquicultura

\footnotetext{
${ }^{1}$ Mestre em Aquicultura pela Universidade Federal de Santa Catarina. http://lattes.cnpq.br/5379550121992668

${ }^{2}$ Doutora em Zootecnia pela Universidade Estadual de Mato Grosso. http://lattes.cnpq.br/5965900440022026
} 
Outros assuntos

que possuem

relação com a

aquicultura e/ou

biologia aquática 


\title{
MOBILE LEARNING: UMA FERRAMENTA DIGITAL PARA A AQUICULTURA NA PALMA DA MÃO
}

\author{
Willian de Vargas ${ }^{1}$; Eduarda Soares Serpa Camboim²; Cíntia Torres ${ }^{3}$; Felipe Cardoso Martins ${ }^{4}$; \\ Lissandra Souto Cavalli ${ }^{5}$.
}

A transformação digital inclui a computação em nuvem, internet das coisas (IoT), Inteligência artificial, big data, mobile learning e machine learning. A substituição de ferramentas e métodos de gestão ultrapassados por sistemas e tecnologias inovadoras fornece uma ferramenta bastante importante no auxílio do aprimoramento das práticas no campo da aquicultura, além de aumentar a qualidade dos serviços prestados no setor.

Apesar de muito importante para o desenvolvimento na área da aquicultura, muitas informações necessárias para a obtenção do conhecimento são bastante escassas. Pensando nisso, foram desenvolvidos três aplicativos focados em mobile learning onde, um é voltado para questões acerca da atenção à saúde do trabalhador da área da aquicultura (AquaSafe) e os outros dois possuindo foco em doenças patogênicas que acometem camarões e tilápias (AquaSaúde e AquaTilápia, respectivamente).

Os três aplicativos foram desenvolvidos para dispositivos da plataforma Android, seguindo recomendações da Google Material Design. O AquaSaúde e o AquaSafe foram desenvolvidos através da linguagem de programação Java 8. Já o AquaTilápia foi desenvolvido com o uso do Framework de desenvolvimento da Google chamado Flutter.

Para o desenvolvimento dos três aplicativos, o ambiente de desenvolvimento escolhido foi o Android Studio, que é um software de desenvolvimento de aplicativos mobile disponibilizado de forma gratuita pela Google. Todos os aplicativos foram desenvolvidos nos idiomas Português, Espanhol e Inglês, adequando-se ao idioma do dispositivo do usuário de forma automática.

O AquaSafe disponibiliza informações acerca de riscos e perigos, fontes e medidas de prevenção em saúde e segurança ocupacional, possuindo ambientes interativos com usuário por meio de jogos sérios, checklists e ferramentas de avaliação de fluxos de processos. Já o AquaSaúde e o AquaTilápia provêm informações acerca da identificação de sinais clínicos de doenças, assim como informações sobre o agente causador, tratamento, prevenção e profilaxia de doenças bacterianas que acometem Camarões e Tilápias, respectivamente. O AquaSafe, AquaSaúde e AquaTilápia contam com 450, 1.600 e 1.140 downloads, respectivamente.

Através do desenvolvimento e disponibilização de aplicativos móveis de fácil acesso, informações científicas tem um novo meio de divulgação entre os produtores e demais interessados. Este tipo de aplicação possibilita que os produtores e trabalhadores da área da aquicultura possam identificar sinais e otimizar seu trabalho e/ou métodos de produção.

Palavras-chave: Mobile learning; Aquicultura; Doenças virais e bacterianas; Saúde do trabalhador

Apoio: CNPq, FAPERGS.

\footnotetext{
${ }^{1}$ Graduando em Informática Biomédica pela UFCSPA. http://lattes.cnpq.br/7676106786483795. willianv@ufcspa.edu.br

2 Graduanda em Informática Biomédica pela UFCSPA. http://lattes.cnpq.br/5772838337420704.

eduardasc@ufcspa.edu.br

3 Graduando em Informática Biomédica pela UFCSPA. http://lattes.cnpq.br/0570129407532557

felipemartins@ufcspa.edu.br

${ }^{4}$ Estudante nível médio pelo IFSUL Charqueadas. http://lattes.cnpq.br/4914918233566403. cintiasilvatorres@gmail.com

${ }^{5}$ Pesquisadora, Pós Doc., DDPA/SEAPDR - RS. http://lattes.cnpq.br/1856000514013464. liscavalli@gmail.com
} 


\title{
ESTUDO DO DESENVOLVIMENTO INICIAL EM PEIXES: CONSIDERAÇÕES ACERCA DAS TÉCNICAS DE OBSERVAÇÃO, COLETA, ANÁLISE E CONSERVAÇÃO DE AMOSTRAS
}

\author{
John Alejandro Clavijo-Ayala ${ }^{1}$
}

O estudo do desenvolvimento inicial em peixes oferece informações relevantes para a compreensão da ontogenia inicial, para a identificação de amostras de ictioplâncton, para o desenvolvimento de técnicas apropriadas na aquicultura e para estudos de conservação das espécies. No entanto, erros na coleta de material conduzem a diversos artefatos nas amostras, gerando falsas interpretações. Este trabalho apresenta observações e considerações derivadas do estudo do desenvolvimento inicial de peixes, analisa protocolos de amostragem, coleta e conservação de ovos, embriões, larvas e juvenis, e discute sobre a sua conveniência de aplicação.

O objetivo da coleta de material deve ser a preservação, ao máximo, da morfologia das amostras para a sua análise posterior. O processo de fixação provoca um estrese osmótico nos tecidos e, de não ser feito da forma adequada, gera alterações na coloração, estrutura, morfologia e morfometria das amostras. A conservação imprópria de amostras é comum, afetando o uso futuro do material.

Uma análise preliminar revelou uma grande quantidade de metodologias de coleta e conservação de amostras. Da revisão de diferentes publicações, projetos de pesquisa e protocolos coleta, conclui-se que são corriqueiras amostragens muito densas, isto é, uma coleta excessiva de material. Isso eleva os custos próprios do processo e conduze ao acúmulo desnecessário de material que posteriormente pode sequer ser analisado, seja pelo grande volume de amostras, seja pelo tempo que implicaria o seu processamento, ou pelo deterioro mesmo do material, muitas das vezes mal fixado ou mal conservado. Além disso, amostragens longas e/ou excessivas geram também um estresse desnecessário para o pesquisador, induzindo a erros na identificação do material ou na manipulação dos fixadores. São frequentes os relatos de acidentes como queimaduras, inalação de vapores e vazamentos químicos, tanto pela falta de experiencia na hora da coleta e manuseio das amostras, quanto pelo uso de recipientes inadequados para o transporte e estoque do material. São frequentes também os relatos de amostras perfeitamente preservadas, mas sem nenhuma identificação.

Em todos os casos se recomenda a elaboração dum fluxograma específico para a coleta de material: Defina claramente qual é o objetivo da pesquisa e como será coletado o material de estudo (amostras de ictioplâncton ou amostras obtidas em condições controladas de laboratório) $\rightarrow$ Analise o tipo de desenvolvimento da espécie(s) alvo do seu estudo, isso permite estabelecer a priori quais são os momentos relevantes para a coleta de material $\rightarrow$ Determine que tipo de análises fará com as amostras, isso define quais fixadores e tampões deverá utilizar, e se será necessária a sua pós-fixação ou transferência a outro tipo de líquidos ou conservantes $\rightarrow$ Escolha o tipo de recipientes de coleta mais adequados e defina como serão rotulados/identificados e armazenados. Coletas copiosas e/ou em todas as substâncias que tiver à disposição só indicam falta de preparo e de claridade do processo de amostragem, e de entendimento do efeito dos fixadores no material de estudo.

Amostras corretamente coletadas preservam a integridade morfológica dos tecidos e permitem a sua análise, manipulação e documentação posterior. As formas iniciais de peixes são materiais extremamente delicados e exigem cuidados especiais na sua coleta e conservação em úmido. Adotar protocolos de coleta claros e objetivos incidirá, diretamente, na qualidade dos seus resultados.

Palavras-chave: Desenvolvimento inicial em peixes. Caracteres de identificação. Protocolos de coleta. Fixadores. Conservação de amostras.

\footnotetext{
${ }^{1}$ Doutor em Aquicultura pelo CAUNESP. ELHF Virtual Lab / JACA Aqua-Paisagismo. Bauru-SP / Brasil. CEP 17047001. http://lattes.cnpq.br/9568445623688297.e-mail: elhf.lab@gmail.com
} 


\section{DIMENSIONAMENTO DE UMA FAZENDA AQUÍCOLA PARA UMA TRIBO INDÍGENA DE ARAQUARI-SC}

Laila Freitas Oliveira de Assis ${ }^{1}$; Tayna Silveira da Costa $^{2}$; Alexandre Rodrigues Mariano ${ }^{3}$.

A aquicultura é uma atividade em constante desenvolvimento que apresenta um papel fundamental para as comunidades ribeirinhas e indígenas que sobrevivem da pesca artesanal, uma vez que possibilita a fixação da população em seu local de origem a partir da capacitação, geração de empregos e renda. Os povos indígenas sofrem por lutas de territórios e são prejudicados pelo avanço econômico não-indígena que trazem como consequências a poluição dos solos e da água. Poucas são as comunidades indígenas que conseguem desenvolver atividades econômicas que gerem independência financeira. A grande maioria das comunidades, principalmente as que ficam localizadas próximos a centros urbanos, tem a confecção de artesanatos como sua principal fonte de subsistência. De etnia Guarani Mbya e localizada no município de Araquari-SC a Aldeia Piraí é uma Terra Indígena tradicionalmente ocupada e está com a situação jurídica regularizada com a posse permanente dos Guarani, permitindo a instalação de projetos sem previsão de conflitos fundiários. Atualmente a Aldeia Piraí conta com dois viveiros escavados, onde desenvolvem o sistema de cultivo extensivo com o policultivo de espécies nativas baseado em ecossistemas naturais e cadeia alimentar; e mesmo de forma irregular e sazonal são a única fonte proteica a base do pescado para a comunidade. Através de cursos de capacitação, o cacique (líder indígena) tomou conhecimentos sobre práticas aquícolas e ao levar esse conhecimento à comunidade, surgiu a decisão de transformar parte da área da aldeia, em fazenda de piscicultura com instalações para aprendizado e extensão. Logo a implementação de um projeto aquícola exige além de capacitação, investimento para construção das estruturas necessárias à produção. Diante do exposto, o objetivo do referente trabalho foi elaborar um projeto para a construção da fazenda de piscicultura na Aldeia Piraí, um projeto de viabilidade econômica que possibilitará o acesso a fundos de investimento e crédito.

Para o delineamento do projeto (dimensionamento da fazenda, instalações e sistema de recirculação) na Aldeia Piraí foi realizada uma visita técnica in loco, onde com auxílio do software Autocad sucedeu o levantamento planialtimétrico prévio e elaboração do primeiro croqui para o reconhecimento do terreno. Para a modelagem dos desenhos técnicos do projeto foi usado o software Revit.

O projeto resultou na modelagem de 15 viveiros 14x29 m e 4 viveiros $22 \times 58 \mathrm{~m}$, um reservatório com capacidade de armazenamento de $15.000 \mathrm{~m}^{3}$ de água, um biofiltro com capacidade de $300 \mathrm{~m}^{3}$, e uma wetland com $493 \mathrm{~m}^{2}$ para tratamento de água e retirada de metabólitos. Como instalações, foram dimensionadas estruturas de apoios como escritório, almoxarifado, laboratório, local de armazenamento de rações e sistema de tratamento de esgoto sanitário.

O referente projeto torna-se viável, uma vez que promoverá a capacitação dos membros da Aldeia Piraí e possibilitar o desenvolvimento de uma atividade rentável, além de apresentar viabilidade econômica com possibilidade de ser encaminhado a ONGs e entidades de desenvolvimento social, bancos e cooperativas de créditos.

Palavra-chave: Aquicultura. Engenharia. Viveiro. Abastecimento. Drenagem. Efluentes.

\footnotetext{
${ }^{1}$ Mestranda em Aquicultura pela Universidade Federal de Santa Catarina. http://lattes.cnpq.br/9115421412242095. assisaquicultura@gmail.com.

${ }^{2}$ Engenheira de Aquicultura pela Universidade Federal de Santa Catarina. http://lattes.cnpq.br/0866352164094028. tayna.aqi@gmail.com.

${ }^{3}$ Graduando em Engenharia de Aquicultura pela Universidade Federal de Santa Catarina. http://lattes.cnpq.br/3386370923558260. al3mariano@gmail.com.
} 


\title{
VARIAÇÃO DOS PREÇOS DE PEIXES COMERCIALIZADOS EM DIFERENTES LOCAIS DA GRANDE ILHA DE SÃO LUÍS-MARANHÃO
}

\author{
Henrique Chaves Silva ${ }^{1}$; Hugo Moreira Gomes²; Lucilia Silva Conceição ${ }^{3}$.
}

O Brasil está entre os países de menor consumo de pescado, influenciado por diversos fatores que contribuem para a existência deste quadro, tais como o alto custo do transporte, encarecendo o produto final e hábitos alimentares que prezam pela carne bovina. Porém, a tendência do mercado é expandir-se cada vez mais, devido ao crescimento da população mundial e consequente elevação da demanda por alimentos o que torna o pescado a recente proteína animal consumida em grande escala pelo homem, apesar de concentrar-se melhor no litoral ou em regiões onde o peixe de água doce é abundante. O objetivo do presente trabalho foi de avaliar os preços dos principais pescados comercializados em diferentes locais da grande ilha de São Luís do Maranhão.

Os estabelecimentos visitados fazem parte de redes logísticas de distribuição e venda de pescado em São Luís. As visitas ocorreram no período de janeiro a fevereiro de 2020, com dados coletados in loco, por registros fotográficos e conversas informais, feitos nos bairros da Cidade Operária, Jardim América e Centro. No qual foi visitado "dois" estabelecimentos por bairro, que serão nomeados como: A (para estabelecimento na Cidade Operária), B (para estabelecimento no Jardim América) e C (para estabelecimento no Centro). No qual observou-se os preços e as espécies mais comercializadas.

Dos dados obtidos, destacam-se as espécies de maior procura e comercialização, são: Pescada amarela (Cynoscion acoupa), Matrinxã (Brycon spp.), Curimatã (Prochilodus spp.), Tambaqui (Colossoma macropomum), Pescadinha (Isopisthus parvipinnis), Pacu (Piaractus mesopotamicus) e Uritinga (Arius proops). Com preços que variaram entre R \$10,00 e 25,00 reais por quilo. Observou-se também a predominância na demanda por espécies marinhas, no entanto não há grande variação de valor das espécies encontradas nos estabelecimentos visitados, sendo que na grande maioria utilizam-se dos mesmos meios de exposição do pescado, além da venda do peixe beneficiado, como: filé, cabeça e etc.

Novos postos de venda estão sendo abertos, e muitas pessoas tem se interessado por este ramo, o que intensifica a sua comercialização. Além disso, o consumidor está consciente das propriedades dos pescados que compõem um grupo de alimentos altamente nutritivos, rico em proteínas, sais minerais, vitaminas diversas e além de apresentar baixos teores de gordura.

Palavras-chave: Consumo. Espécies marinhas. Pescado.

\footnotetext{
${ }^{1}$ Graduando em Engenharia de Pesca pela Universidade Estadual do Maranhão. http://lattes.cnpq.br/2623210524440728 hchaves65@gmail.com.

${ }^{2}$ Mestrando em Aquicultura pela Universidade Federal de Santa Catarina. http://lattes.cnpq.br/1057679857841026 moreirahugo32@gmail.com.

${ }^{3}$ Graduanda em Administração pela Universidade Estadual do Maranhão. http://lattes.cnpq.br/1004967224527177 luuh.sylva8@gmail.com.
} 


\section{METODOLOGIAS PARTICIPATIVAS PARA A CARACTERIZAÇÃO DA MARISCAGEM NO MUNICÍPIO DE AREZ-RN}

Renata Bezerra Gomes Rebouças ${ }^{1}$; Izaura Recy Souza Freire Sales²; André Luiz Machado Trajano³; Ellano José da Silva ${ }^{4}$.

O município de Arez, localizado no litoral Sul do estado do Rio Grande do Norte, faz parte do complexo lagunar Bonfim Guaraíra, onde muitas famílias da comunidade de Patané vêm apoiando sua renda na extração de moluscos, com destaque para a espécie Anomalocardia brasiliana, popularmente conhecida como "liliu". O objetivo geral deste trabalho foi traçar o perfil da atividade de mariscagem e apontar ações de extensão para o desenvolvimento da atividade no município de Arez-RN.

No mês de novembro de 2017, foi aplicado um Diagnóstico Rural Participativo (DRP). O DRP consiste na aplicação de metodologias participativas além de entrevistas individuais, com perguntas abertas e de múltipla escolha. Foi aplicado um questionário etnozoológico (com perguntas referentes à bioecologia animal/ambiente, extração e processamento) e socioeconômico. Os dados do DRP e dos questionários individuais foram tabulados e traçado um perfil da atividade na comunidade.

Foi entrevistado um total de 16 marisqueiros, maior parte composta por mulheres. Em termos gerais, a coleta do "liliu" é feita de forma artesanal e em bancos de areia nomeados tradicionalmente. A maior parte extrai por cinco dias semanais, nas marés mais baixas e tendo o período da manhã como preferido. Por trabalharem expostos a intempéries (dentro da água e ao sol), a prioridade pelo período, está relacionada às temperaturas mais amenas nas primeiras horas do dia o que provoca menor exaustão. Todos os entrevistados afirmaram coletar apenas moluscos grandes, o que demonstra consciência ecológica do grupo quanto a preservação do recurso. Em contrapartida, $75 \%$ afirmaram que houve diminuição do recurso nos bancos de coleta, fato observado pela menor abundância capturada durante a extração, se comparado a anos anteriores, o que pode estar relacionado ao aumento do esforço de captura, provocado pela entrada de novos marisqueiros e baixa taxa de renovação dos estoques. O processamento (pré-cozimento e desconchamento) do "liliu" ocorre em sua totalidade às margens do estuário, onde o resíduo gerado (conchas) é descartado ali mesmo, ficando exposto e sem destino.

Esta pesquisa permitiu a identificação das principais características da atividade no município e demonstrou a necessidade da prática de forma mais eficiente, o que pode trazer melhores condições de trabalho e renda. Sugere-se que sejam implementadas medidas de manejo com base em pesquisas já realizadas para a espécie, promovendo a exploração racional de $A$. brasiliana, bem como traçado um plano de ação específico para atender as demandas do grupo, promovendo o aperfeiçoamento no processo produtivo, agregação de valor ao produto, destinação adequada de resíduos e melhoria de renda para os marisqueiros.

Palavras-chave: Pesca. Extrativismo. Molusco. Extensão rural.

Apoio: EMATER-RN.

\footnotetext{
${ }^{1}$ Renata Bezerra Gomes Rebouças: Doutoranda em Ciência Animal pela Universidade Federal Rural do Semi-Árido. http://lattes.cnpq.br/1669052436025595.rbgufersa@gmail.com.

${ }^{2}$ Izaura Recy Souza Freire Sales: Assistente Social no Serviço Nacional de Aprendizagem Rural do Rio Grande do Norte. http://lattes.cnpq.br/4408993326848950. izaurarecy@gmail.com.

3 André Luiz Machado Trajano: Mestre em Produção Animal pela Universidade Federal Rural do Semi-Árido. http://lattes.cnpq.br/4085769391770938. andreluiz.trajano44@gmail.com.

4 Ellano José da Silva: Doutorando em Aquicultura pela Universidade Federal do Rio Grande. http://lattes.cnpq.br/0624850227547215. ellanosilva7@gmail.com.
} 